\title{
Characterization of Thermally Induced Flavor Compounds from the Glucosinolate Progoitrin in Different Matrices via GC-TOF-MS
}

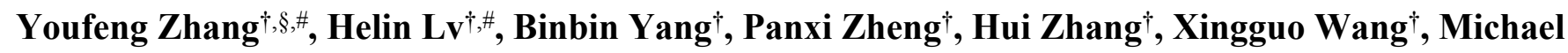
Granvogl ${ }^{\S} *$, and Qingzhe Jin ${ }^{\dagger, *}$

${ }_{\dagger}^{\dagger}$ International Joint Research Laboratory for Lipid Nutrition and Safety, State Key Lab of Food Science and Technology, Collaborative Innovation Center of Food Safety and Quality Control in Jiangsu Province, School of Food Science and Technology, Jiangnan University, Wuxi, 214122, China

$\S$ Department of Food Chemistry and Analytical Chemistry (170a), Institute of Food Chemistry, University of Hohenheim, Garbenstrasse 28, 70599 Stuttgart, Germany

*Corresponding author.

Michael Granvogl, *Email: michael.granvog1@uni-hohenheim.de

Qingzhe Jin, *Email: jqzwx12@163.com

\#These authors contributed equally to this work. 


\section{Mass sepctra of the compounds in sample}

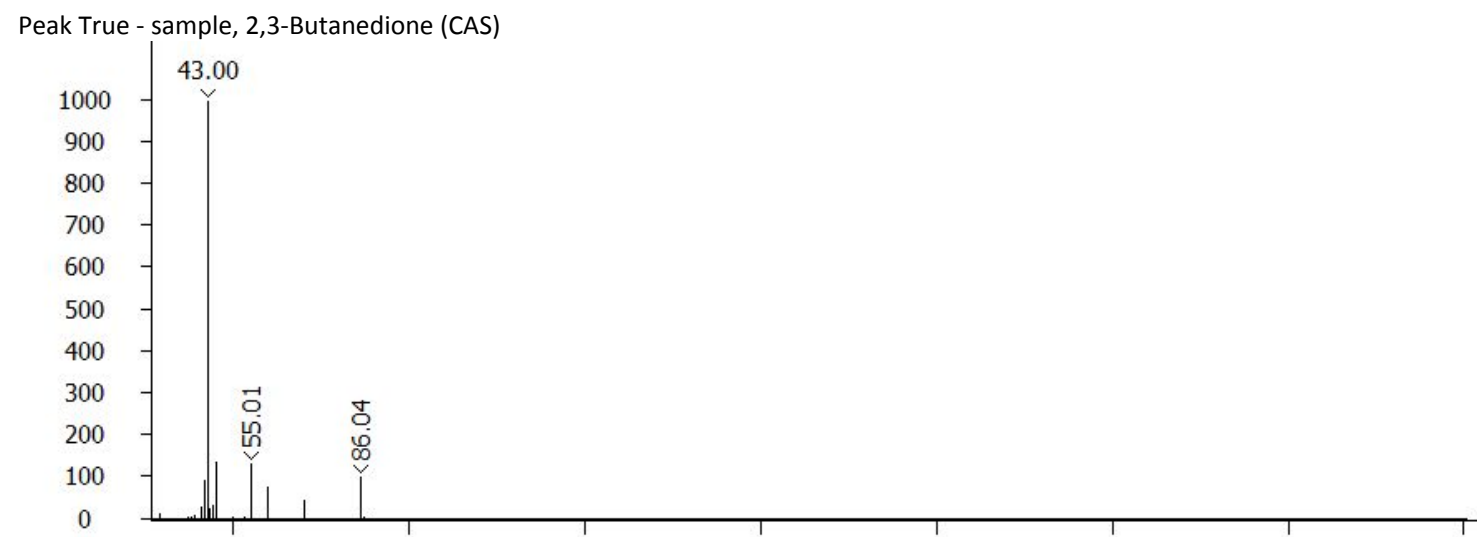

Library Hit - Similarity: 822 - Library: Wiley9 - 2,3-Butanedione (CAS), Abundance
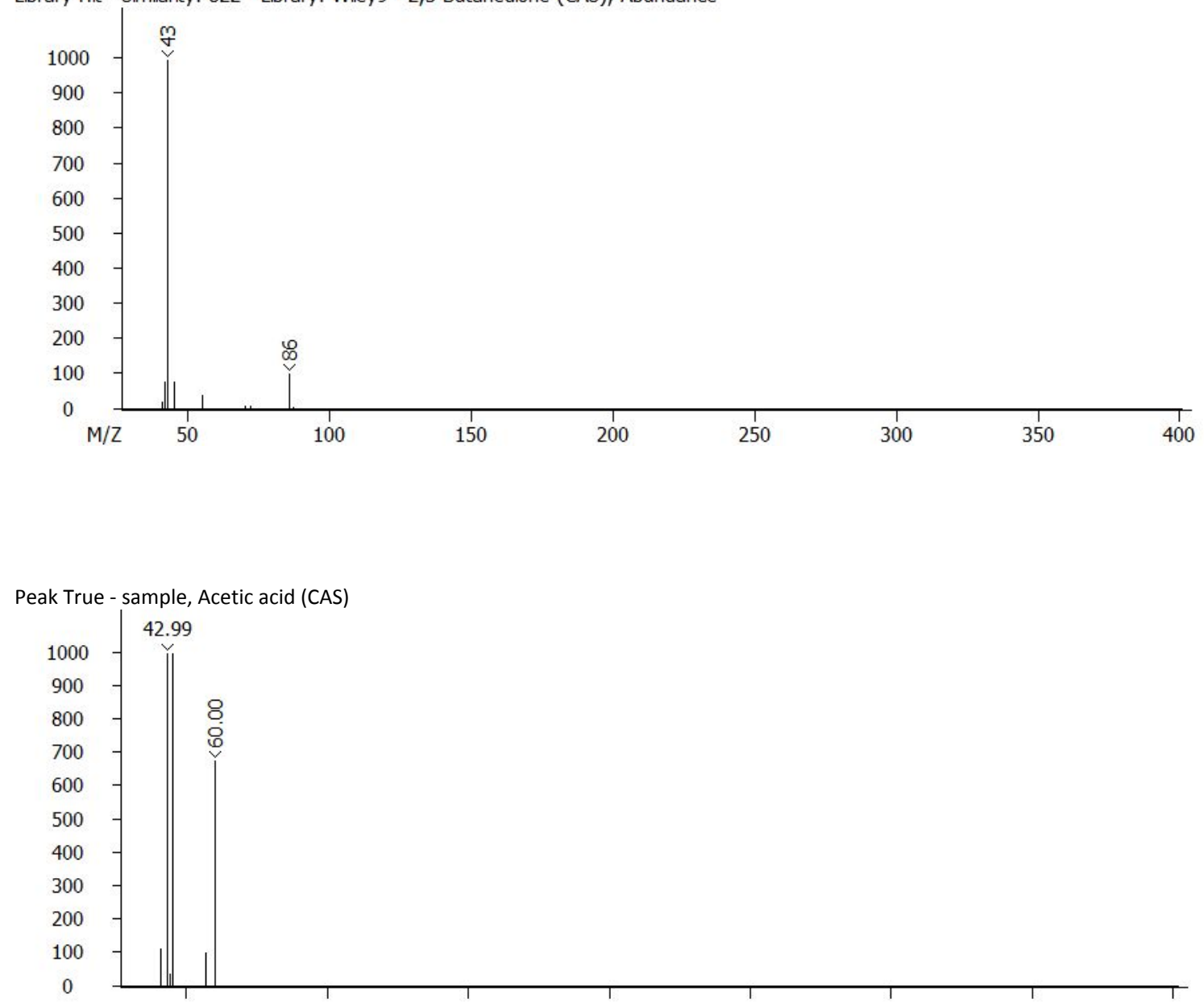

Library Hit - Similarity: 915 - Library: Wiley9 - Acetic acid (CAS), Abundance

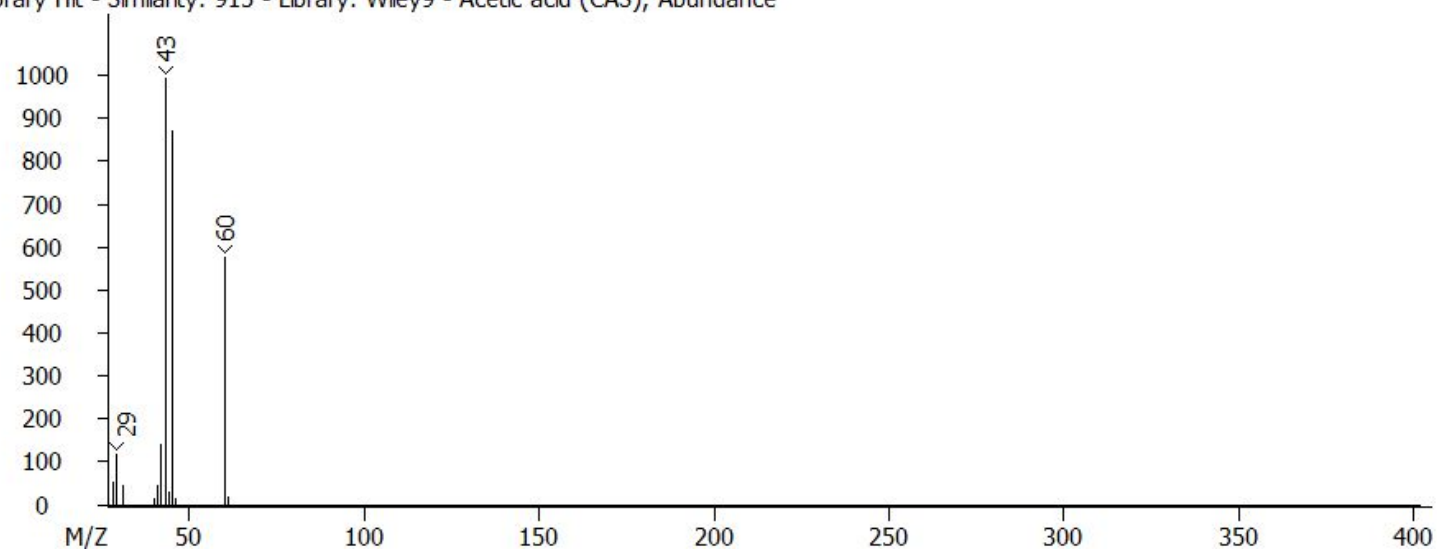


Peak True - sample, 2-Butenal (CAS)

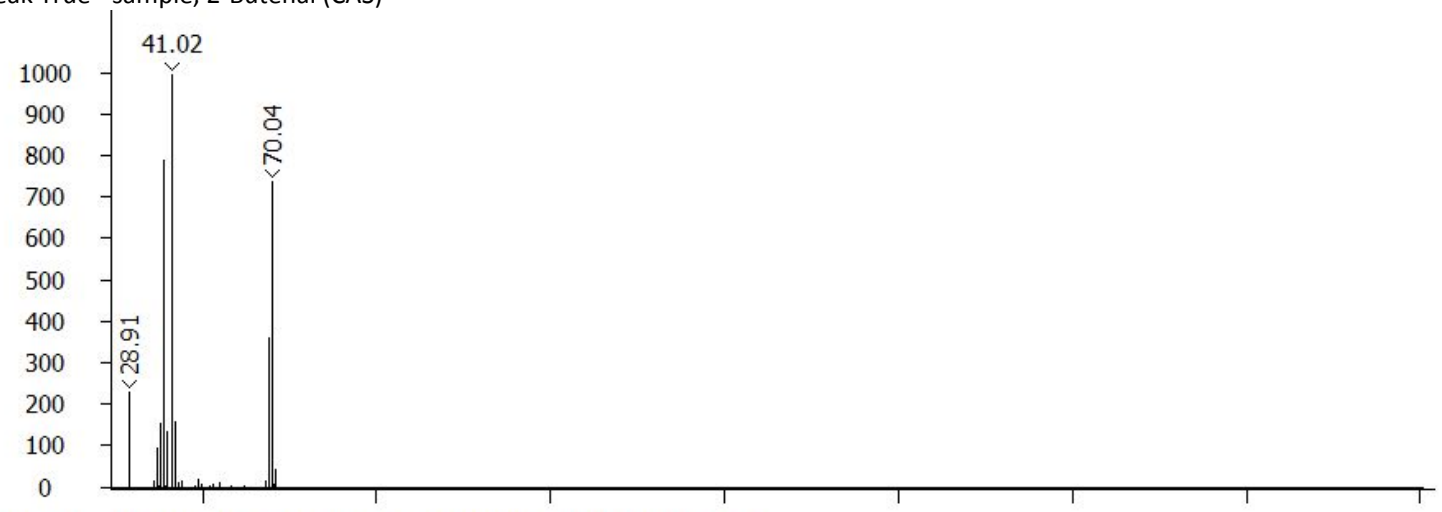

Library Hit - Similarity: 964 - Library: Wiley9 - 2-Butenal (CAS), Abundance

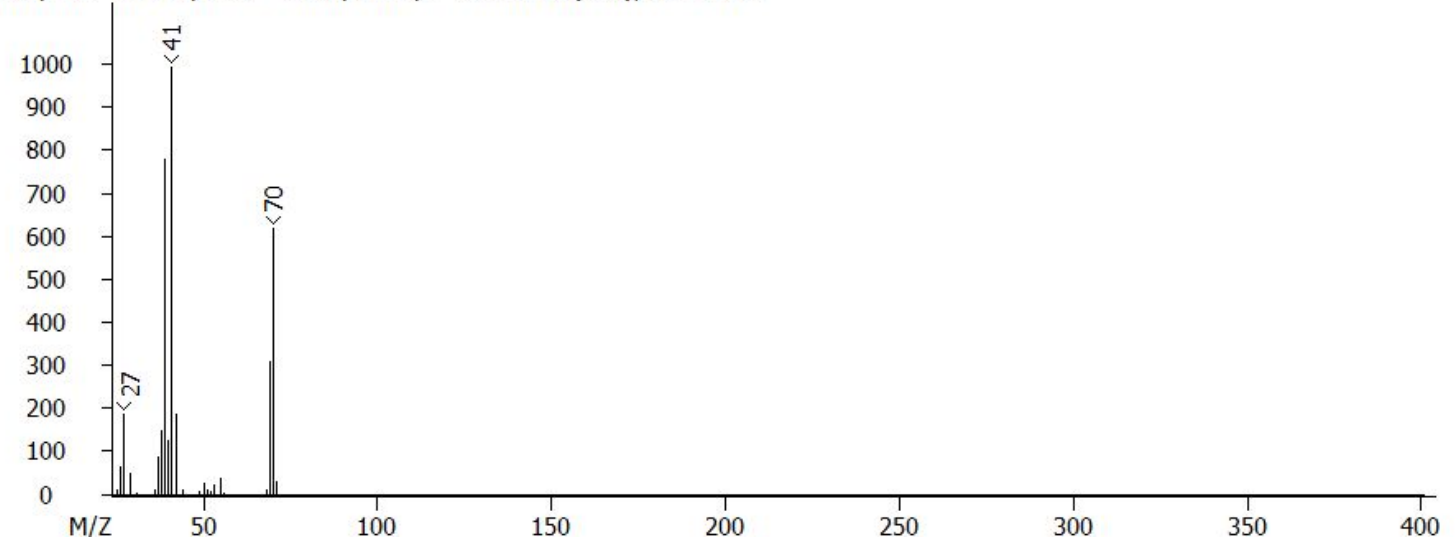

Peak True - sample, Thiophene

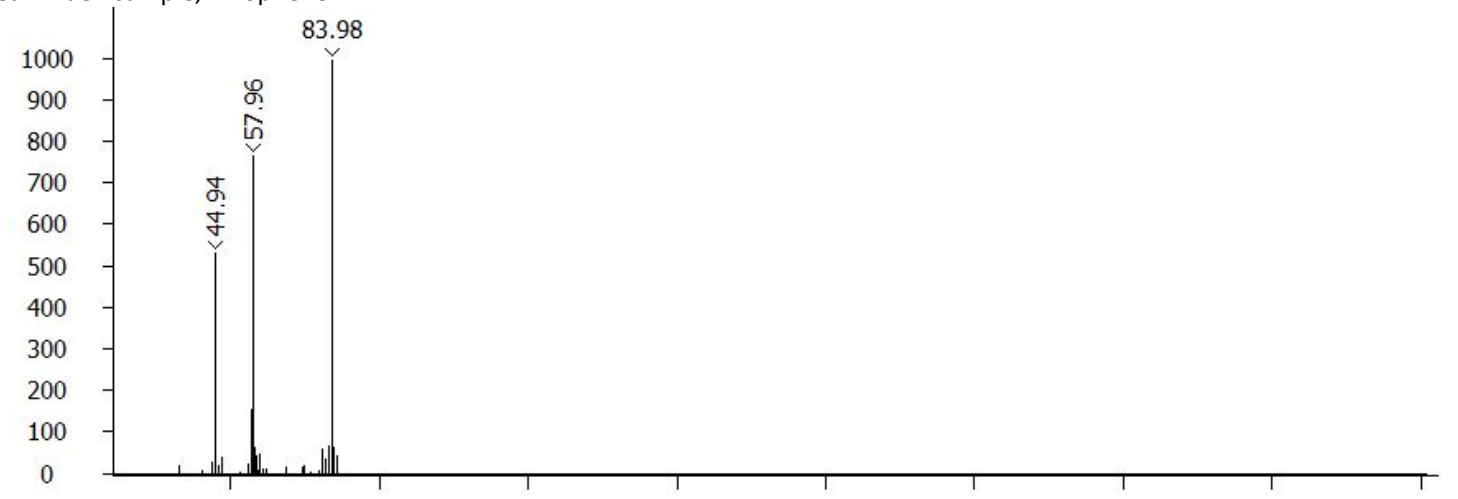

Library Hit - Similarity: 880 - Library: mainlib - Thiophene, Abundance

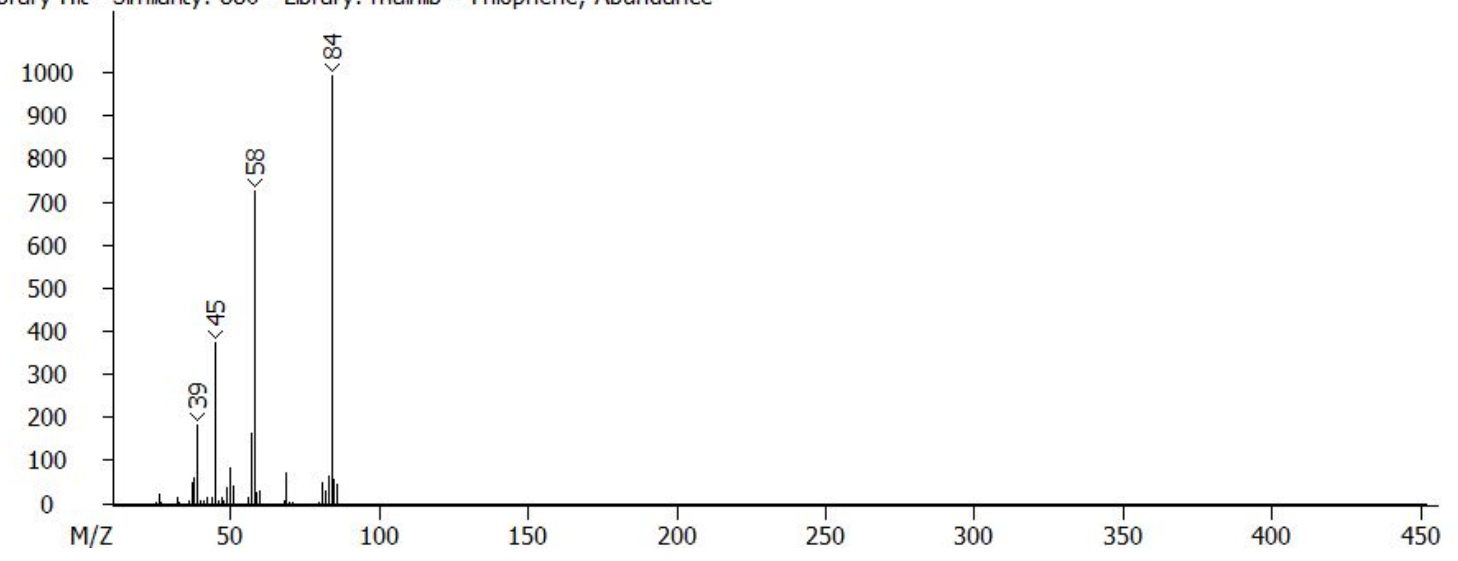




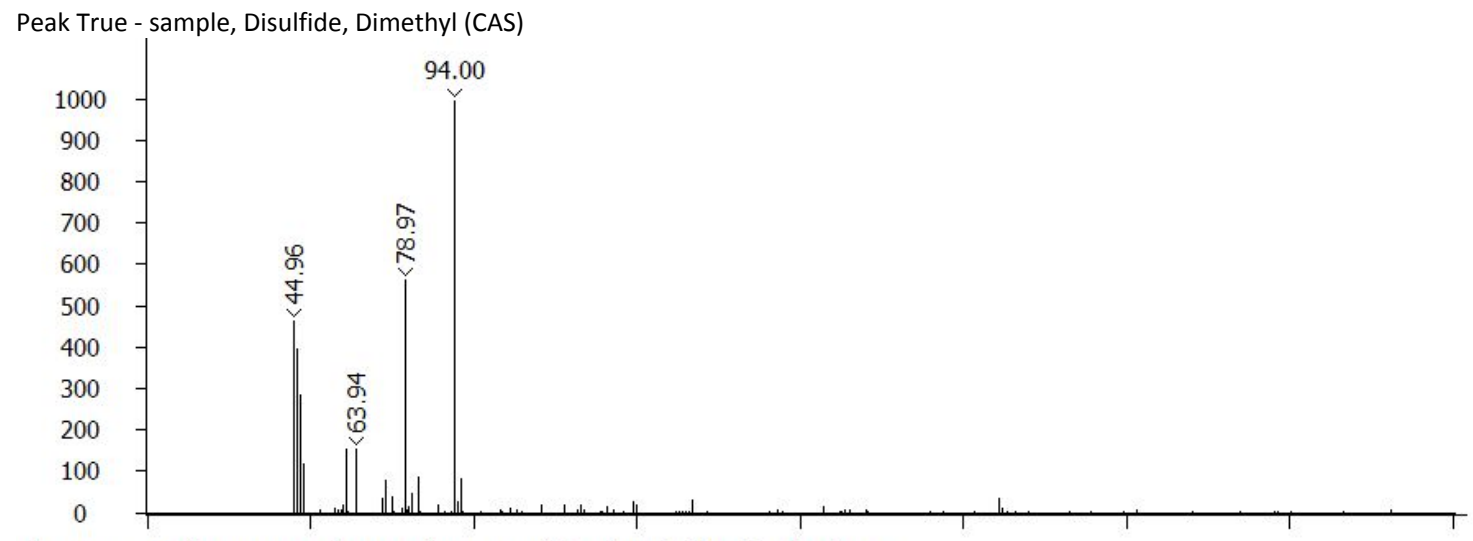

Library Hit - Similarity: 814 - Library: Wiley9 - Disulfide, dimethyl (CAS), Abundance
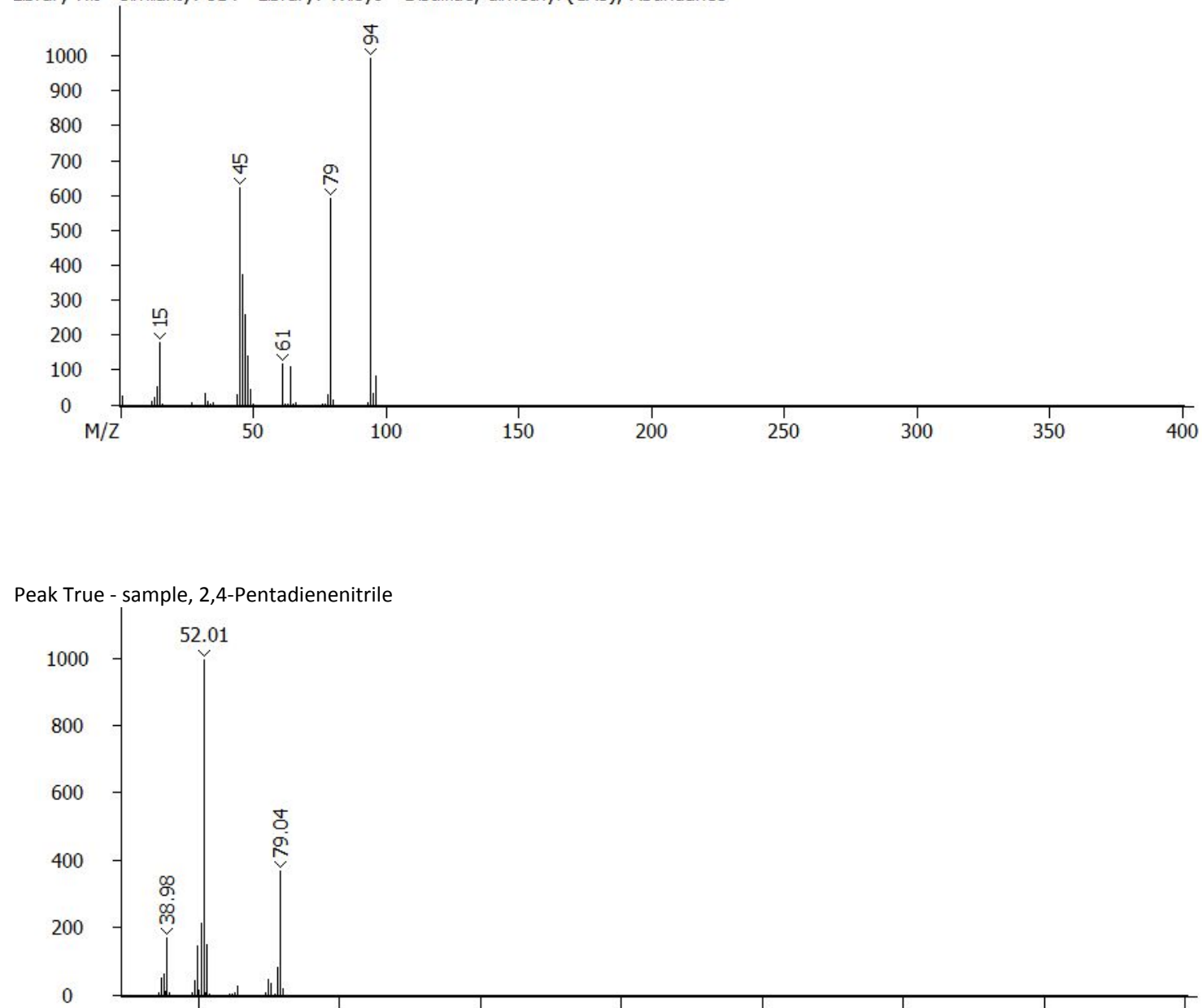

Library Hit - Similarity: 970 - Library: mainlib - 2,4-Pentadienenitrile, Abundance

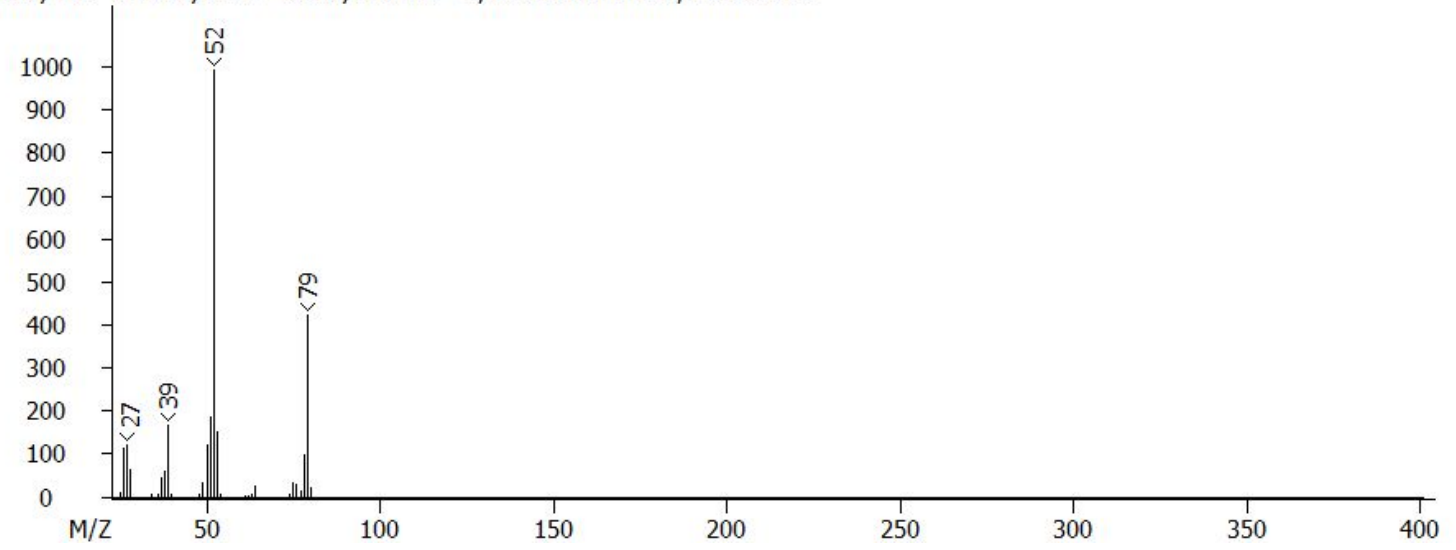




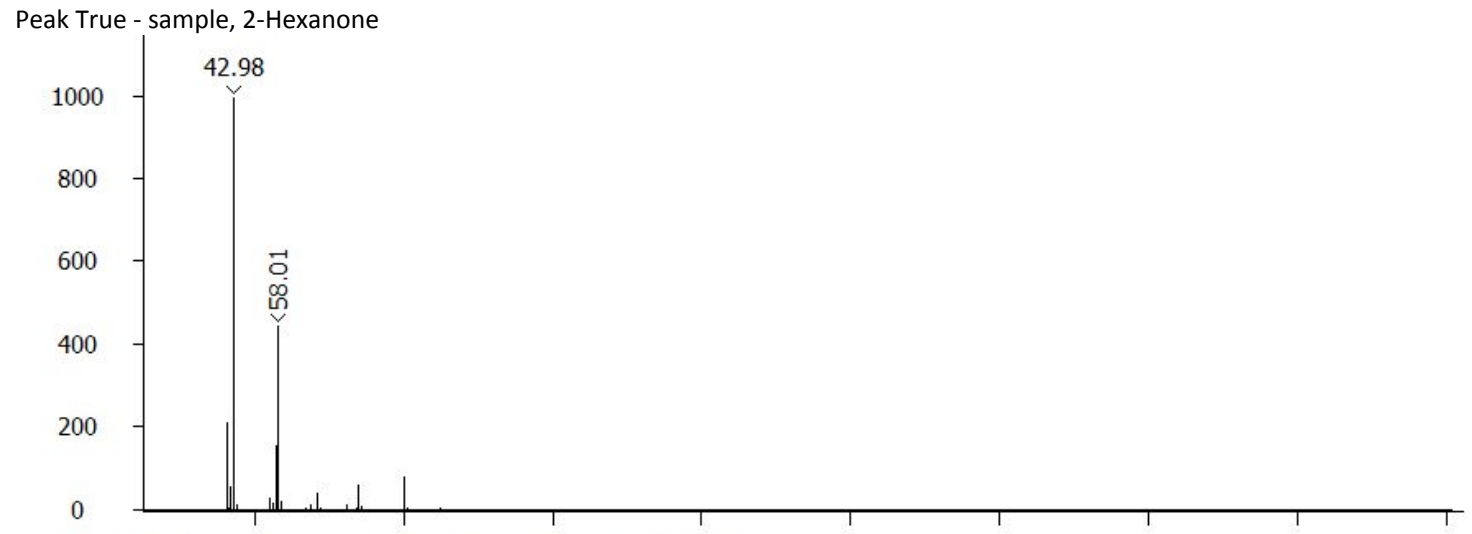

Library Hit - Similarity: 942 - Library: mainlib - 2-Hexanone, Abundance

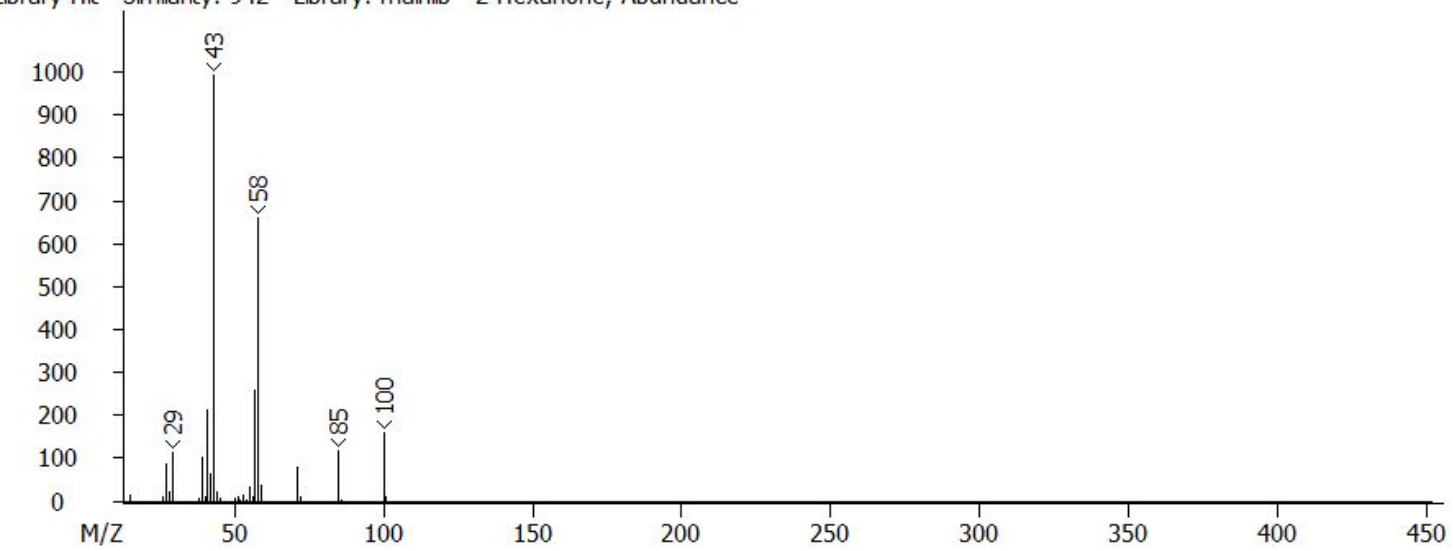

Peak True - sample, 2-FURANCARBOXALDEHYDE

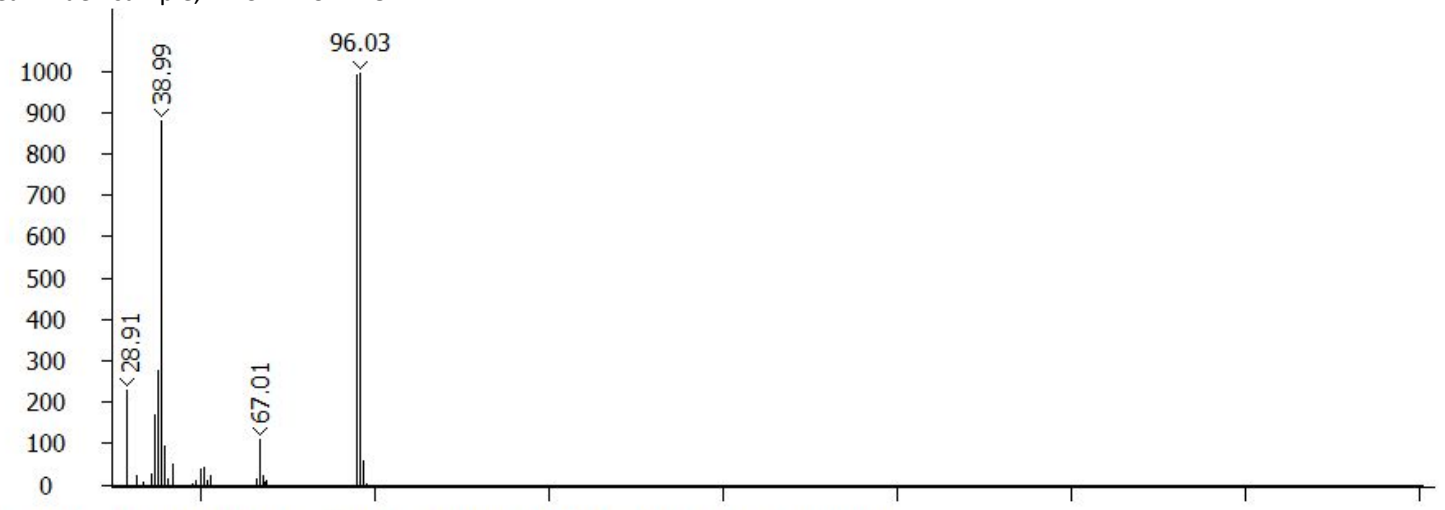

Library Hit - Similarity: 969 - Library: Wiley9 - 2-FURANCARBOXALDEHYDE, Abundance

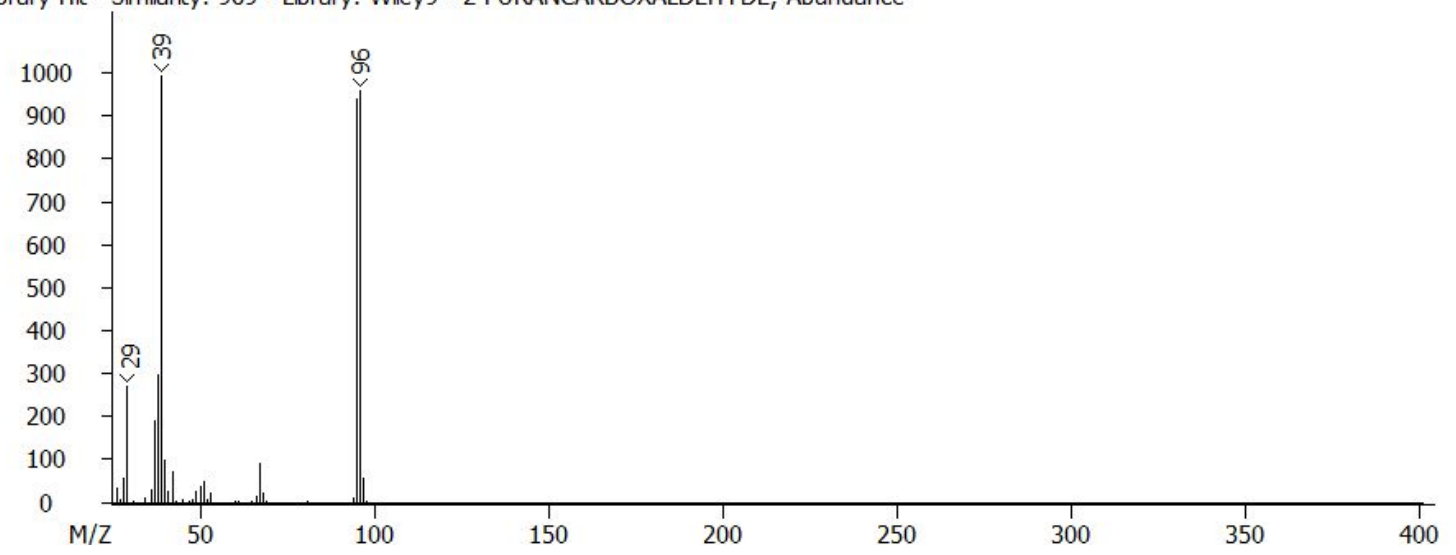




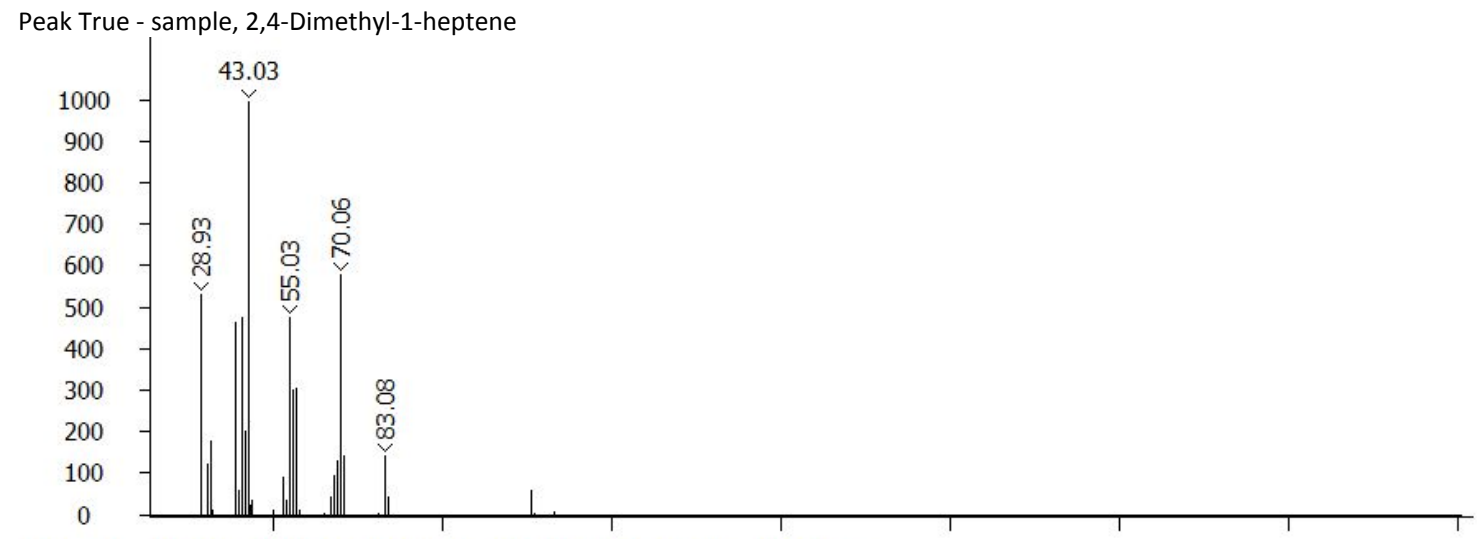

Library Hit - Similarity: 950 - Library: replib - 2,4-Dimethyl-1-heptene, Abundance
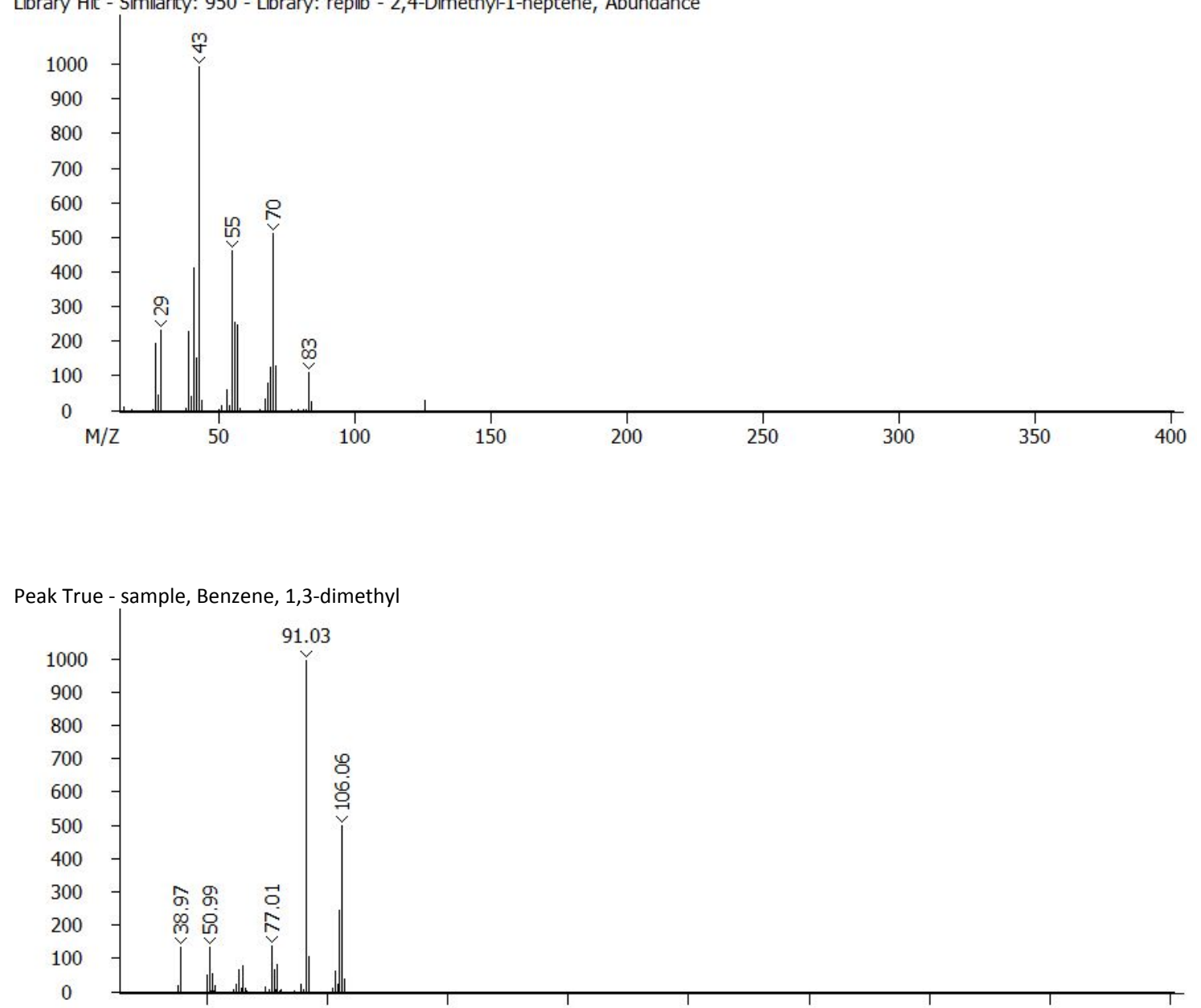

Library Hit - Similarity: 960 - Library: mainlib - Benzene, 1,3-dimethyl-, Abundance

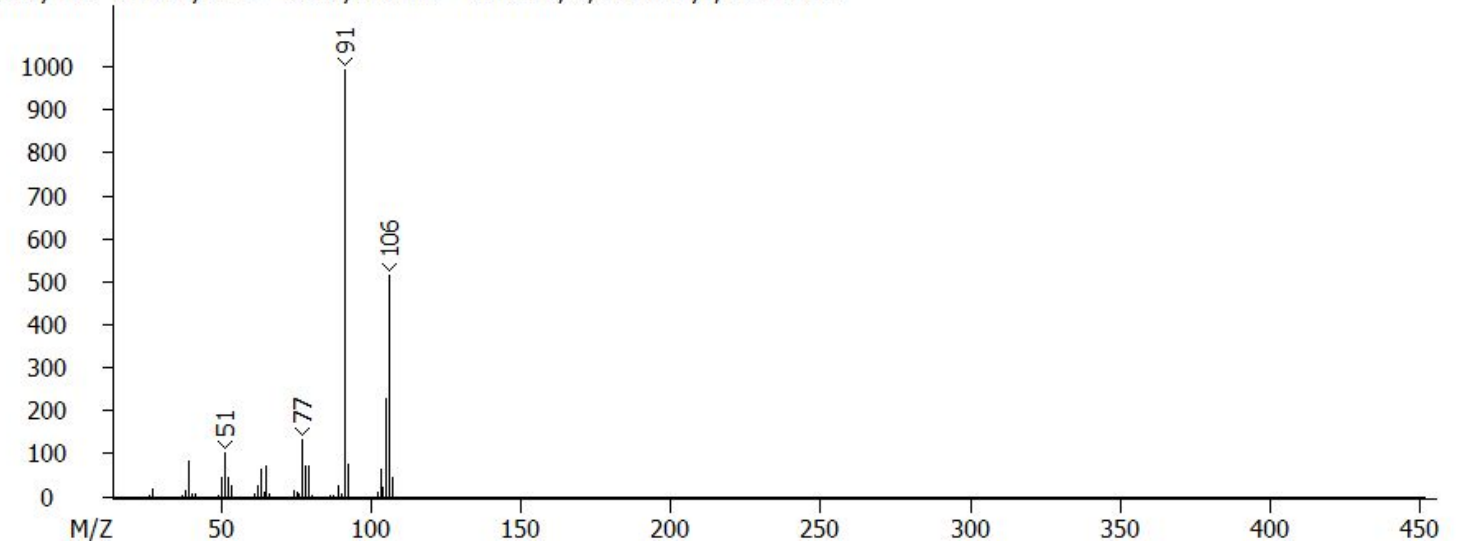




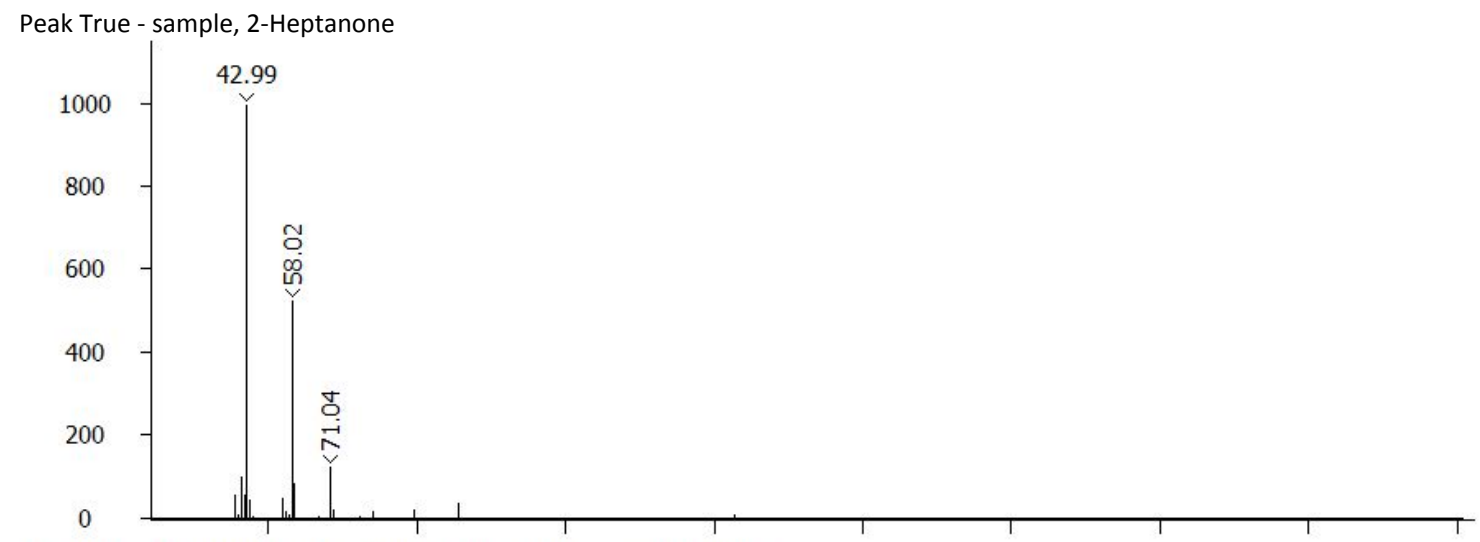

Library Hit - Similarity: 928 - Library: mainlib - 2-Heptanone, Abundance
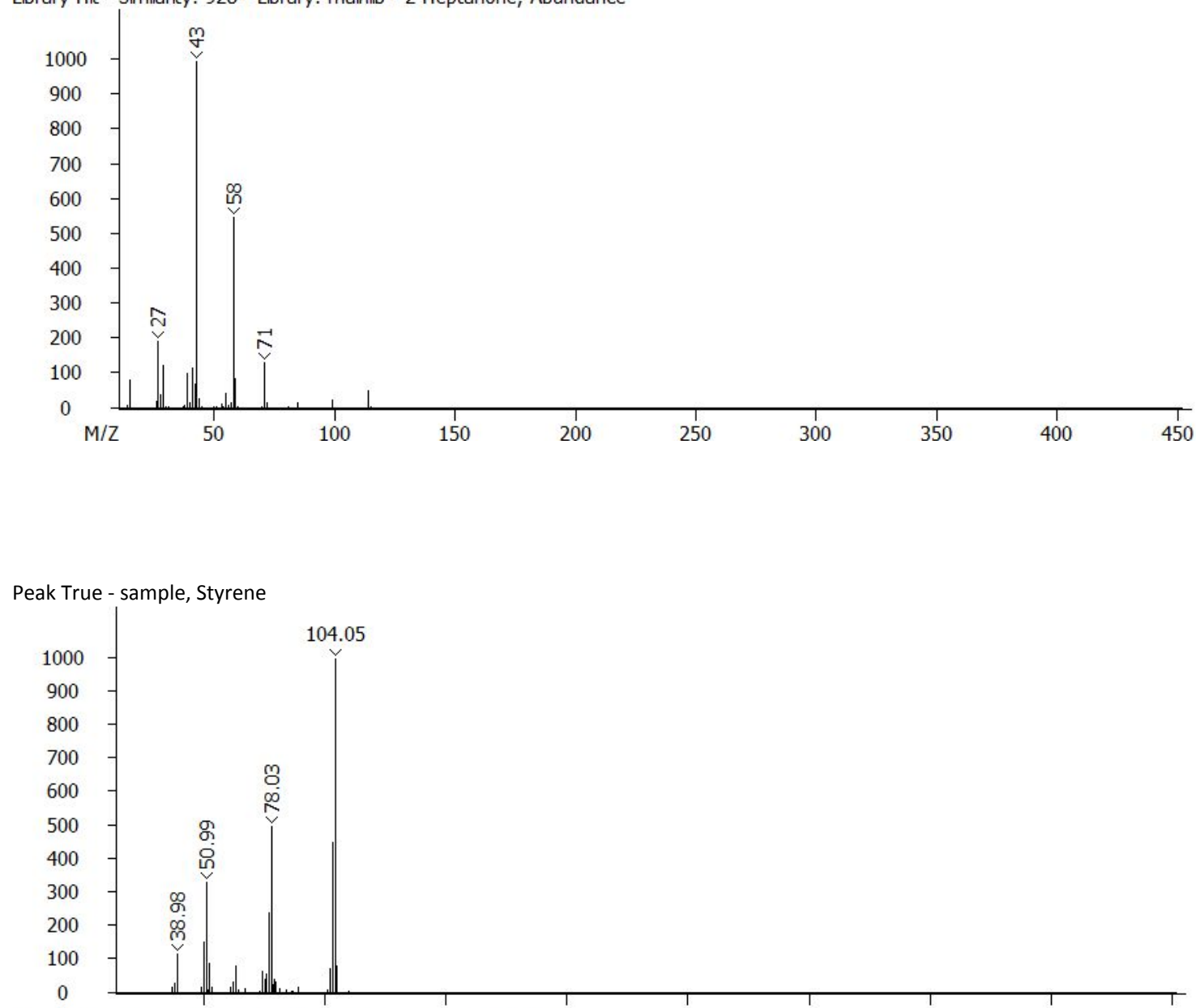

Library Hit - Similarity: 941 - Library: mainlib - Styrene, Abundance

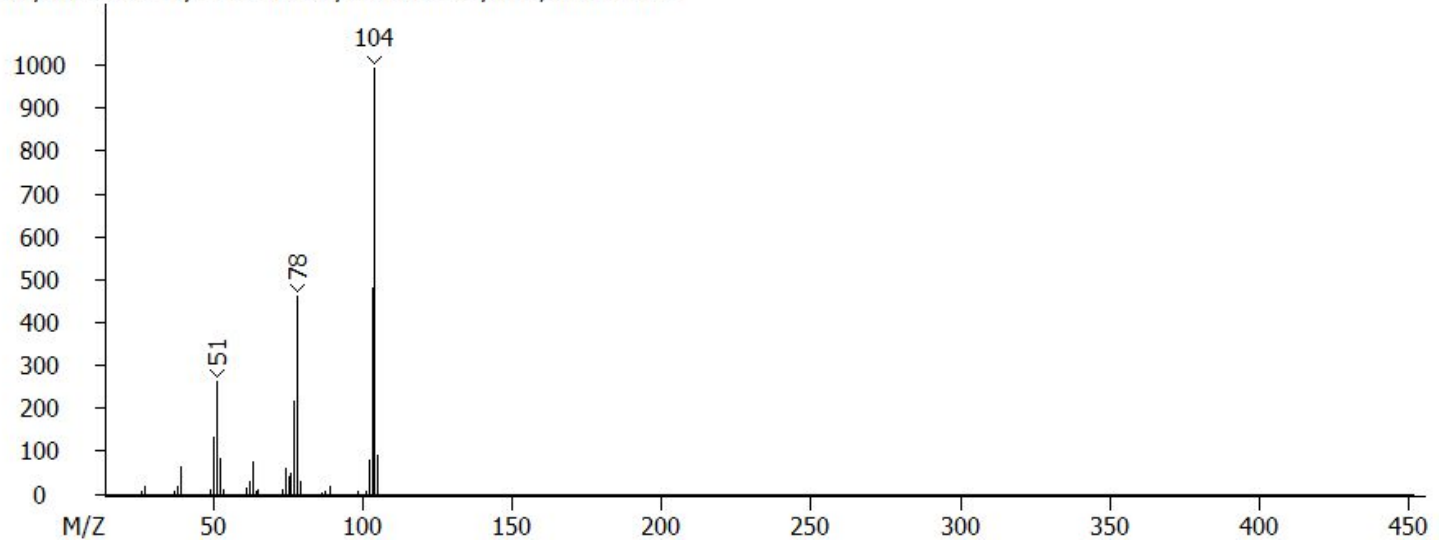




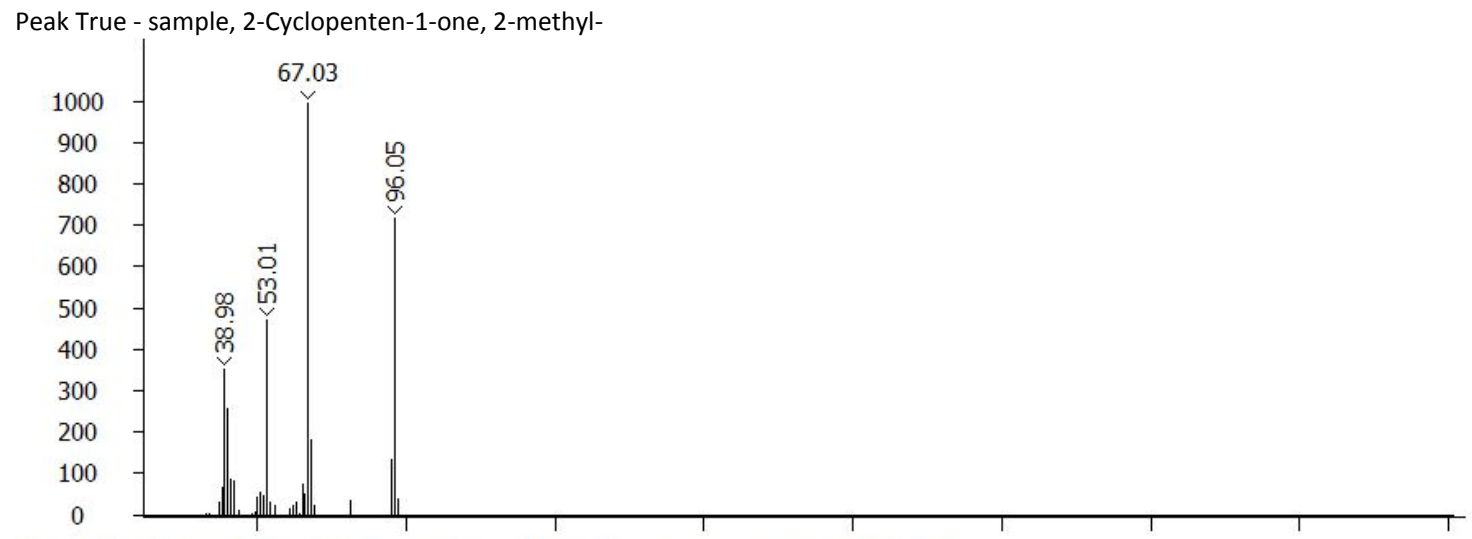

Library Hit - Similarity: 930 - Library: mainlib - 2-Cyclopenten-1-one, 2-methyl-, Abundance
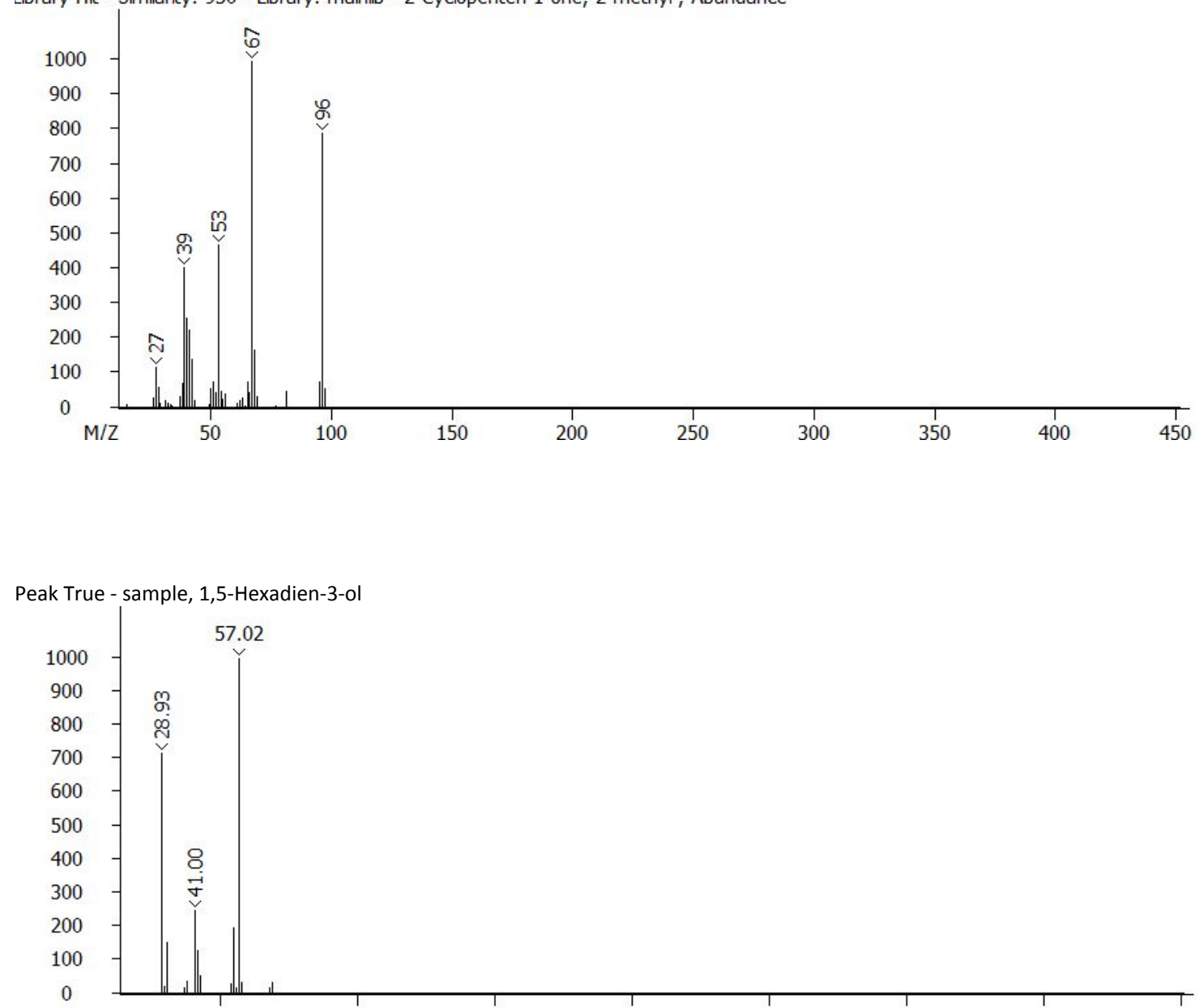

Library Hit - Similarity: 846 - Library: Wiley9 - 1,5-Hexadien-3-ol, Abundance

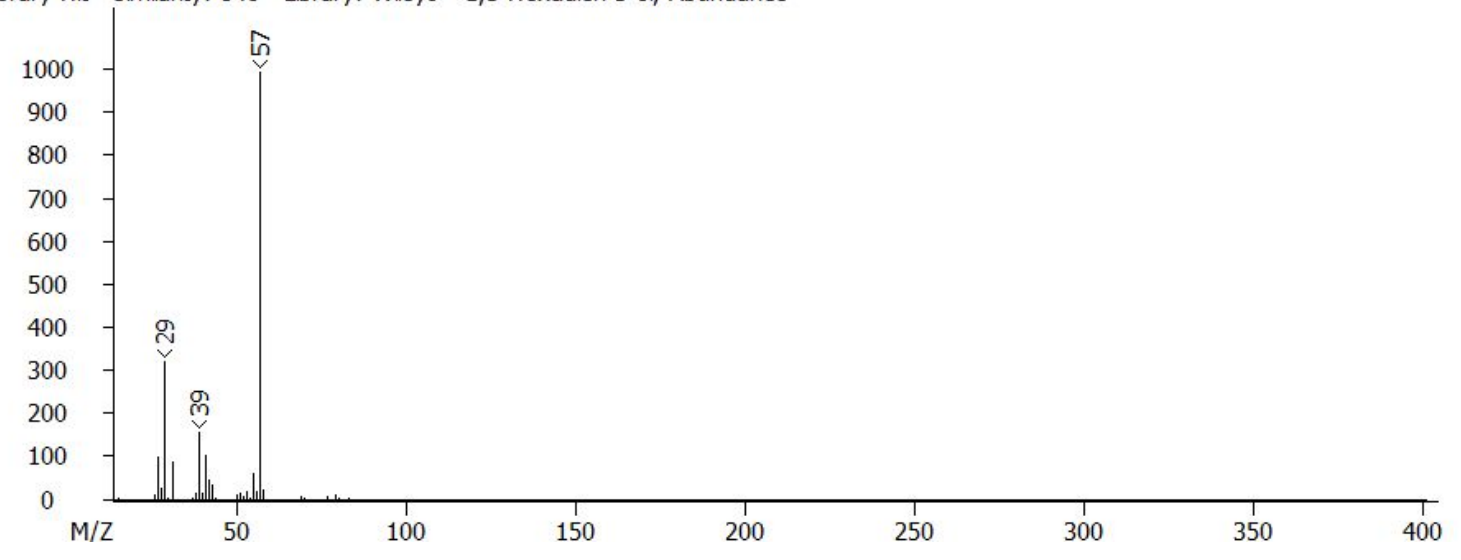




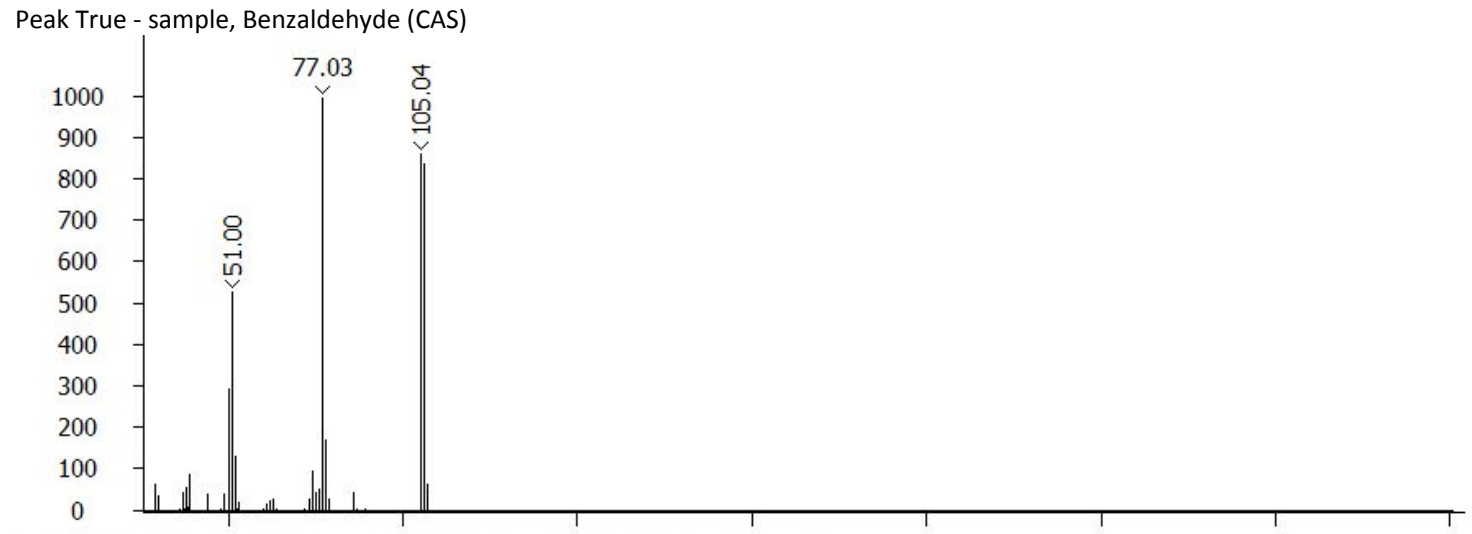

Library Hit - Similarity: 949 - Library: Wiley9 - Benzaldehyde (CAS), Abundance

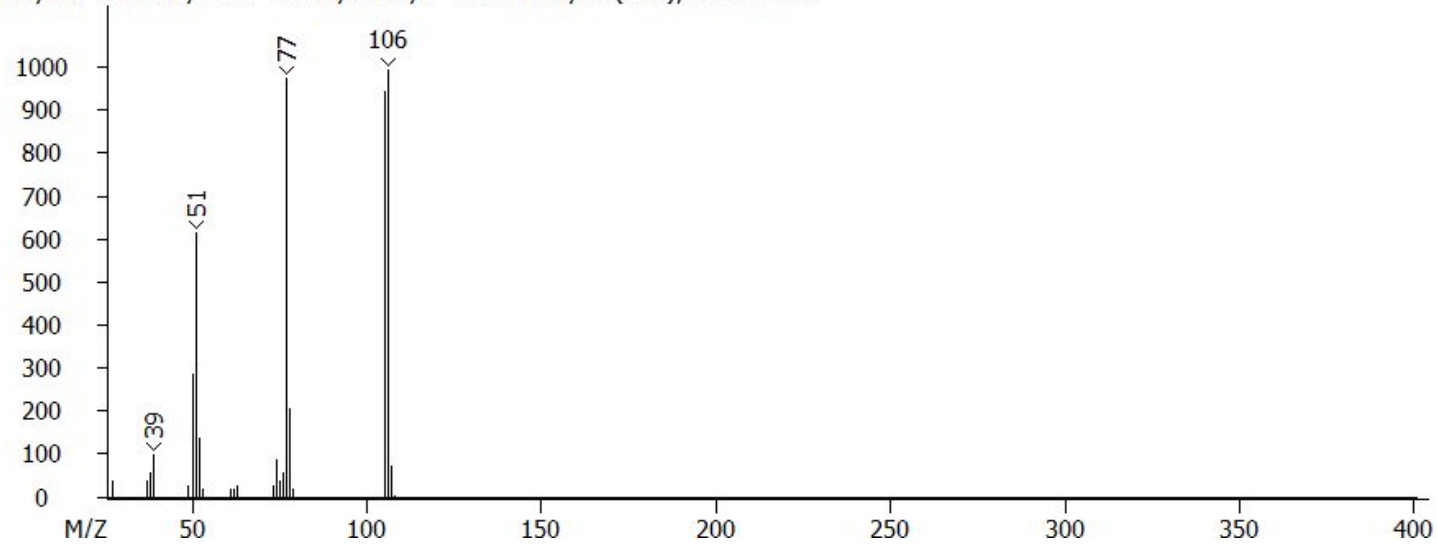

Peak True - sample, 2-Furancarboxaldehyde, 5-methyl-

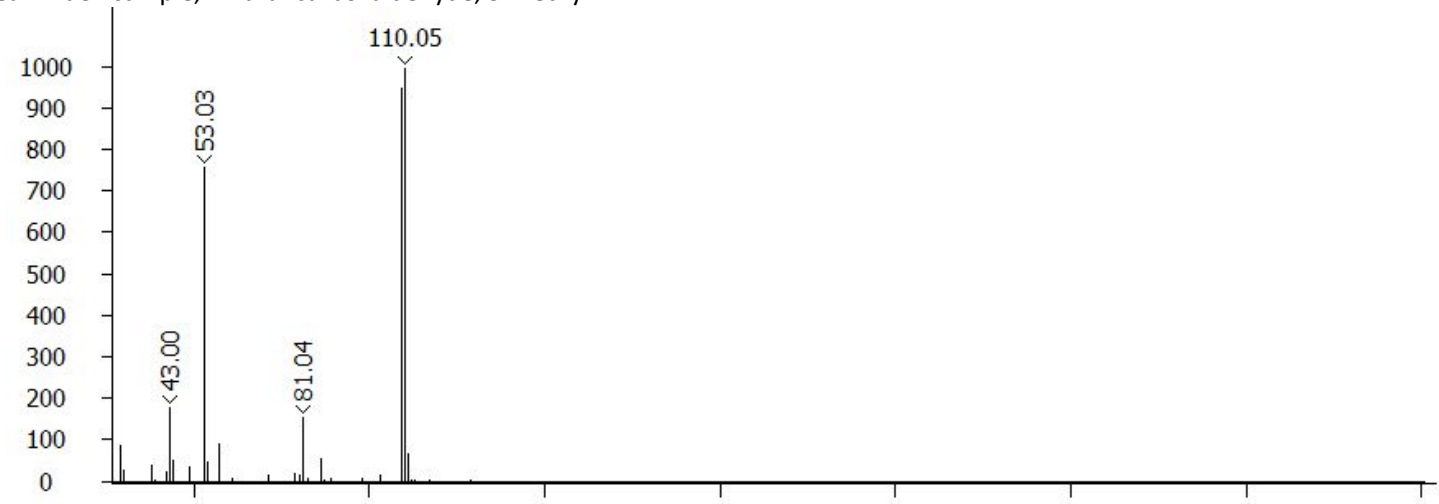

Library Hit - Similarity: 936 - Library: Wiley9 - 2-Furancarboxaldehyde, 5-methyl- (CAS), Abundance

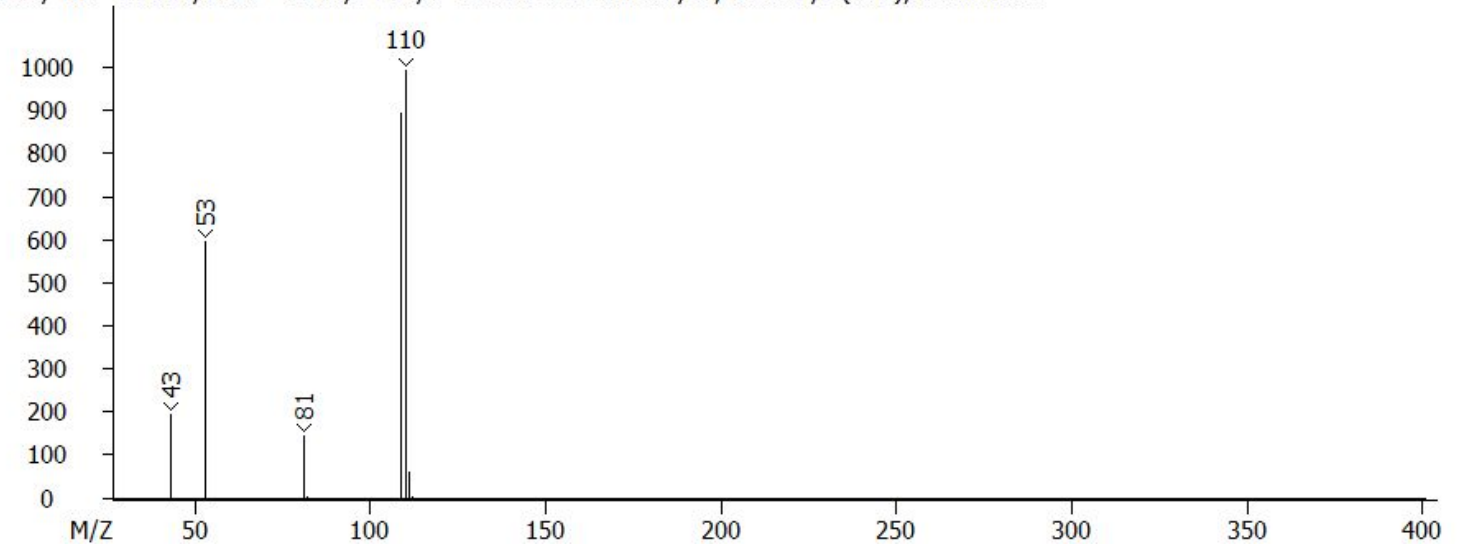




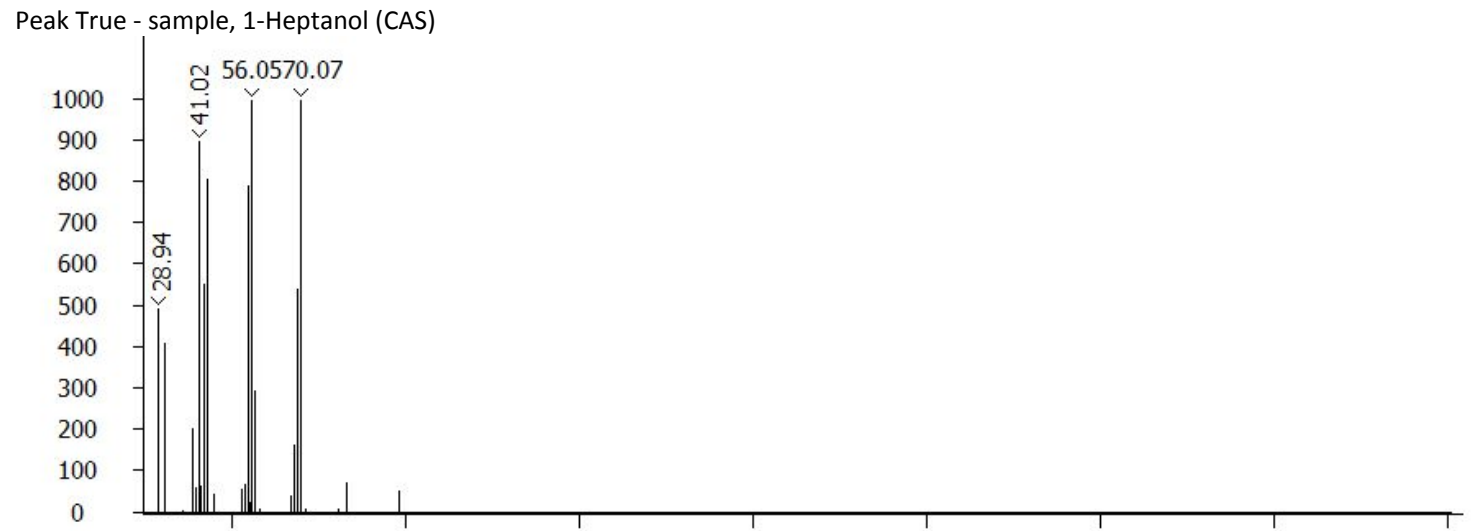

Library Hit - Similarity: 960 - Library: Wiley9 - 1-Heptanol (CAS), Abundance
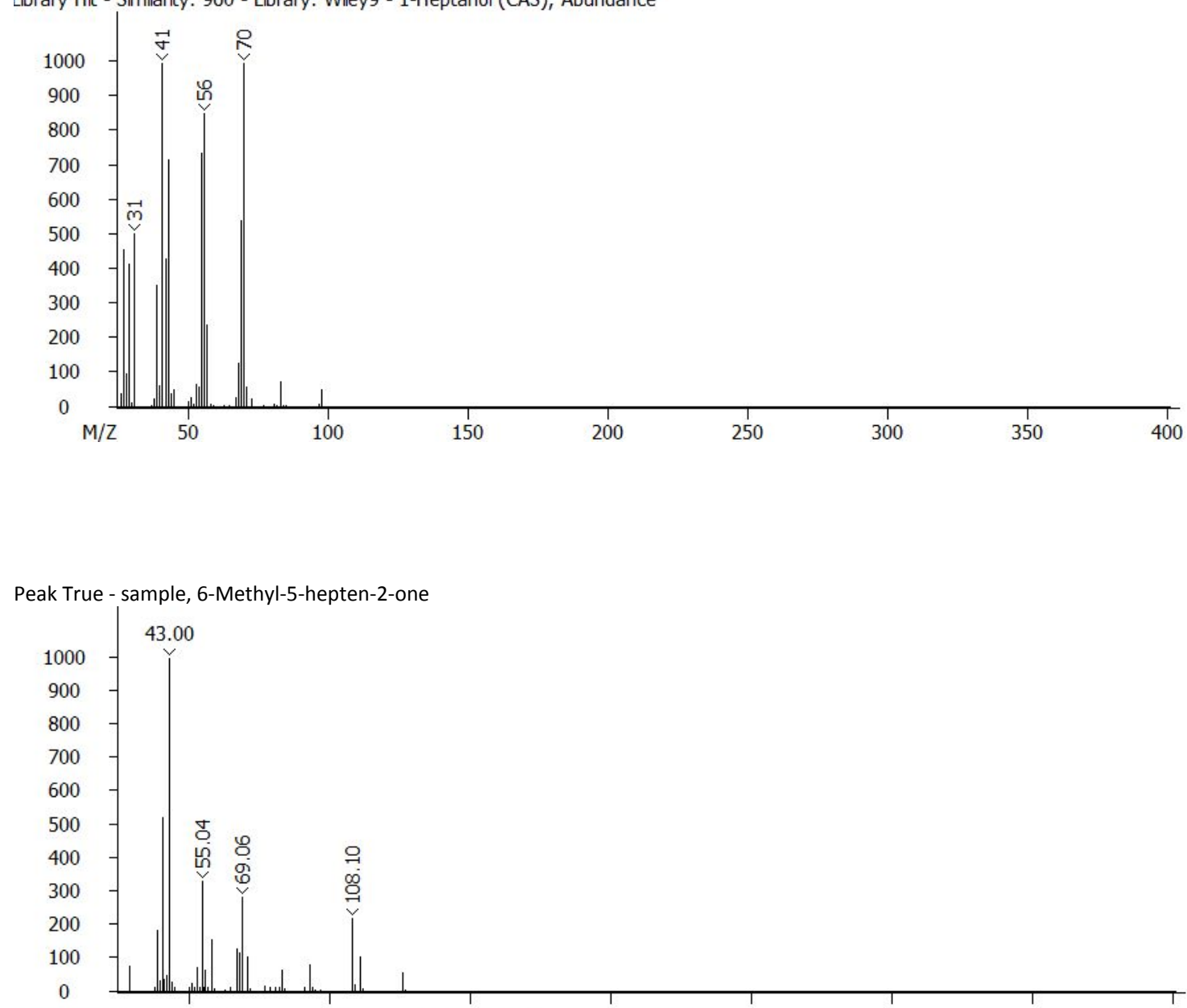

Library Hit - Similarity: 950 - Library: Wiley9 - 6-Methyl-5-hepten-2-one, Abundance

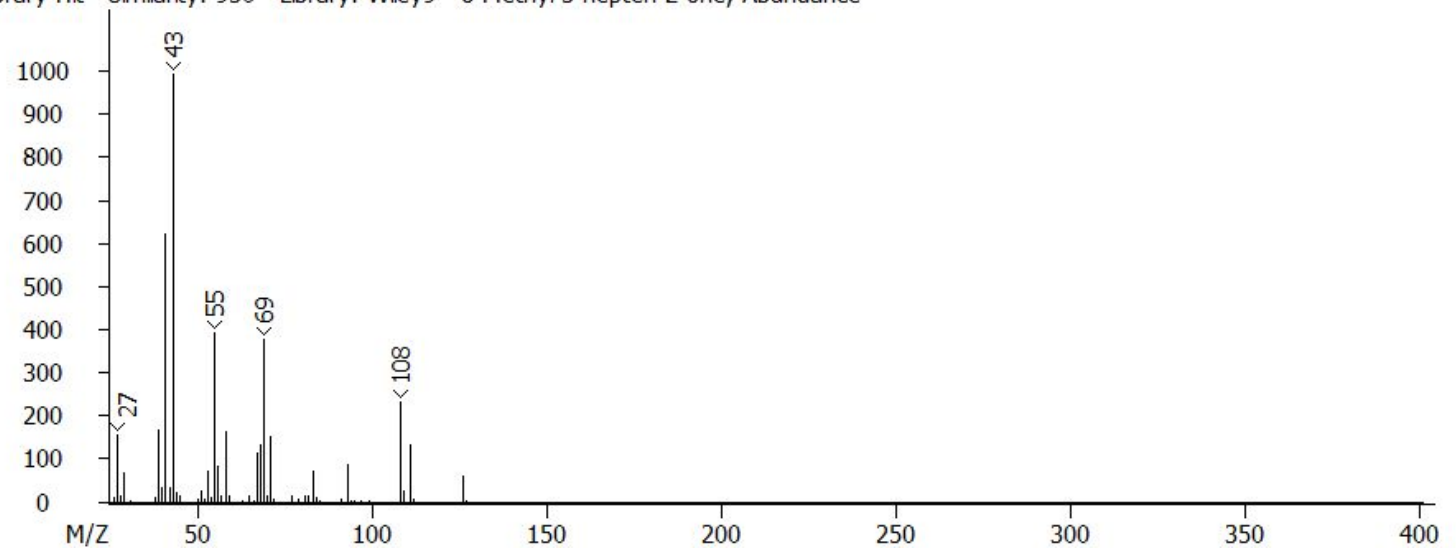




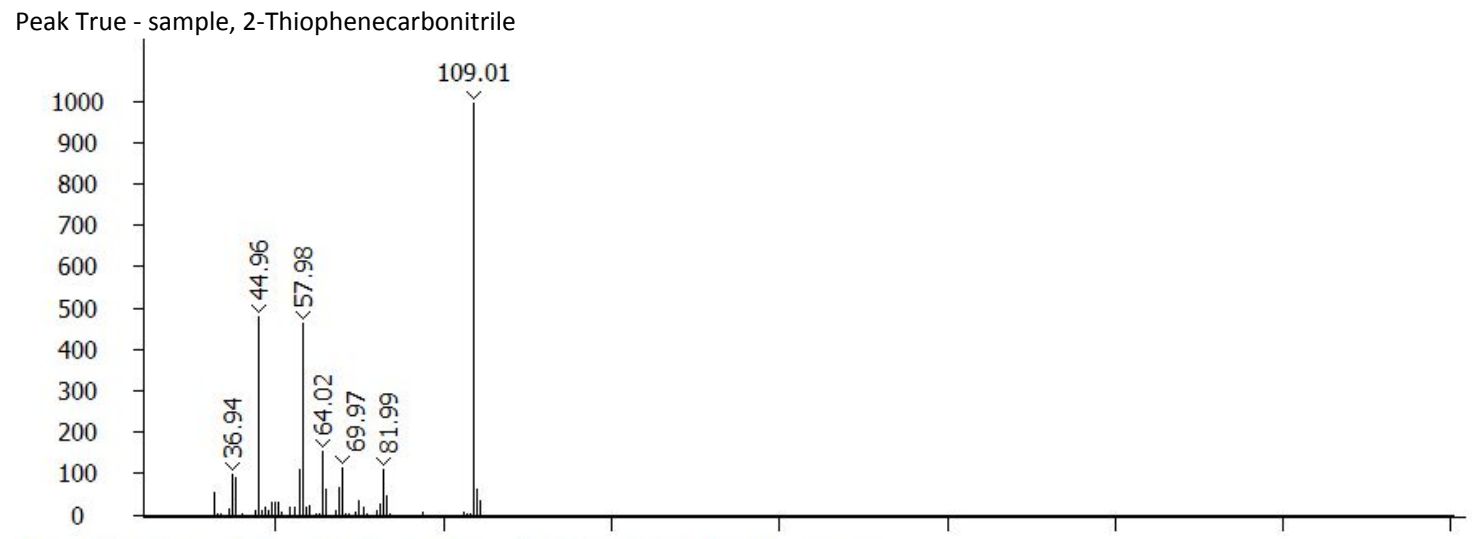

Library Hit - Similarity: 957 - Library: mainlib - 2-Thiophenecarbonitrile, Abundance
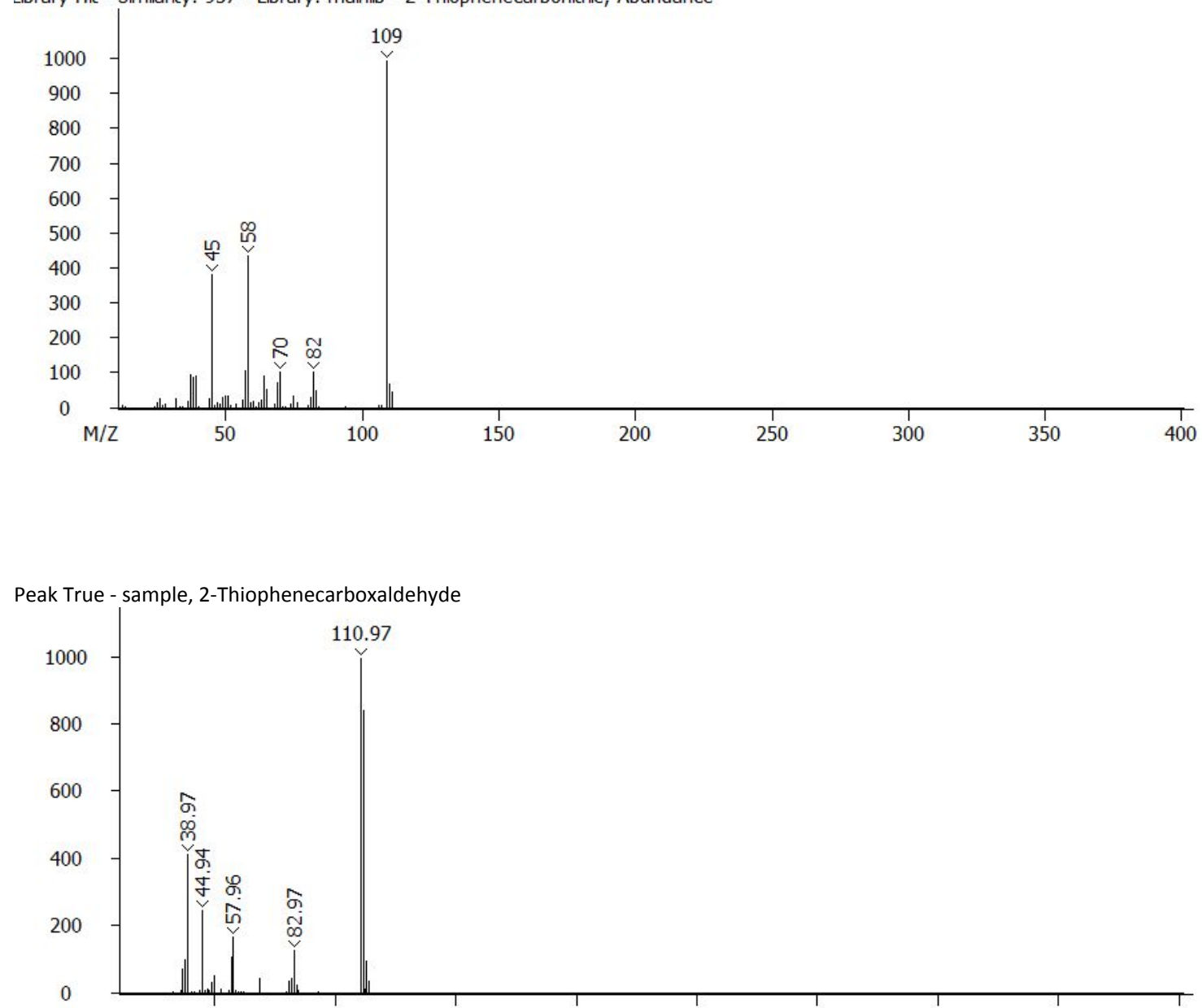

Library Hit - Similarity: 953 - Library: mainlib - 2-Thiophenecarboxaldehyde, Abundance

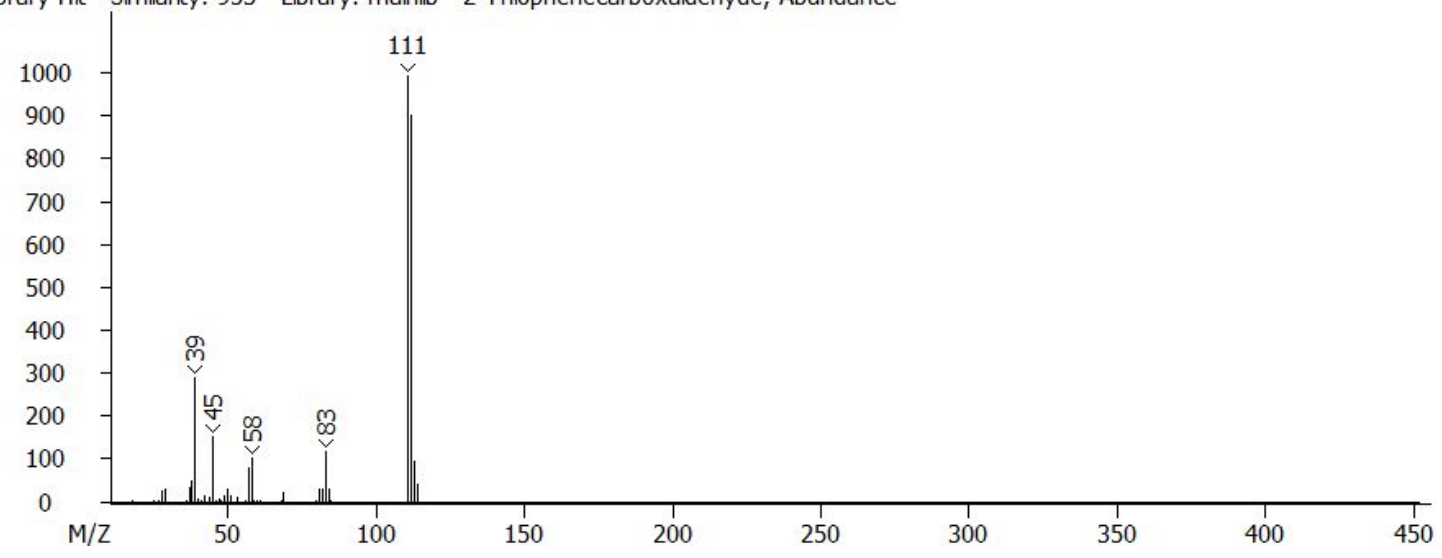


Peak True - sample, 1-Hexanol, 2-ethyl-

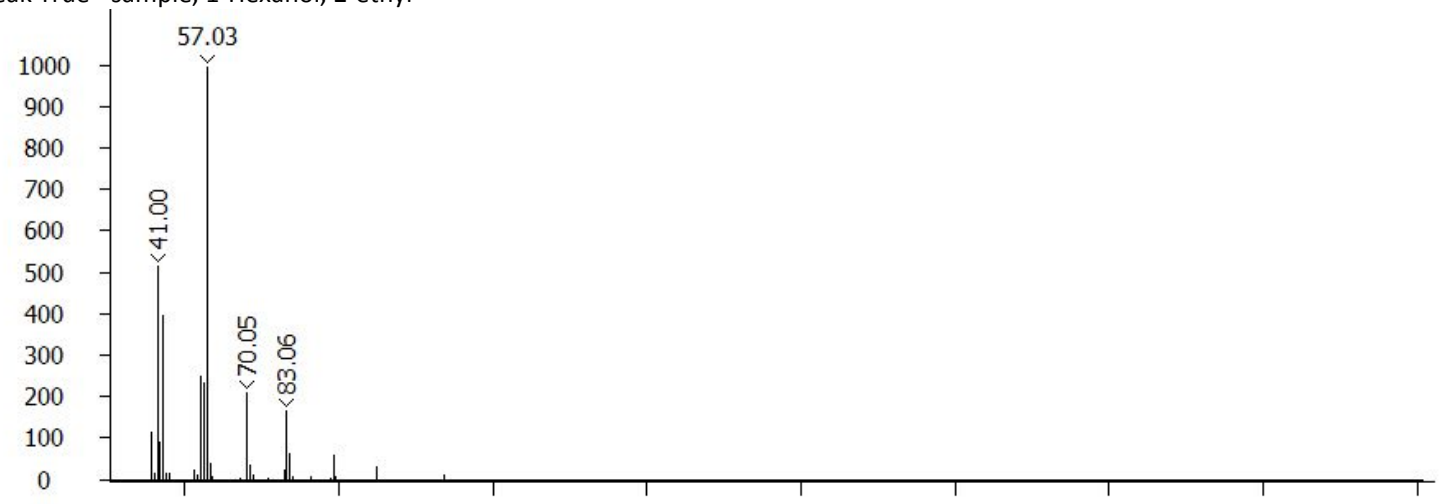

Library Hit - Similarity: 930 - Library: mainlib - 1-Hexanol, 2-ethyl-, Abundance

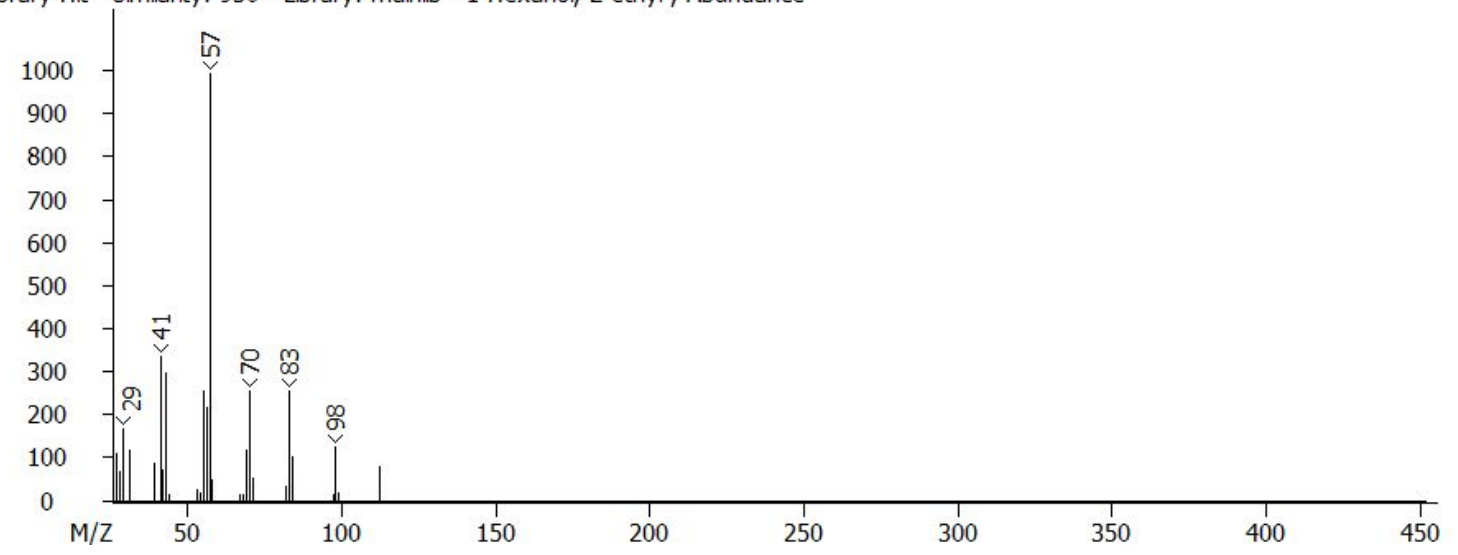

Peak True - sample, 2(5H)-Thiophenone

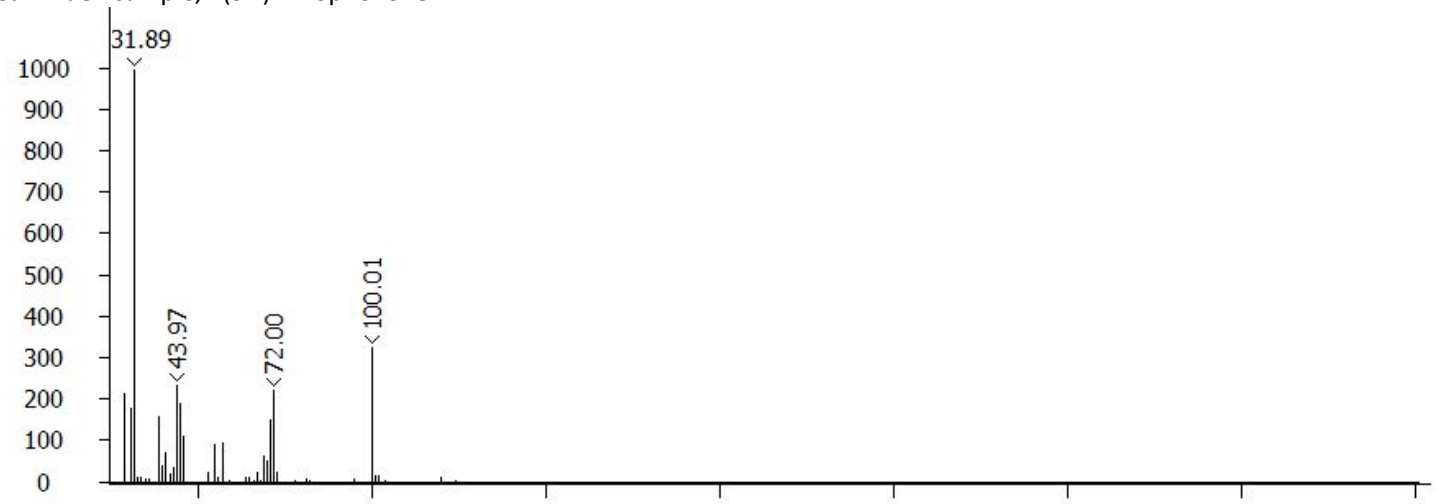

Library Hit - Similarity: 845 - Library: mainlib - 2(5H)-Thiophenone, Abundance

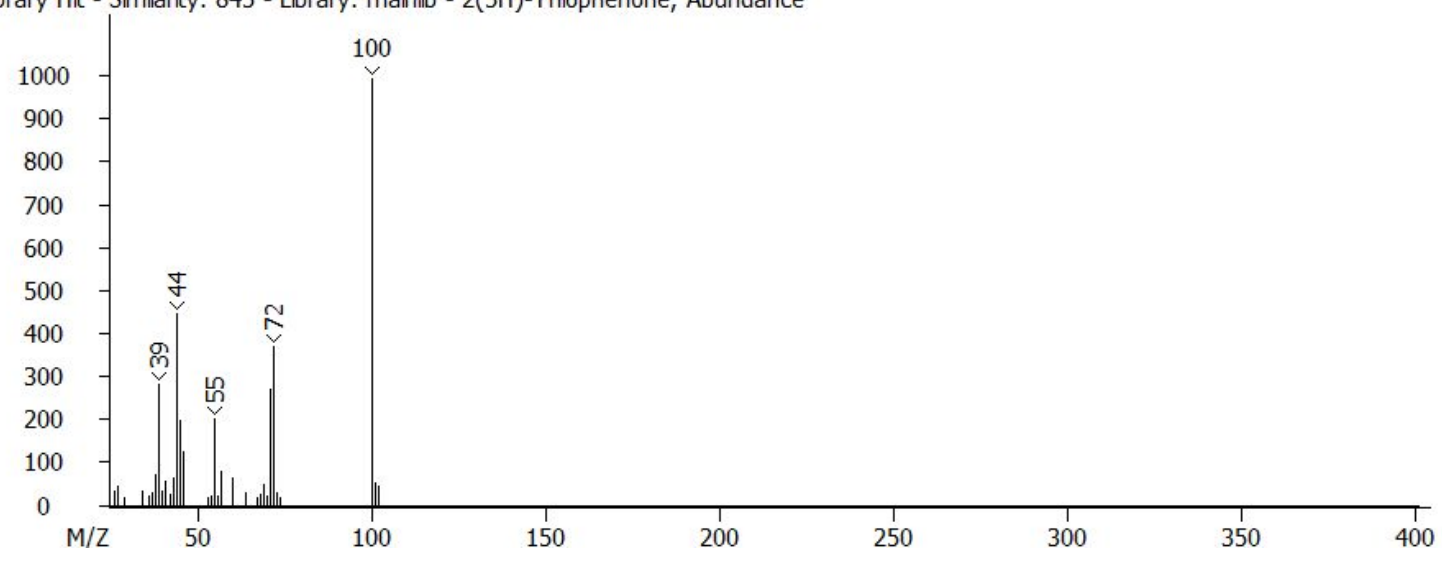




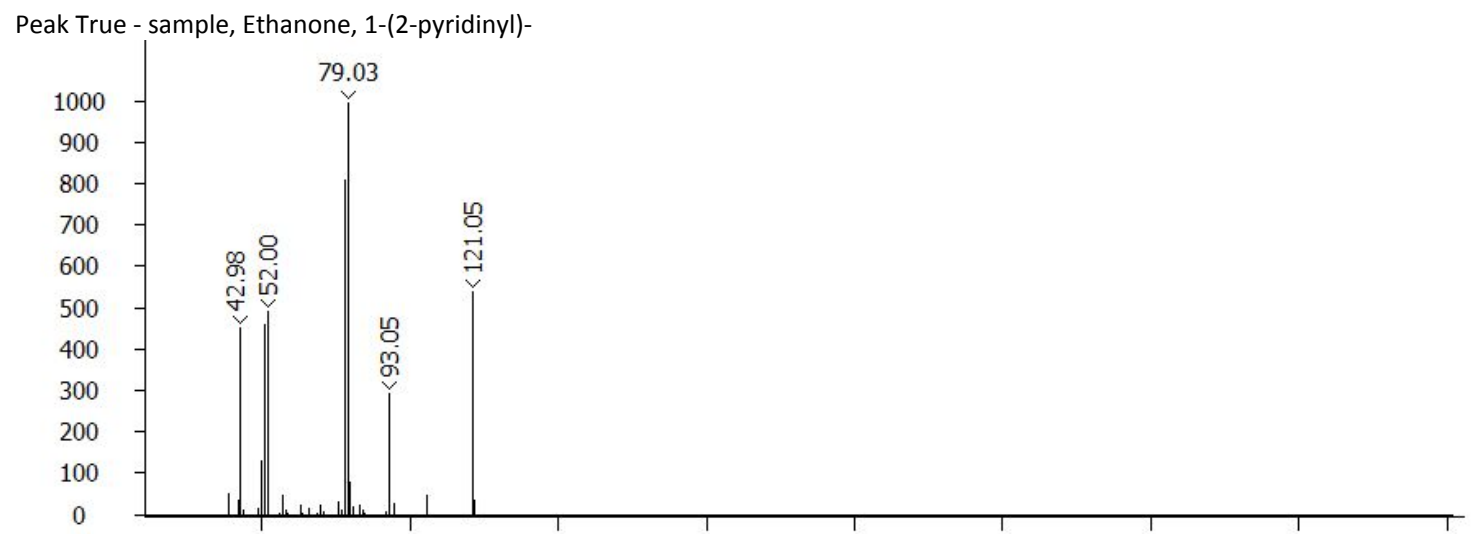

Library Hit - Similarity: 890 - Library: mainlib - Ethanone, 1-(2-pyridinyl)-, Abundance
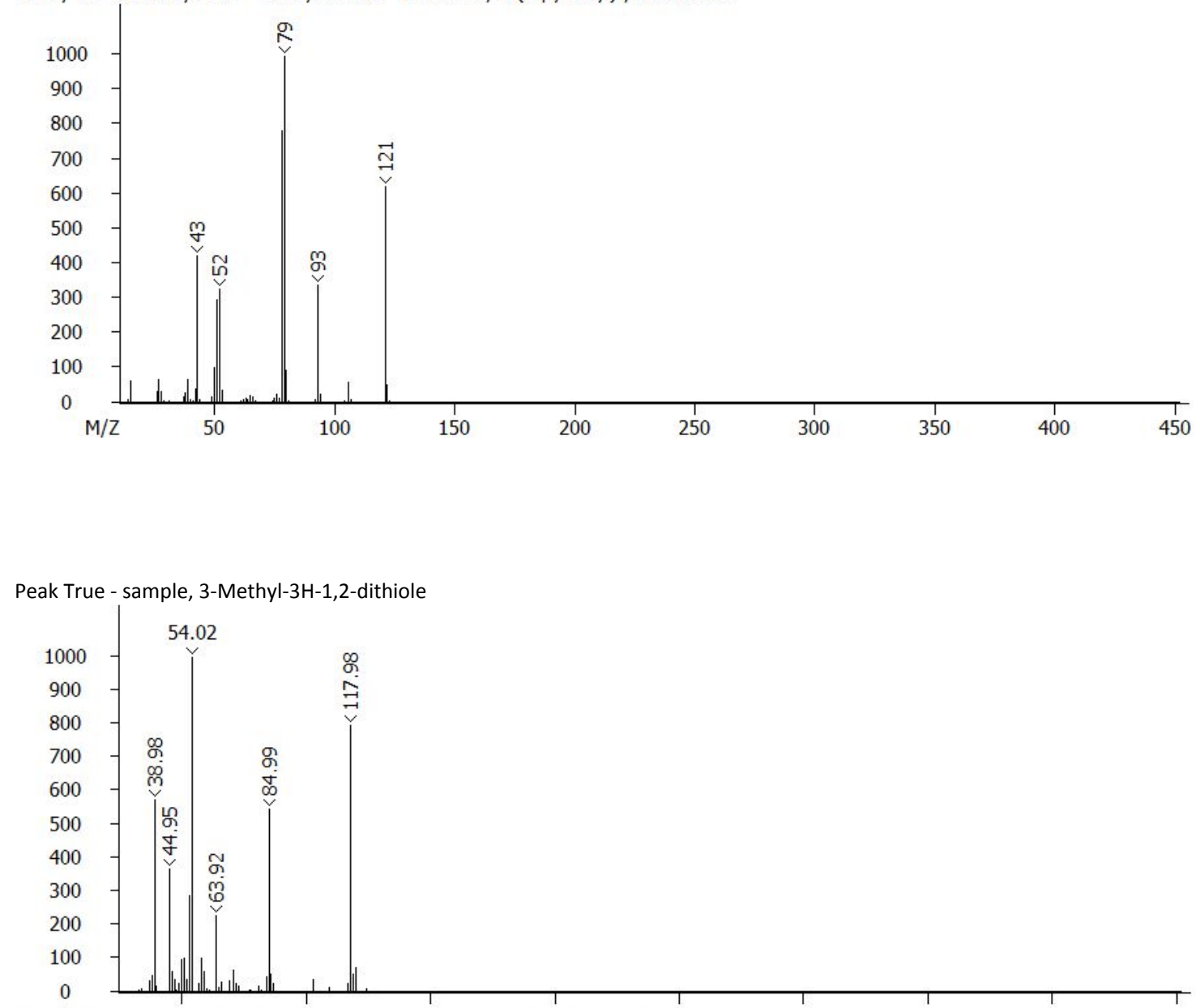

Library Hit - Similarity: 797 - Library: mainlib - 3-Methyl-3H-1,2-dithiole, Abundance

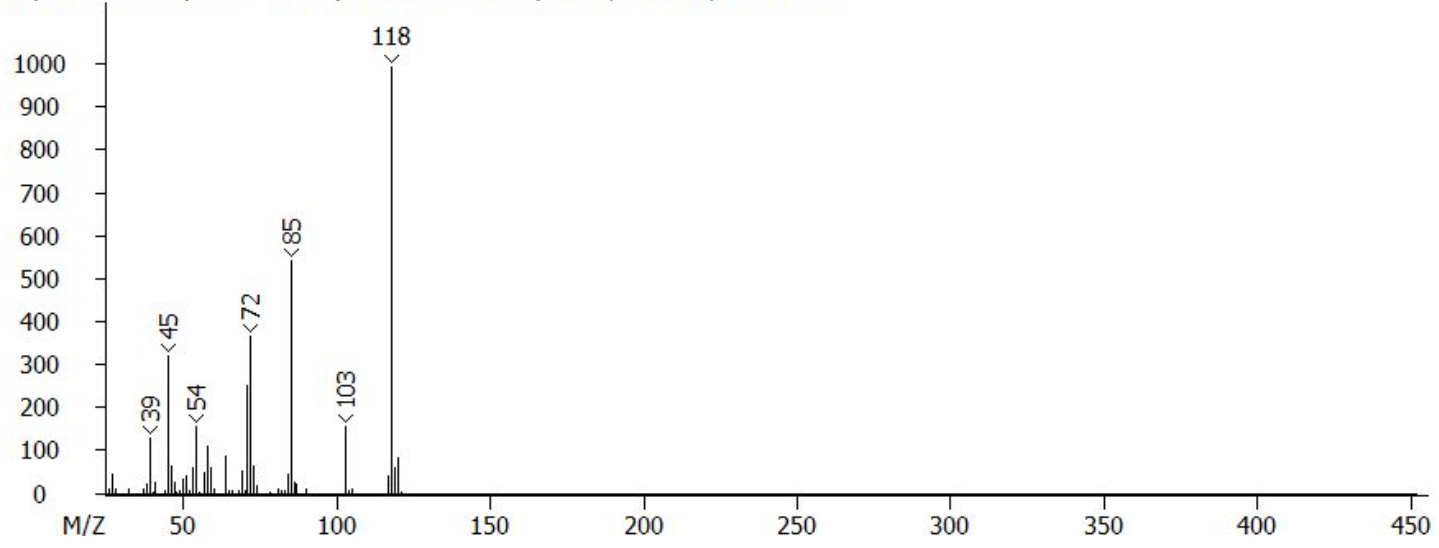




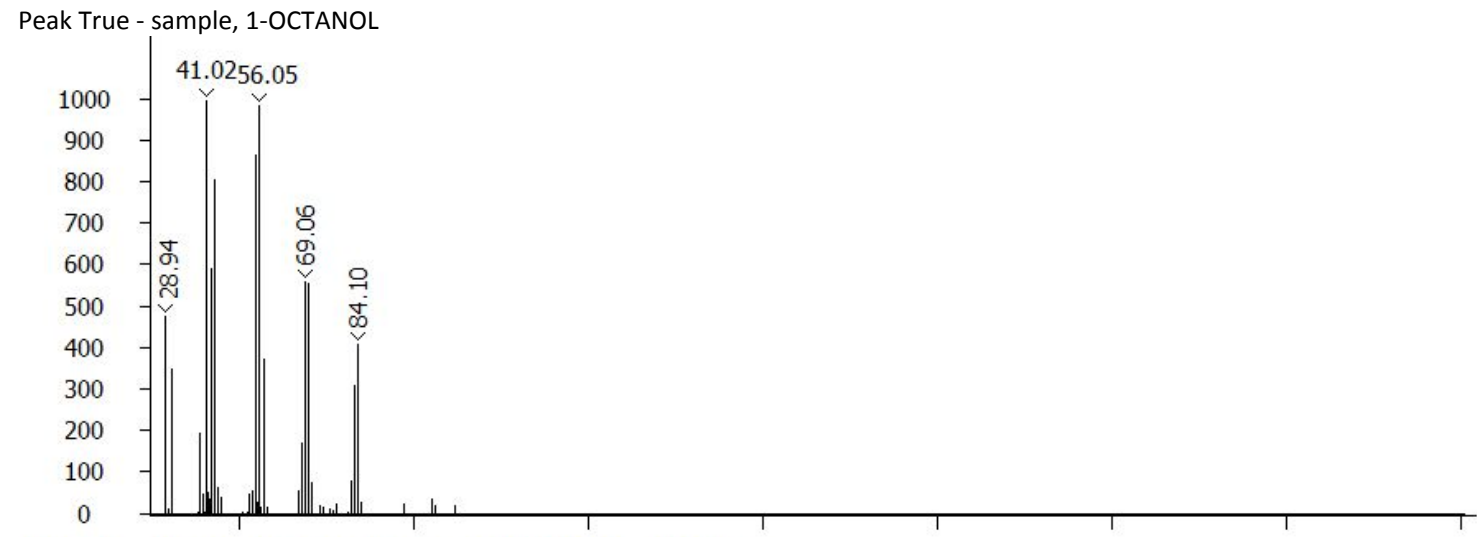

Library Hit - Similarity: 962 - Library: Wiley9 - 1-OCTANOL, Abundance
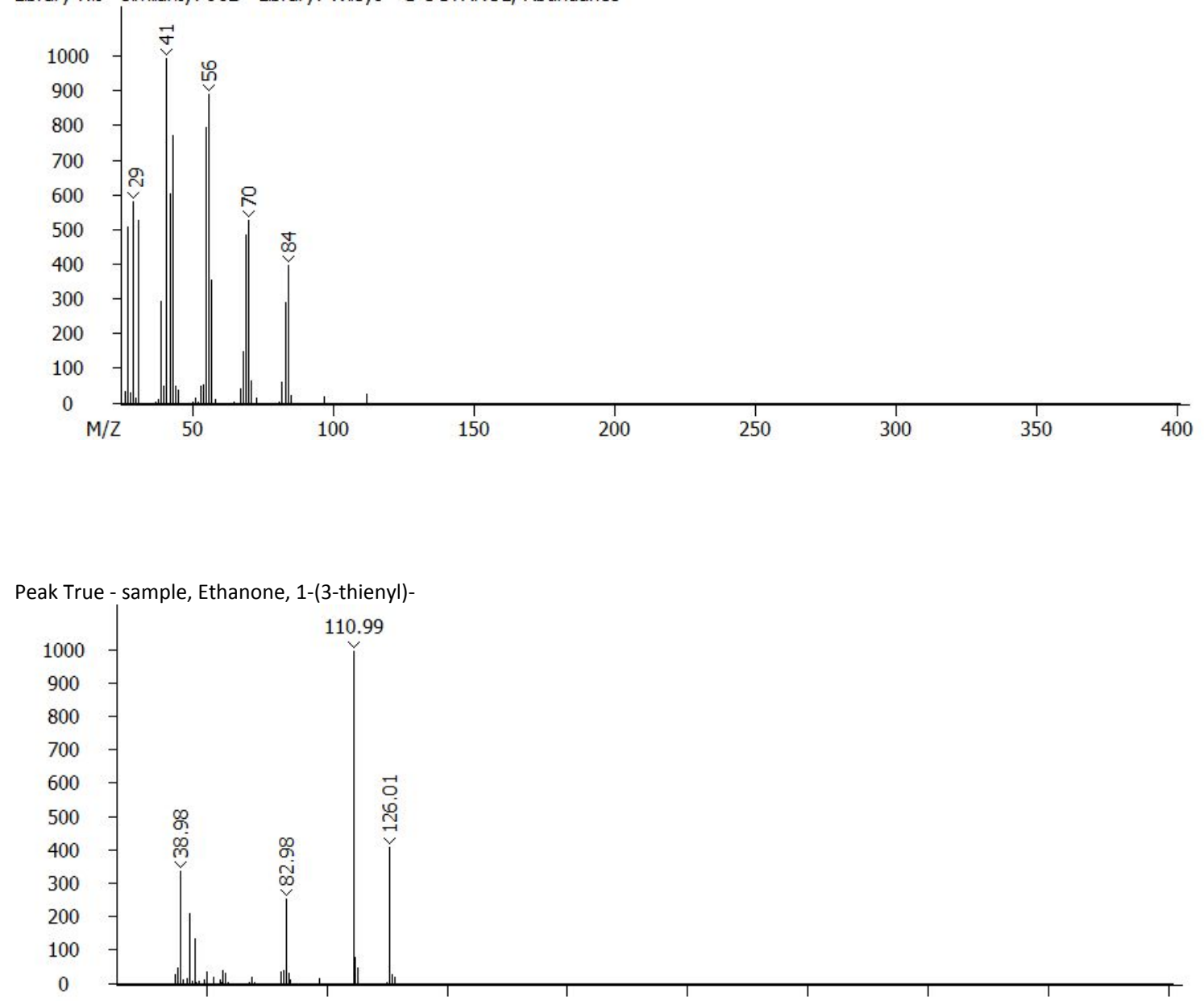

ibrary Hit - Similarity: 941 - Library: mainlib - Ethanone, 1-(3-thienyl)-, Abundance

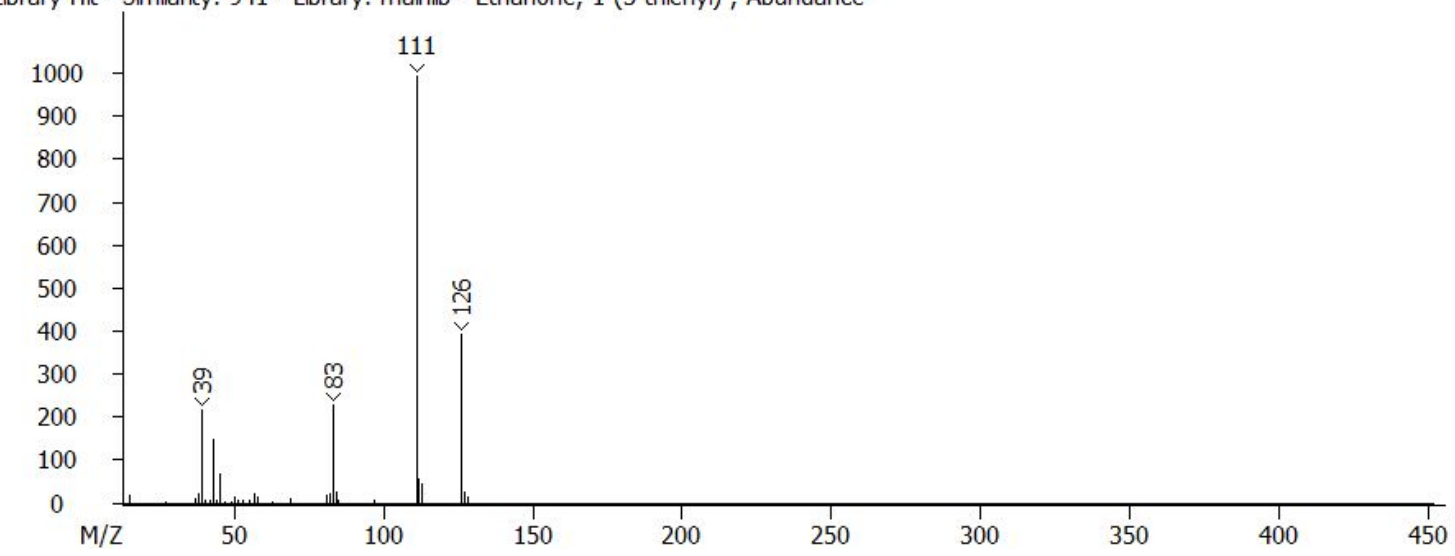




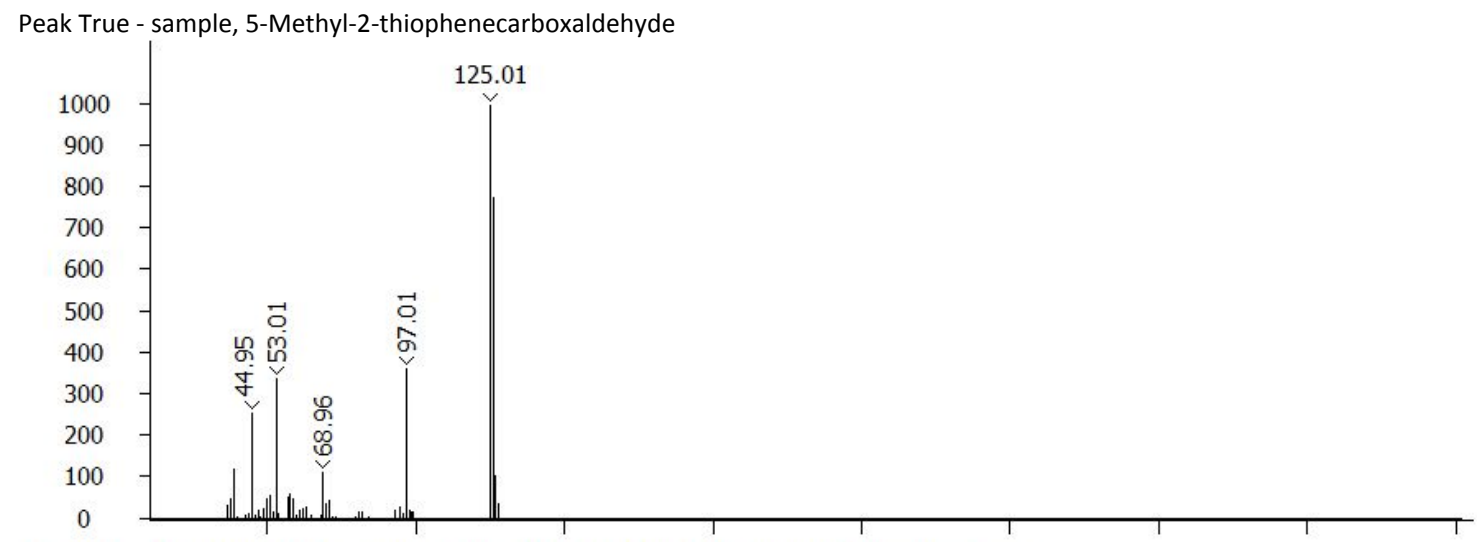

Library Hit - Similarity: 950 - Library: mainlib - 5-Methyl-2-thiophenecarboxaldehyde, Abundance
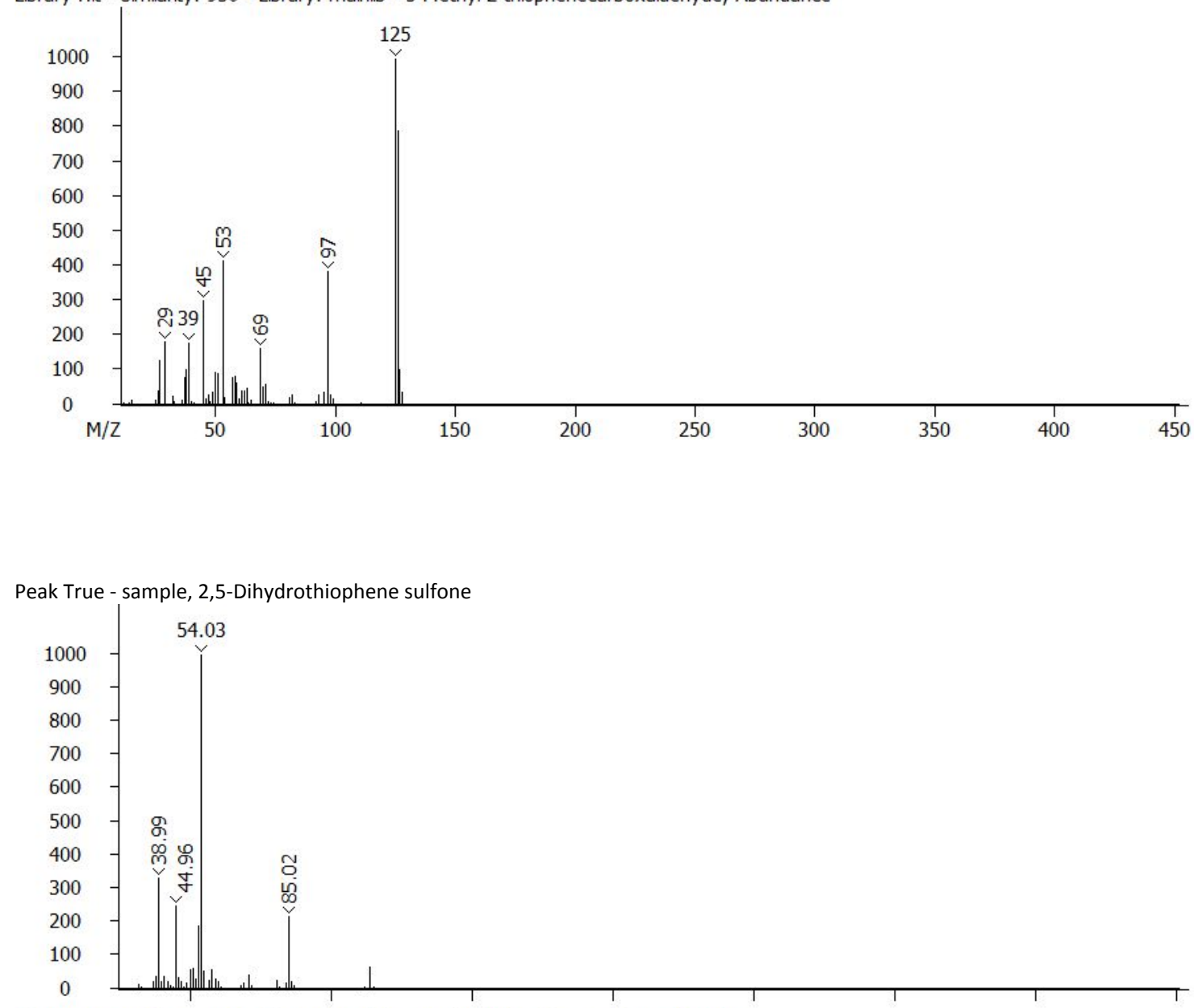

Library Hit - Similarity: 729 - Library: mainlib - 2,5-Dihydrothiophene sulfone, Abundance

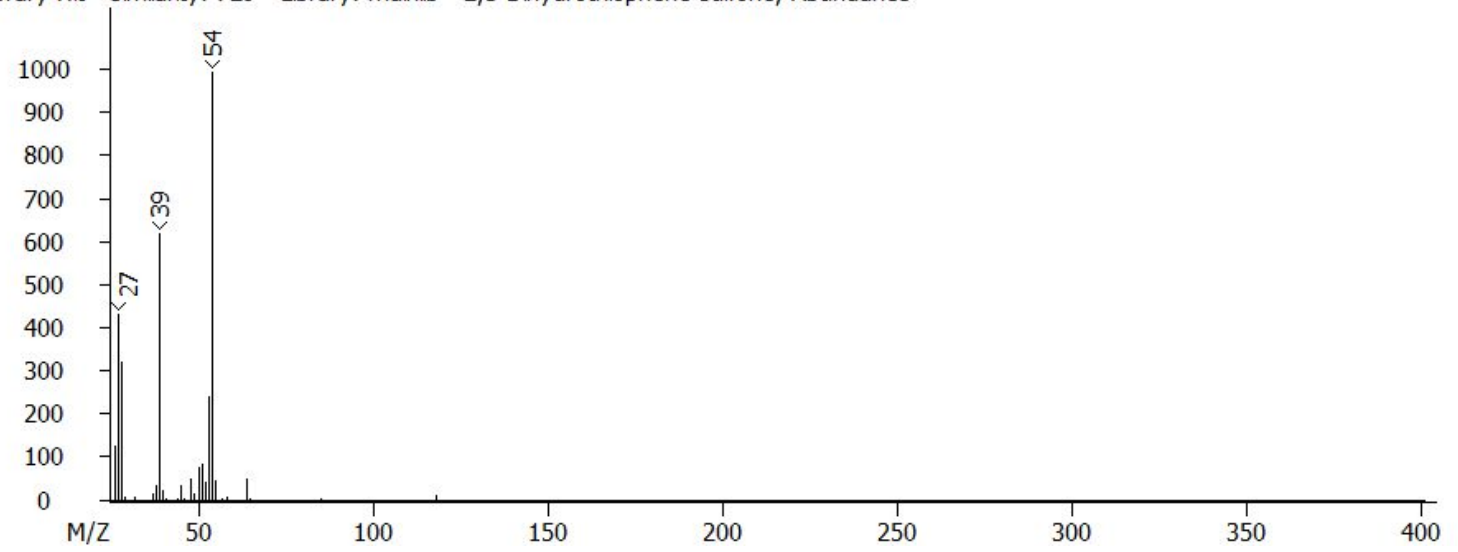




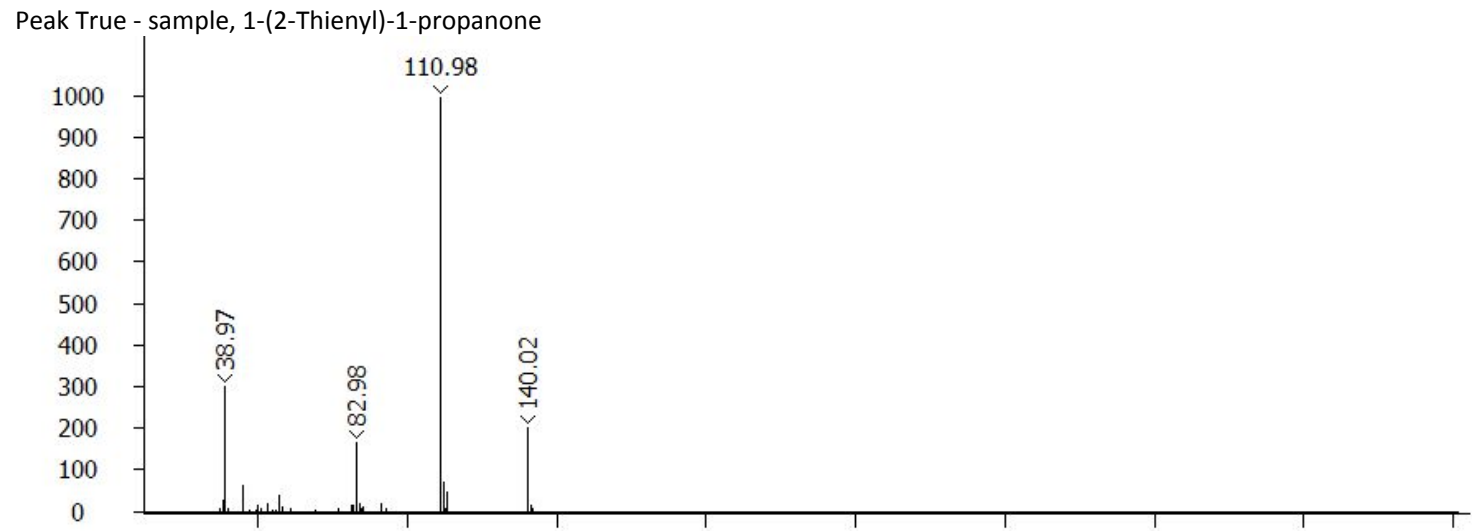

Library Hit - Similarity: 914 - Library: mainlib - 1-(2-Thienyl)-1-propanone, Abundance
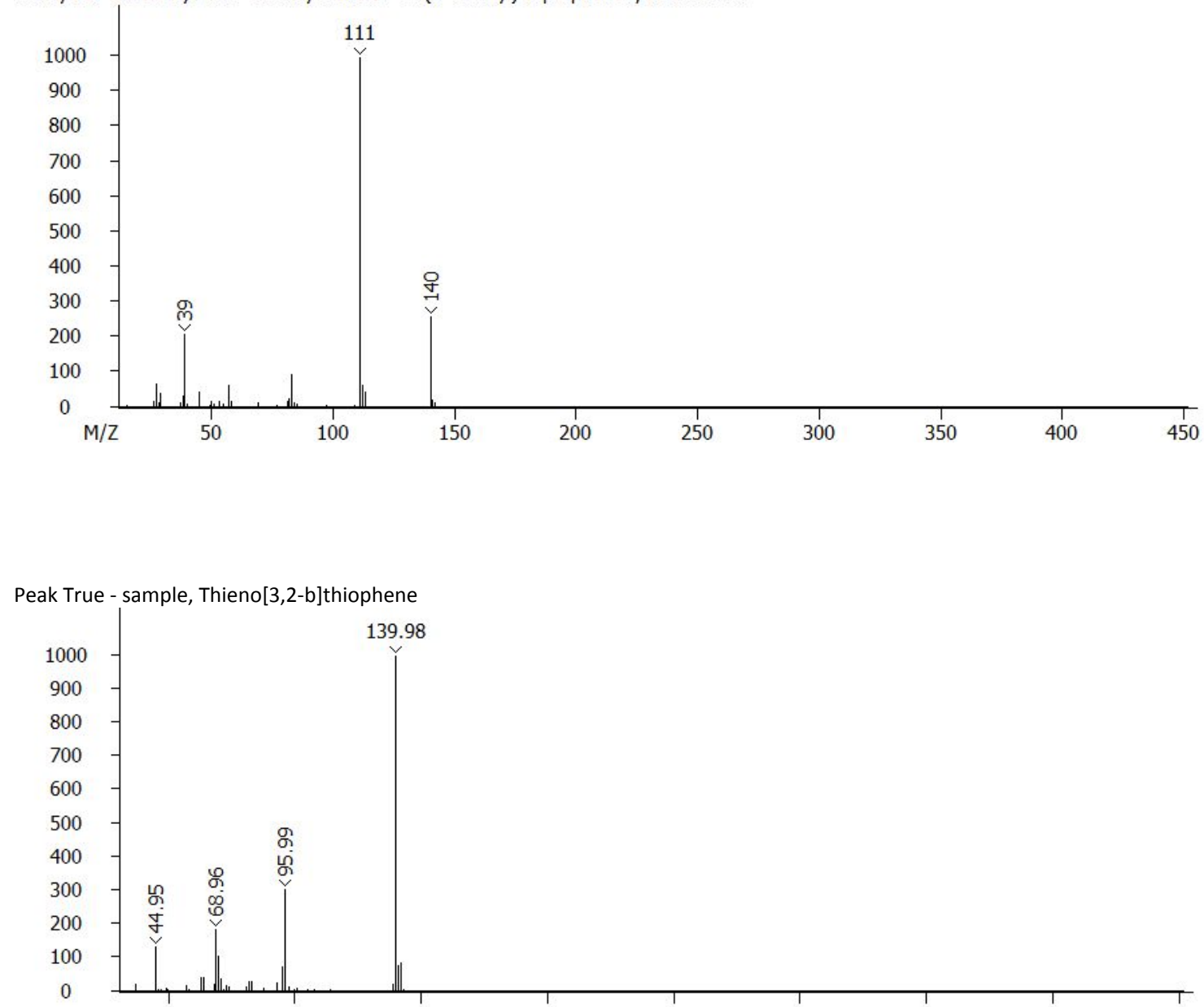

Library Hit - Similarity: 949 - Library: mainlib - Thieno[3,2-b]thiophene, Abundance

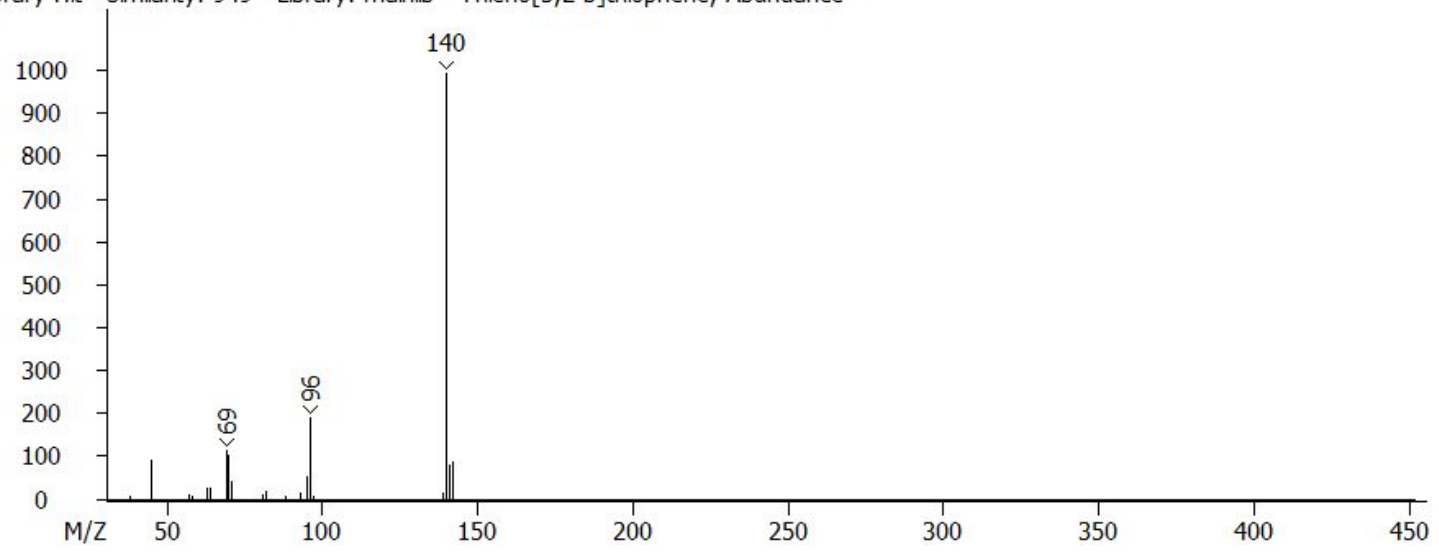




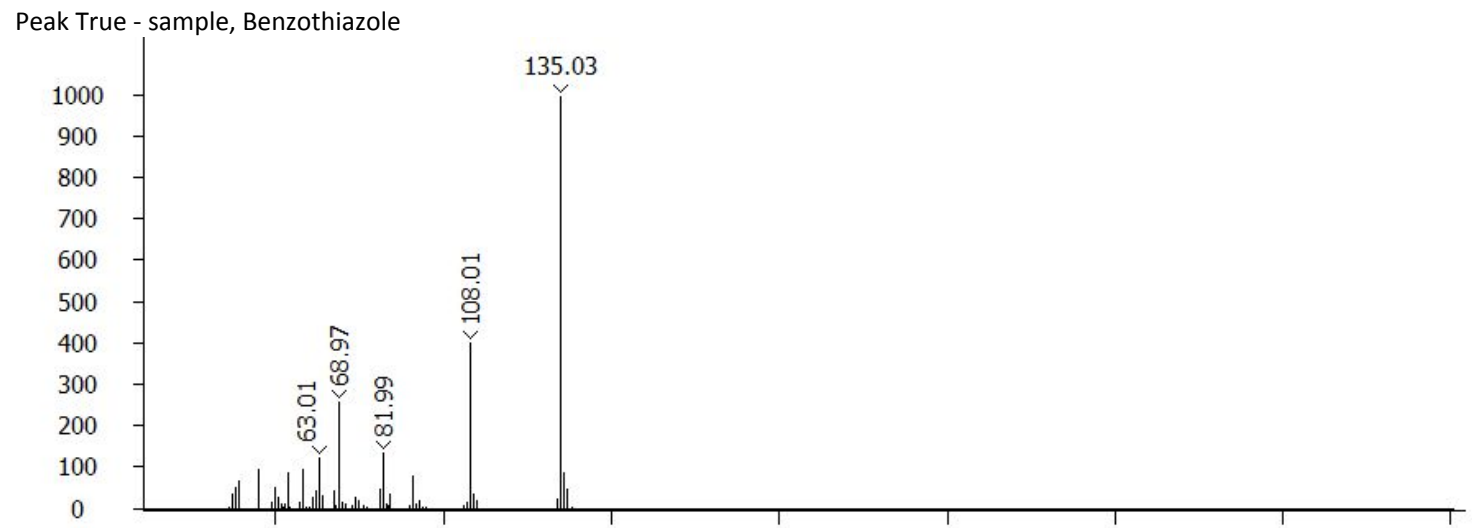

Library Hit - Similarity: 953 - Library: replib - Benzothiazole, Abundance
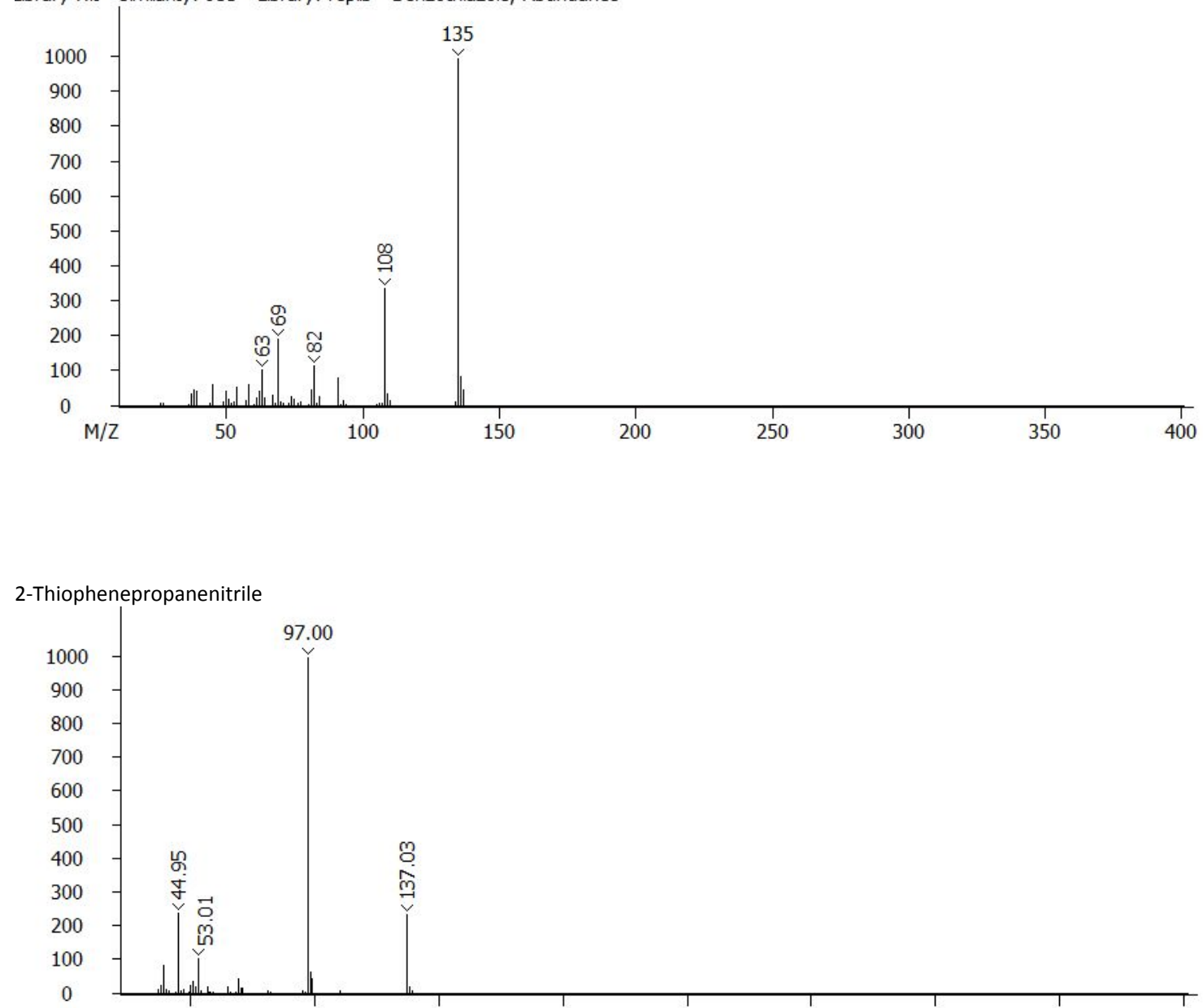

Library Hit - Similarity: 944 - Library: mainlib - 2-Thiophenepropanenitrile, Abundance

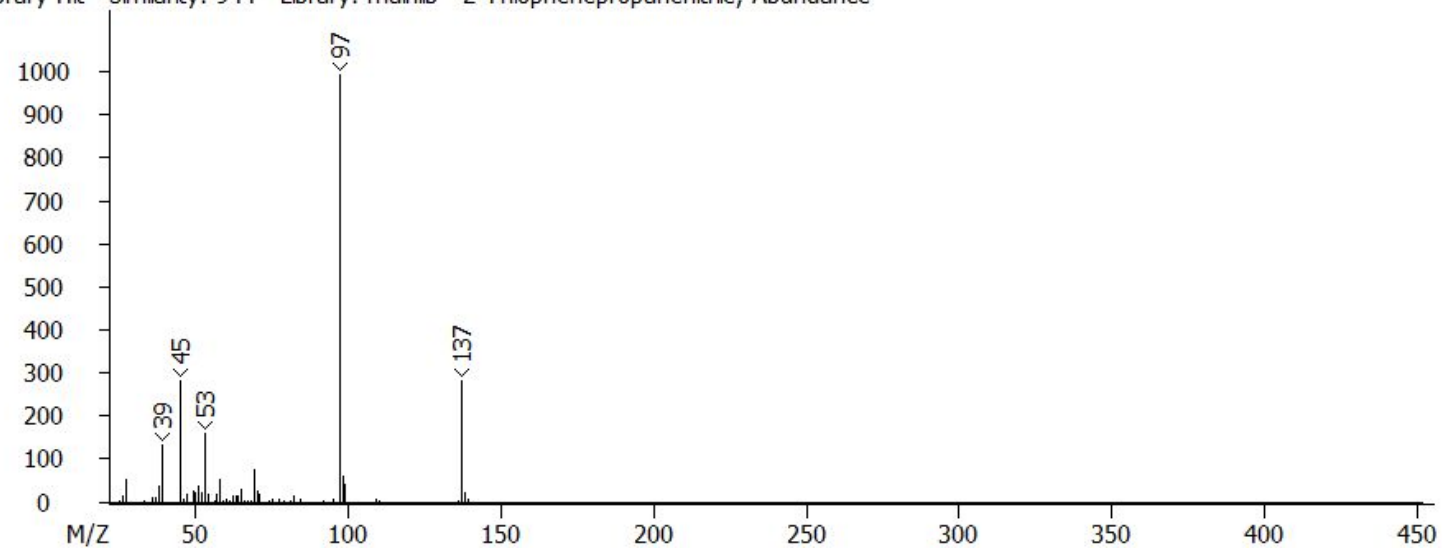




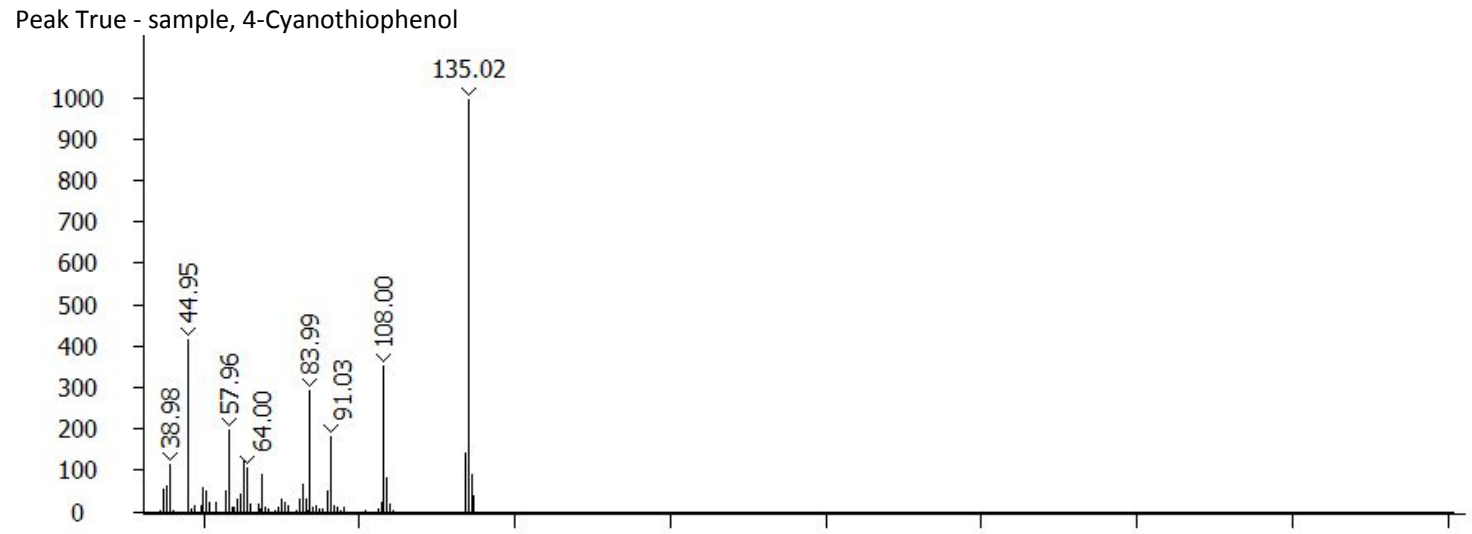

Library Hit - Similarity: 857 - Library: mainlib - 4-Cyanothiophenol, Abundance

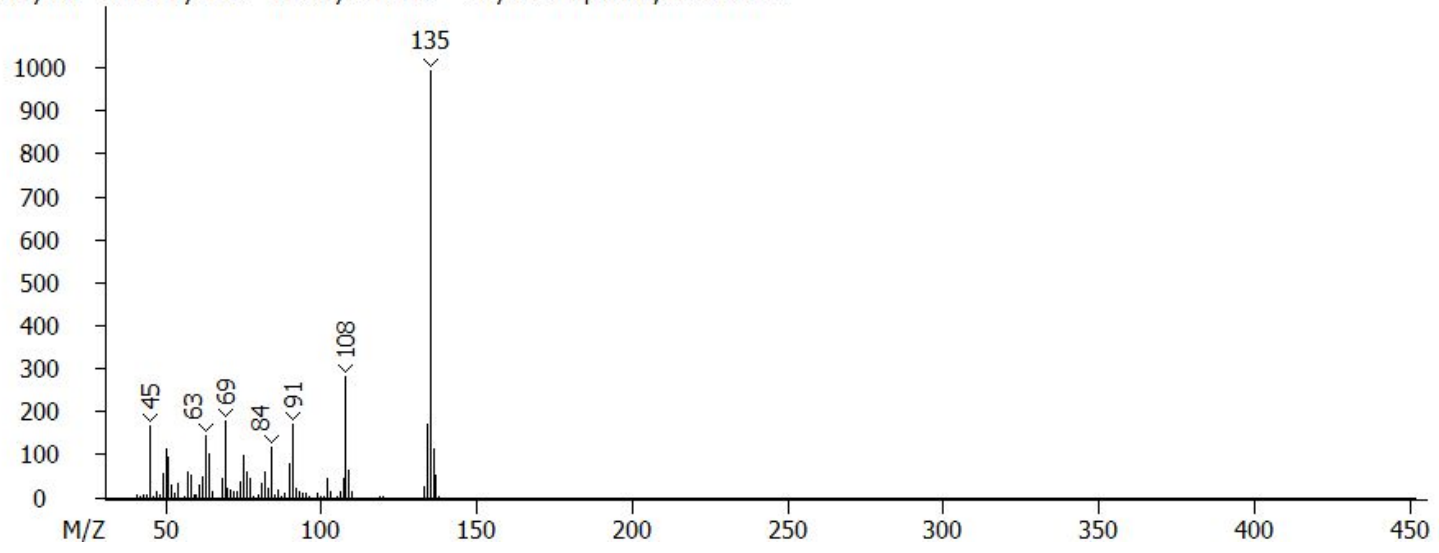




\section{Mass sepctra of standards}

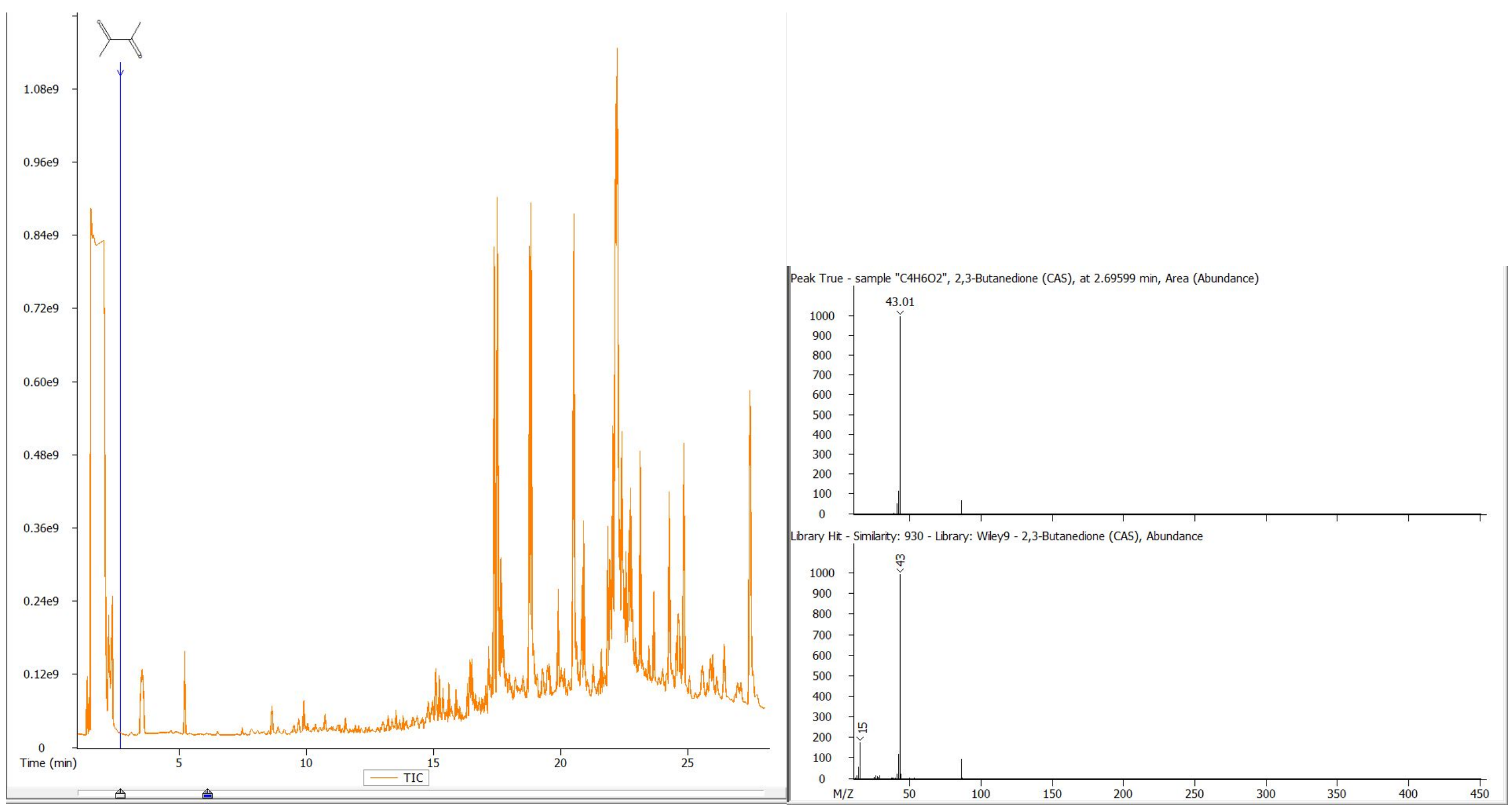




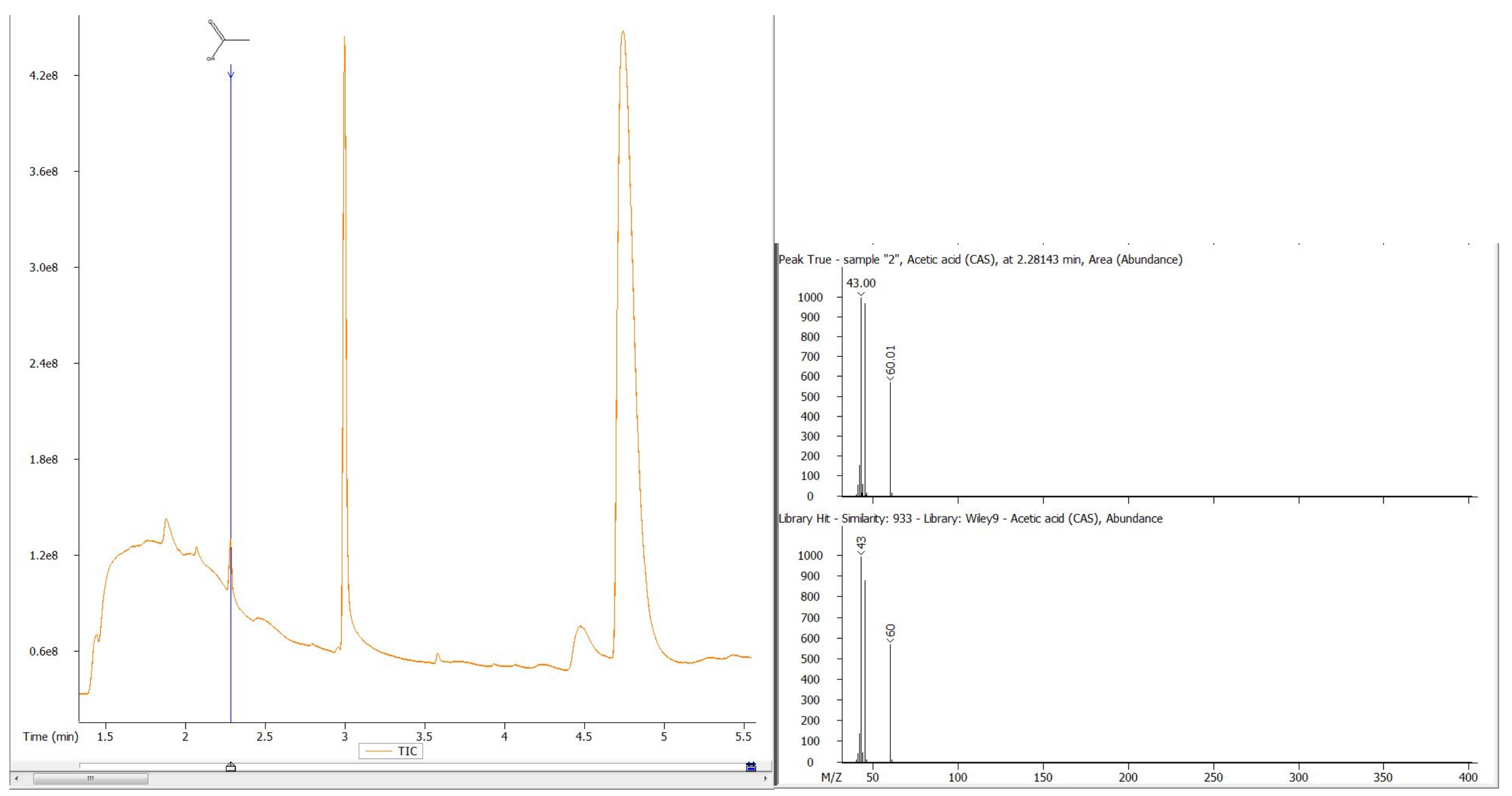




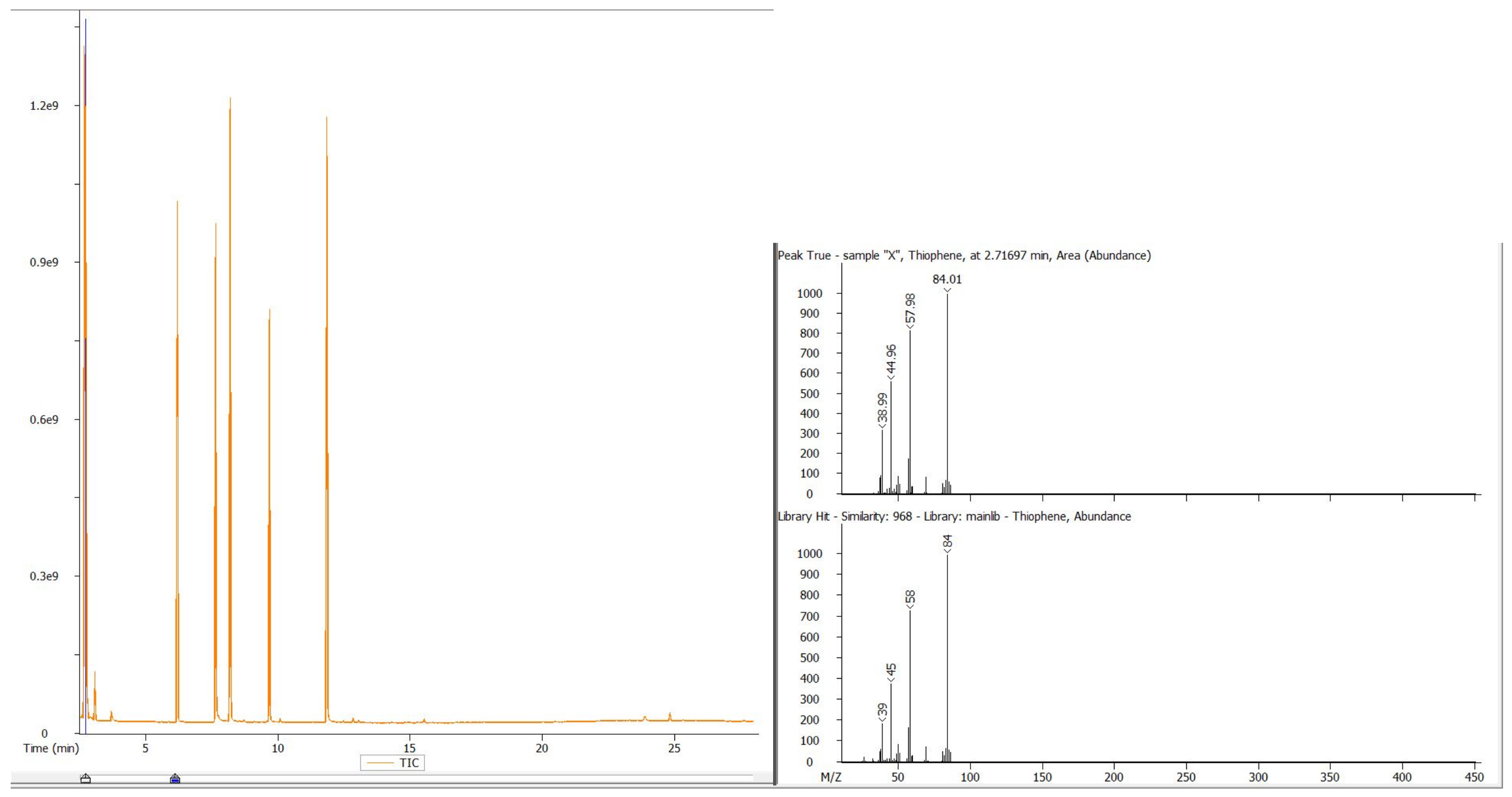




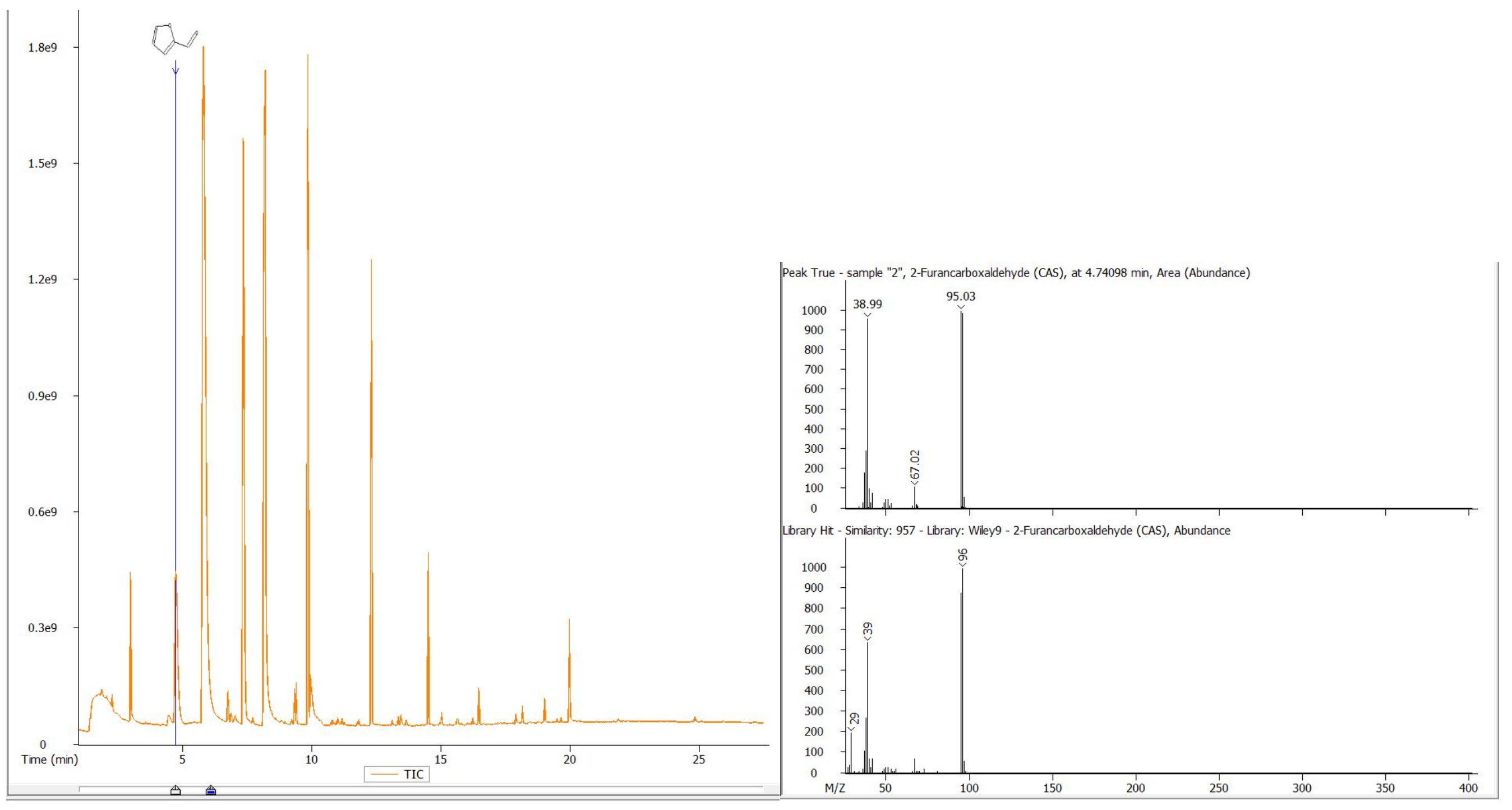




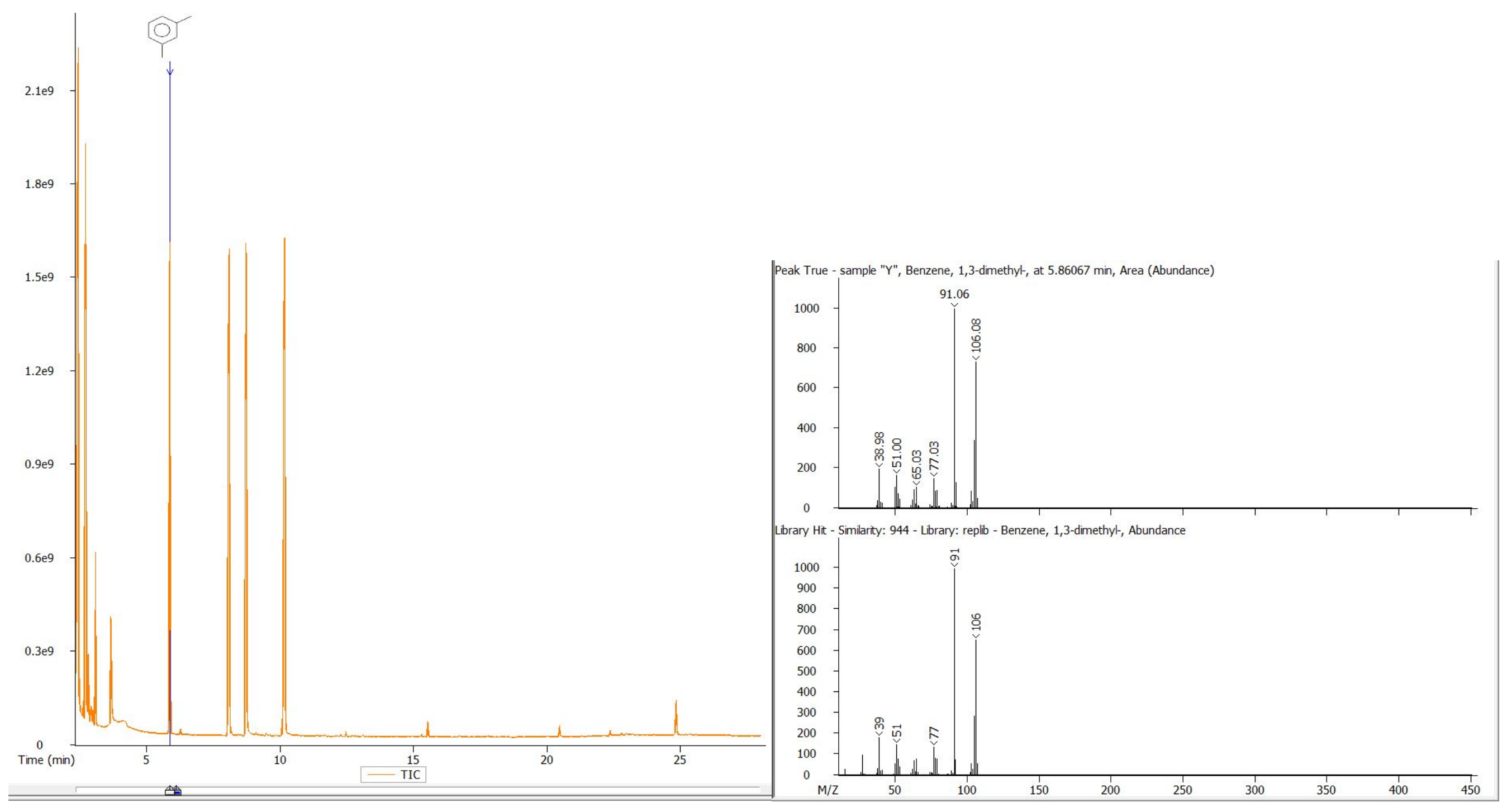




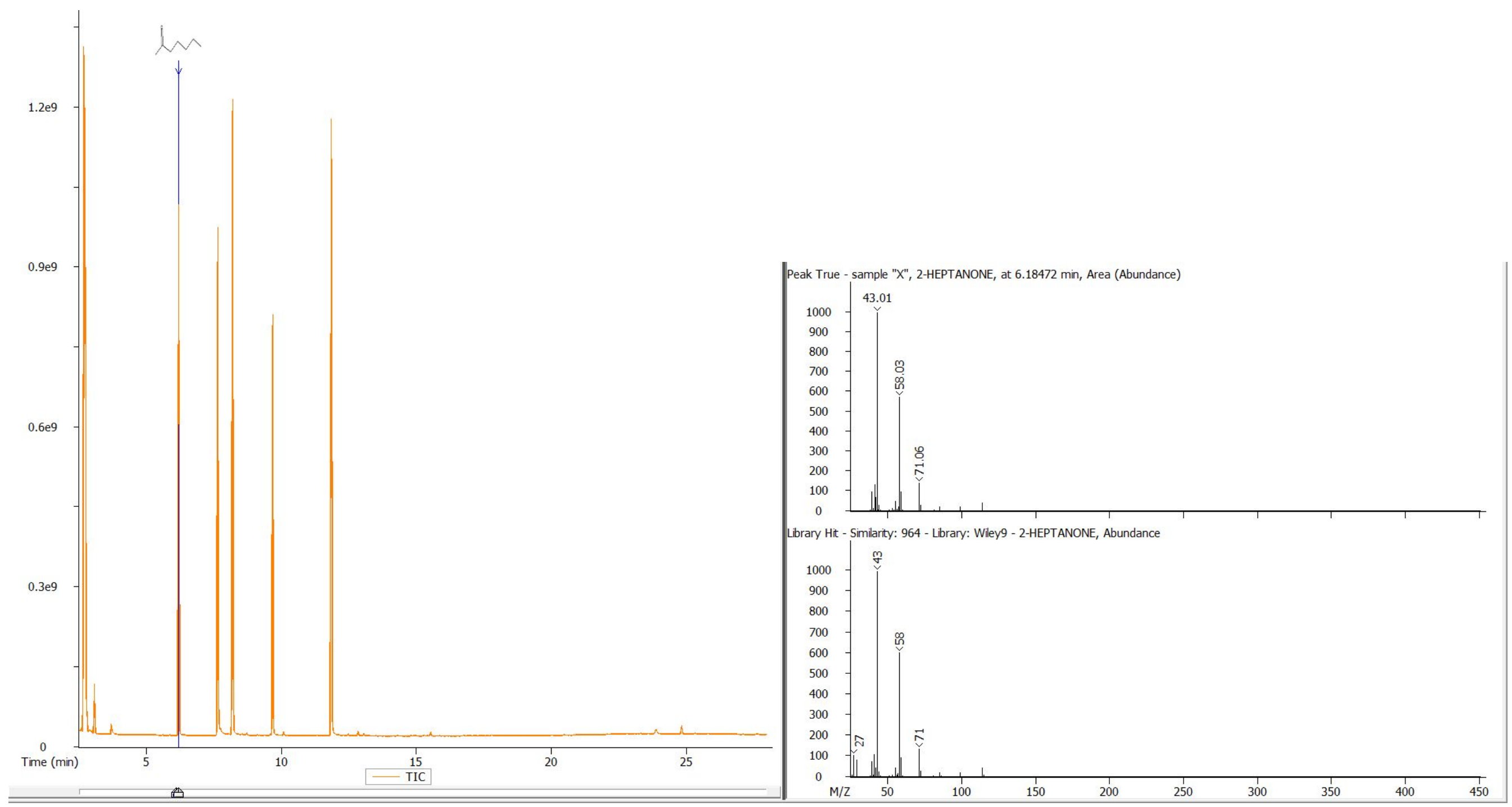




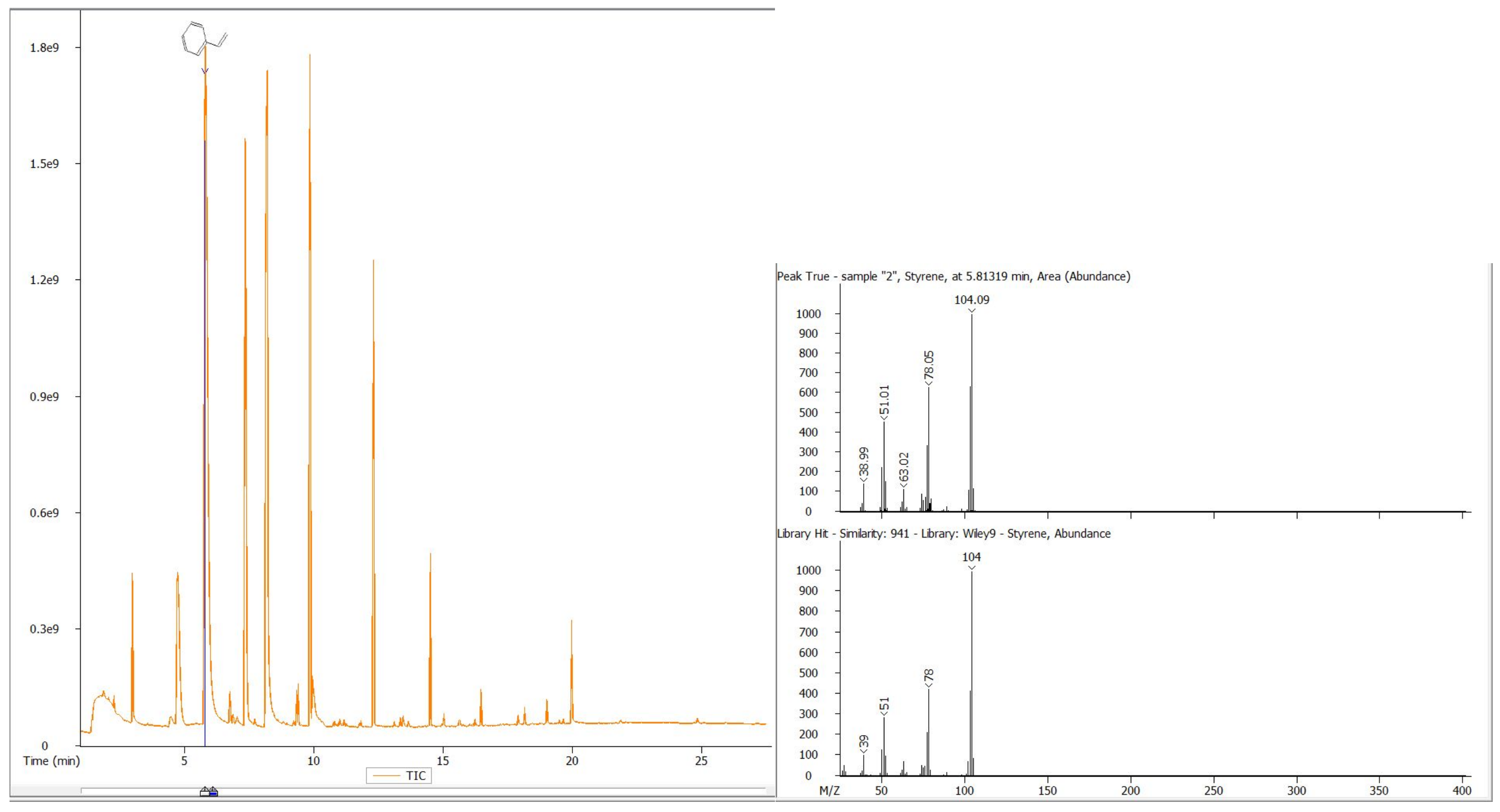




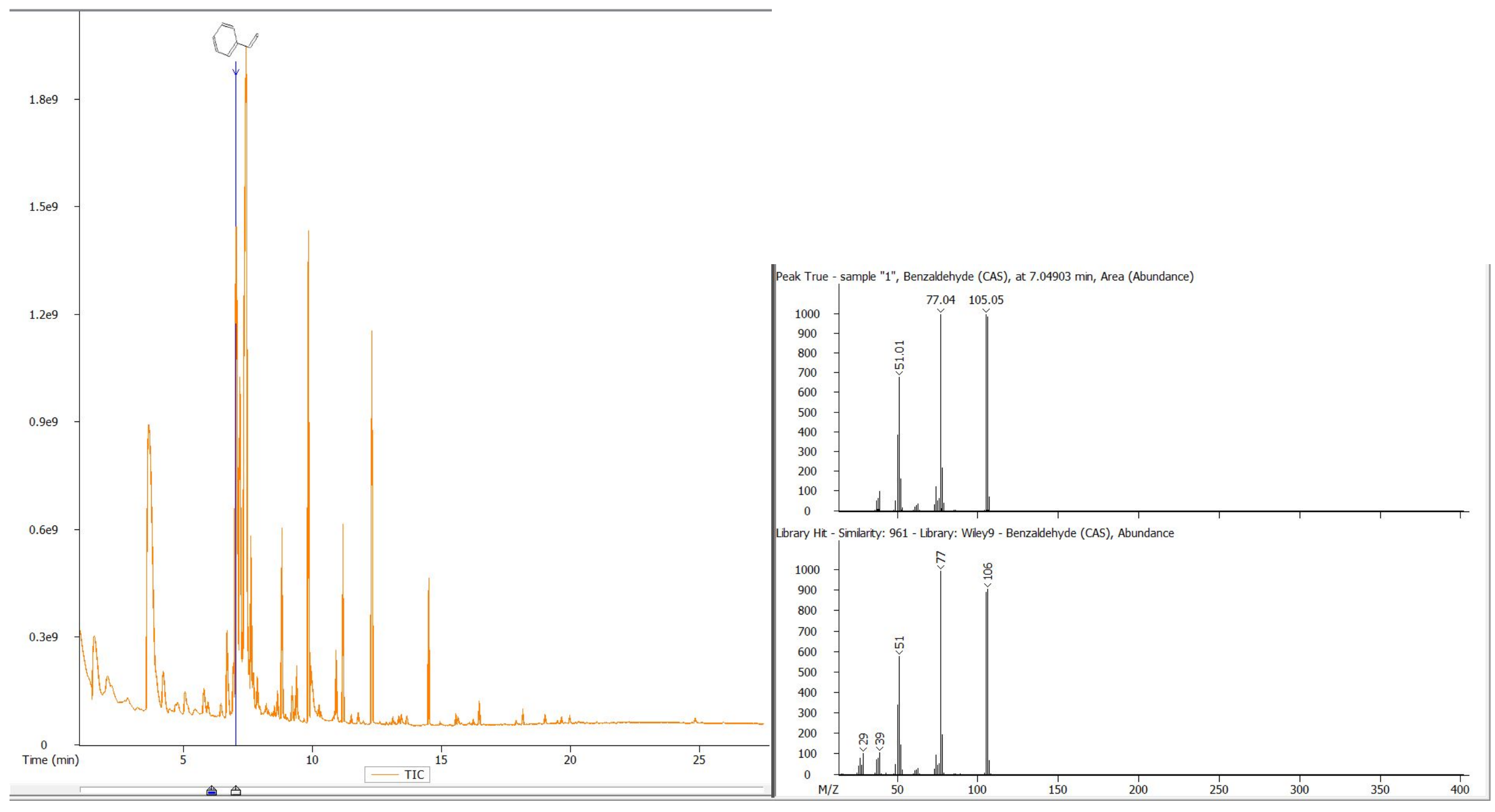




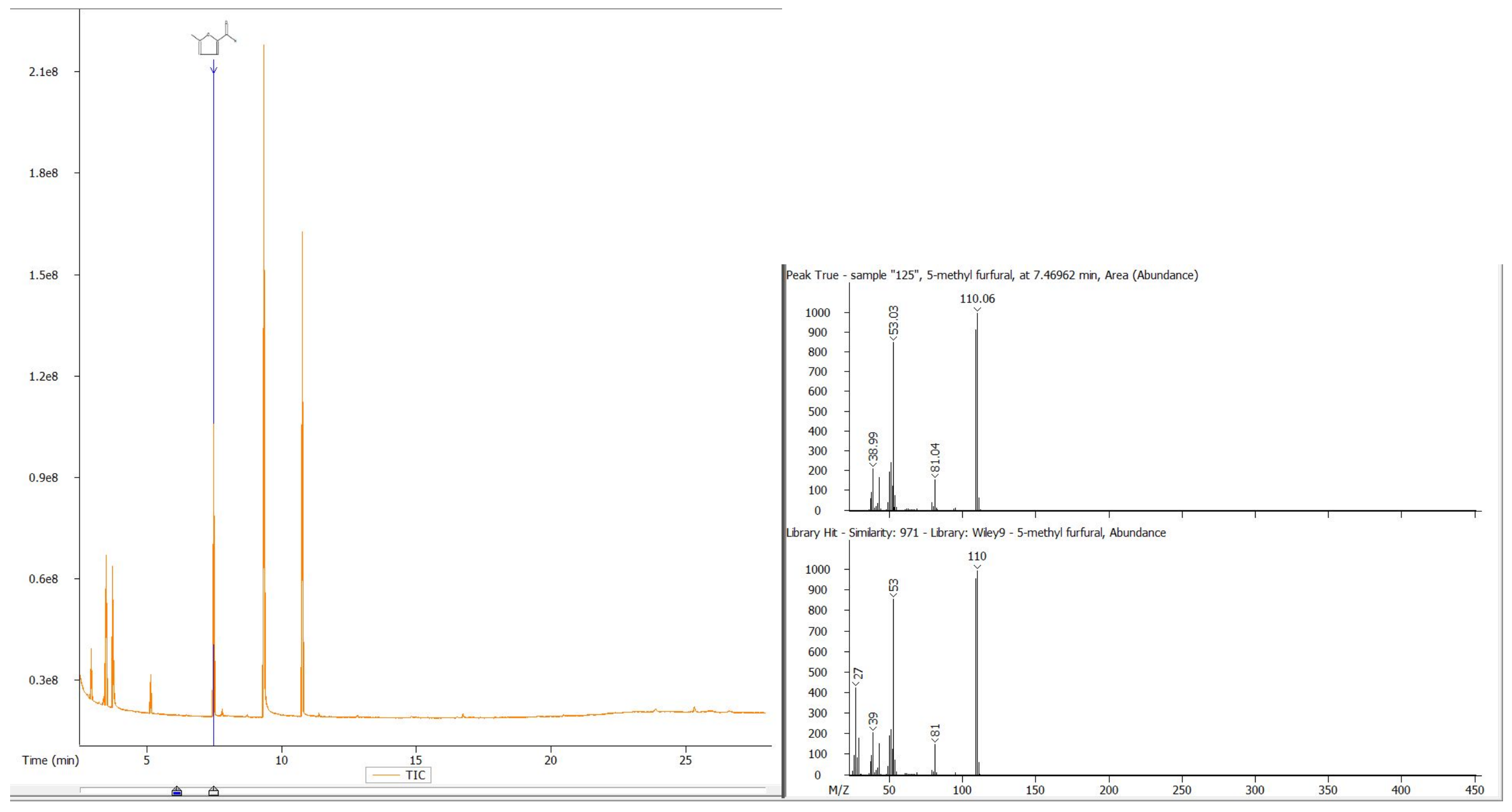




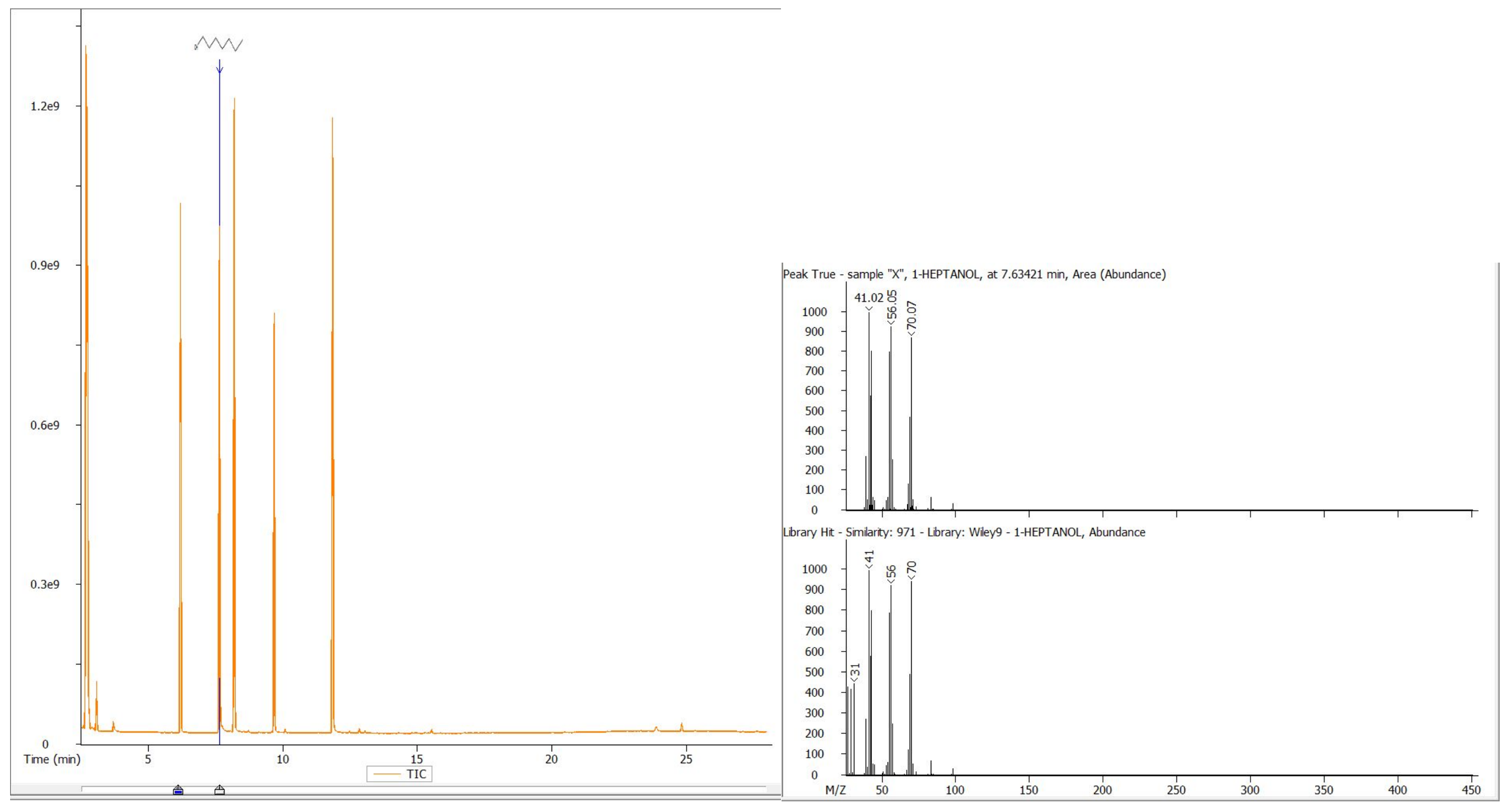




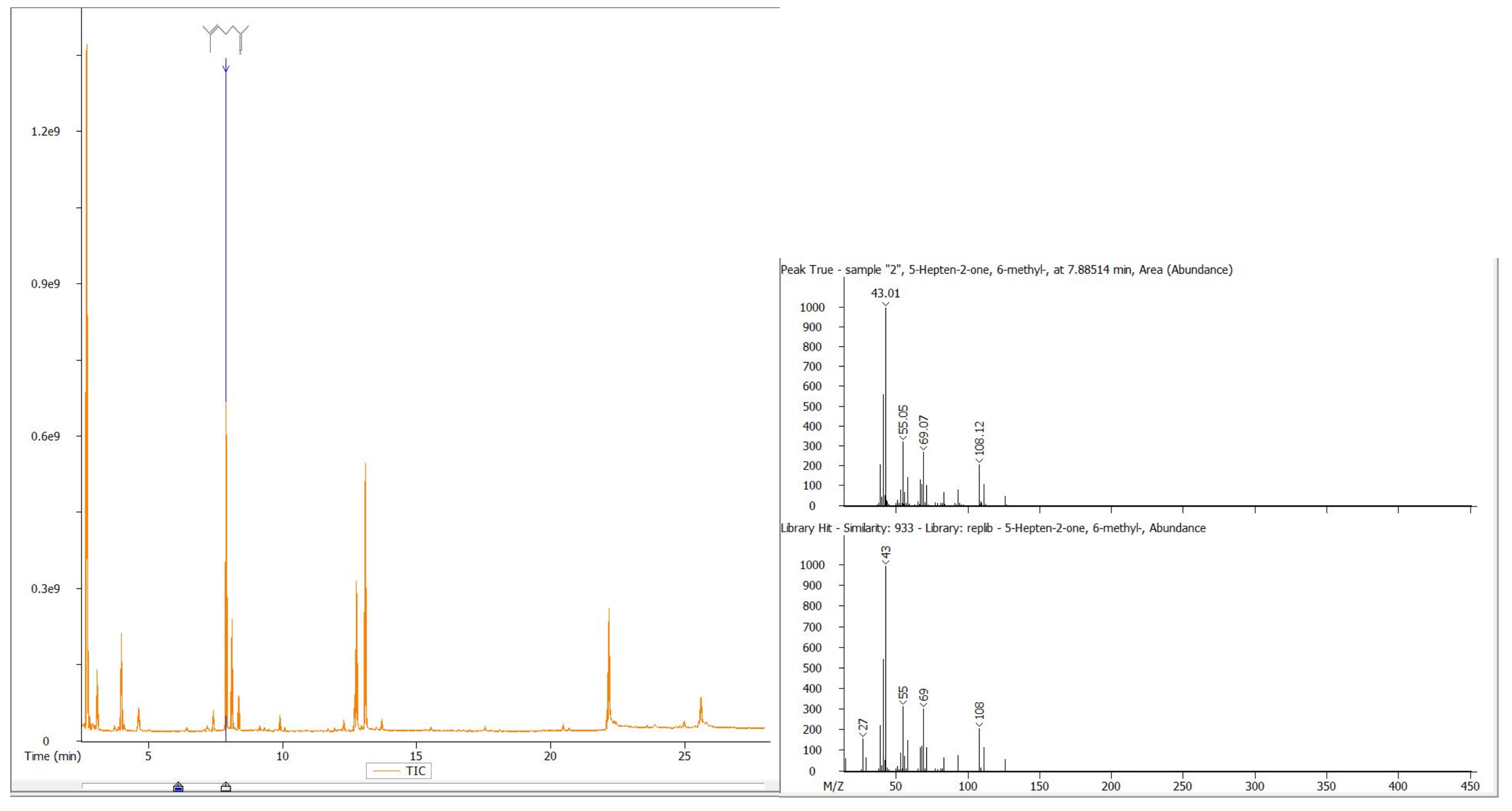




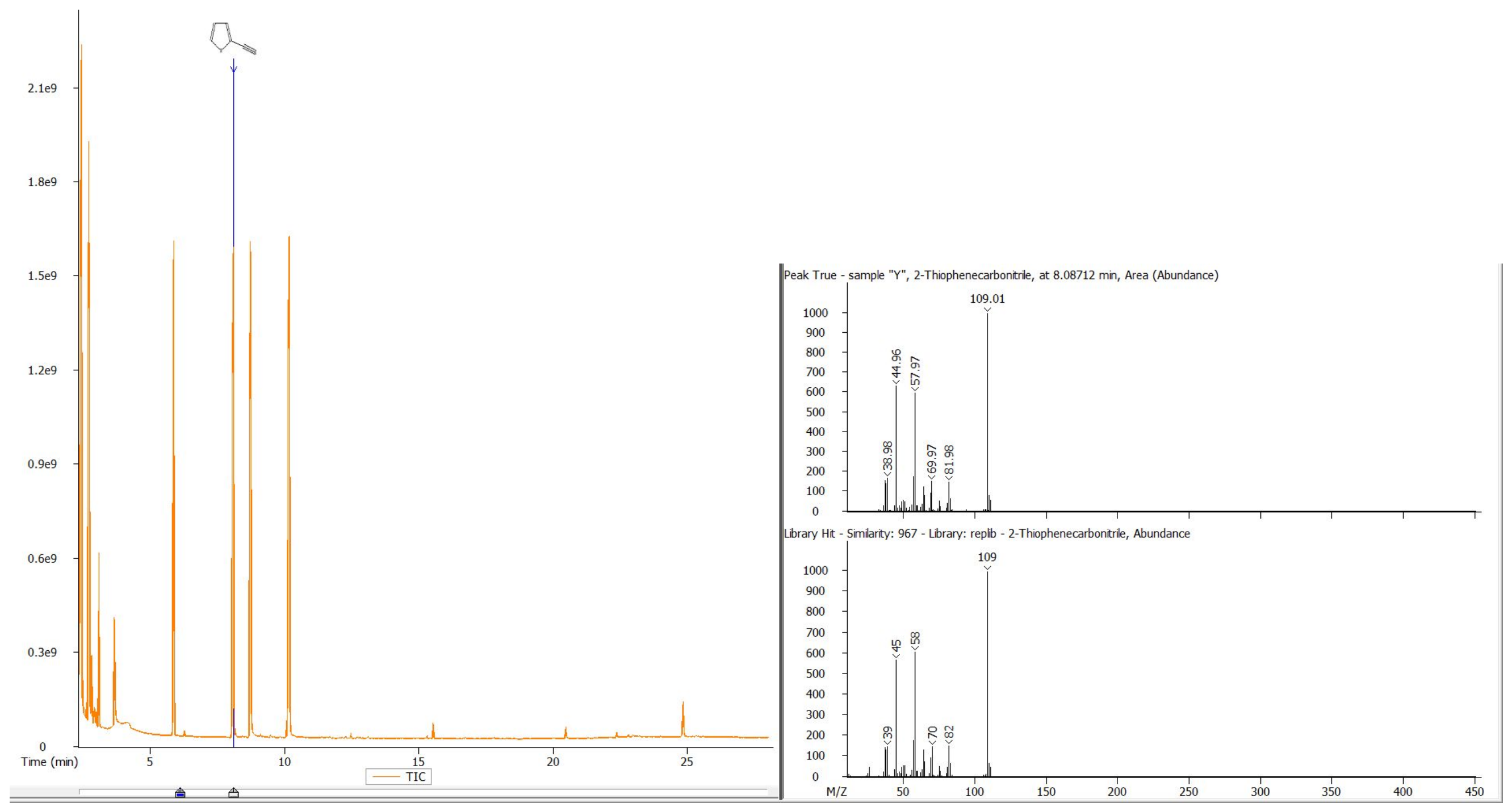



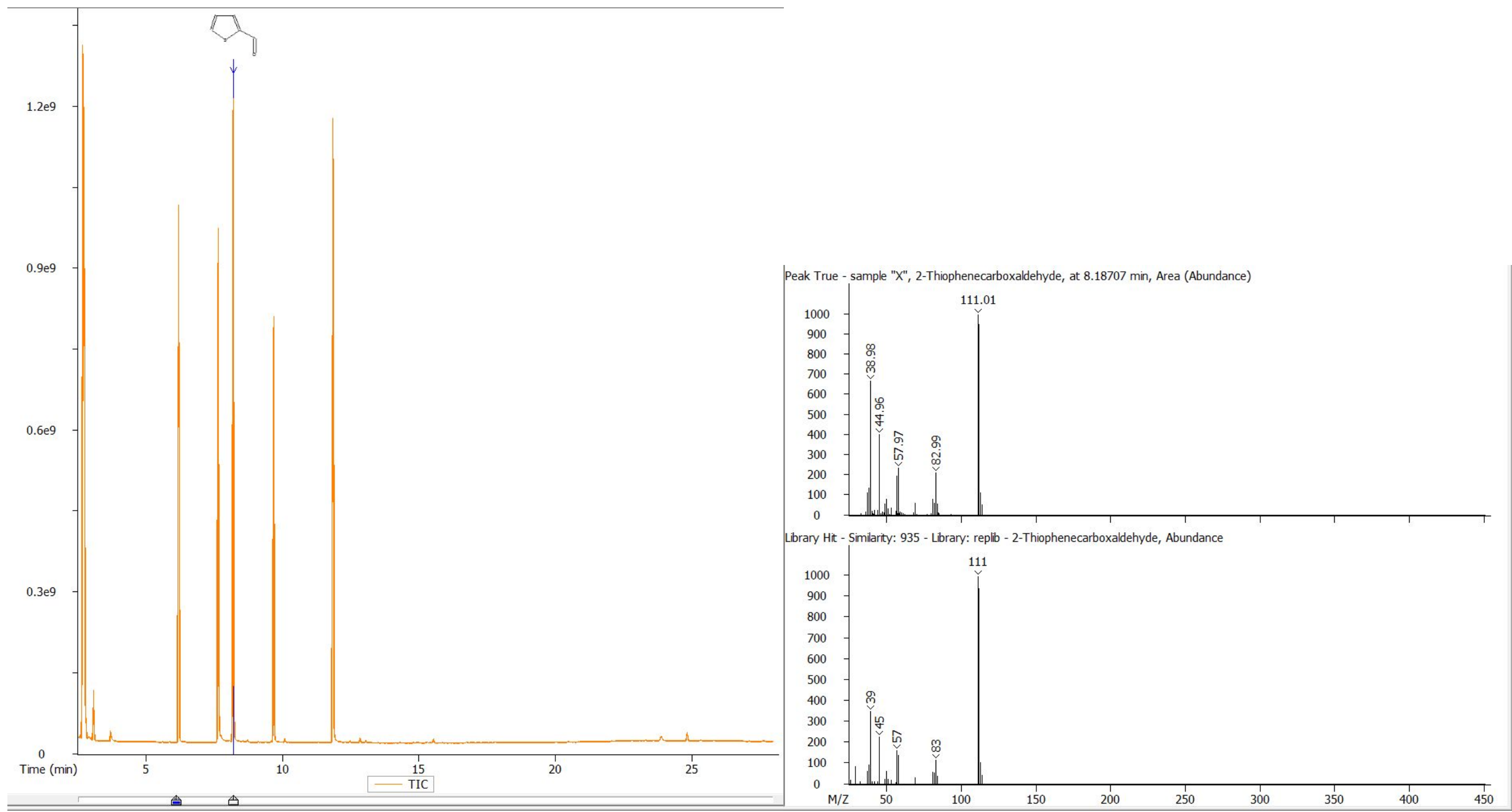


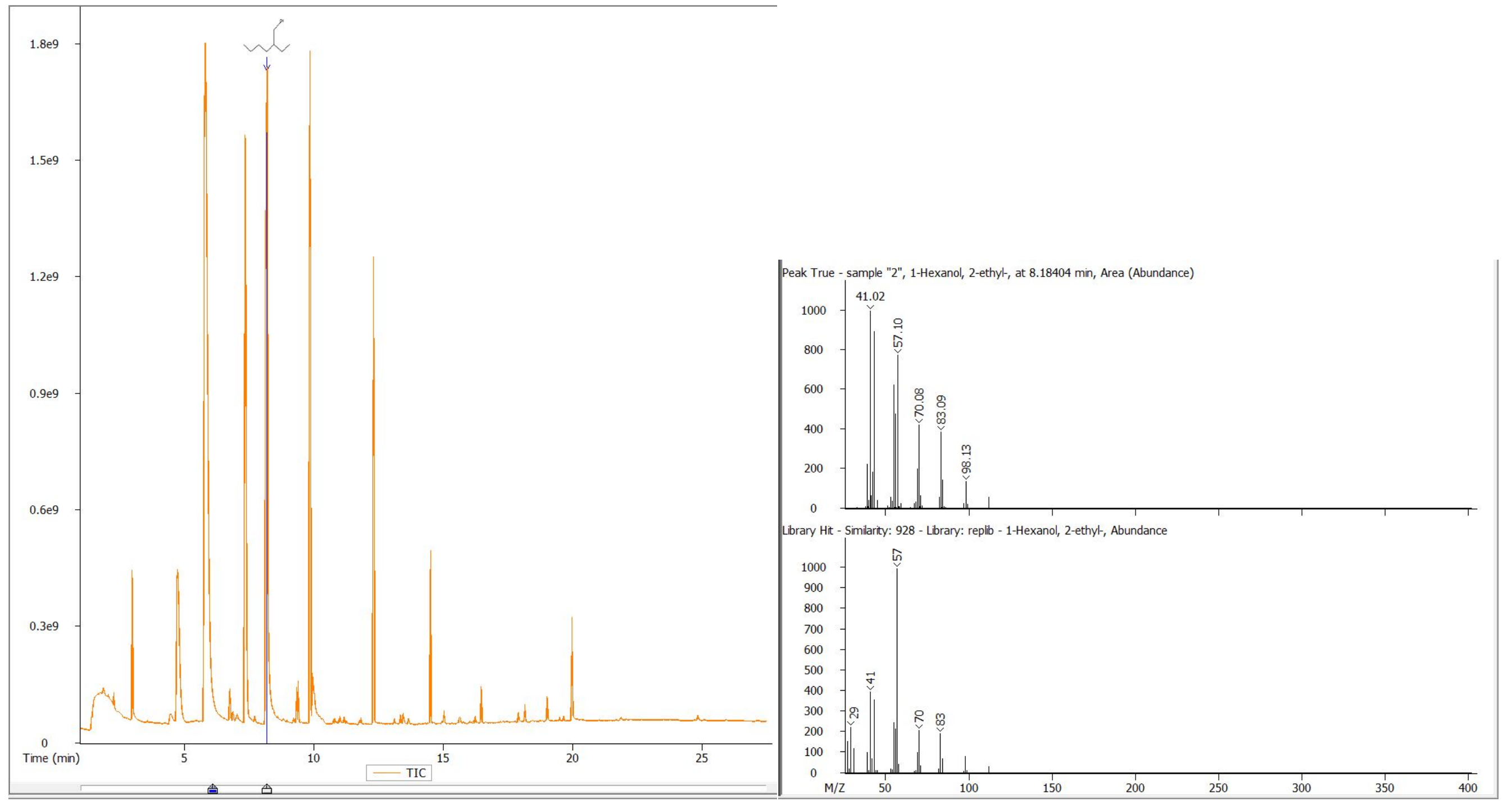




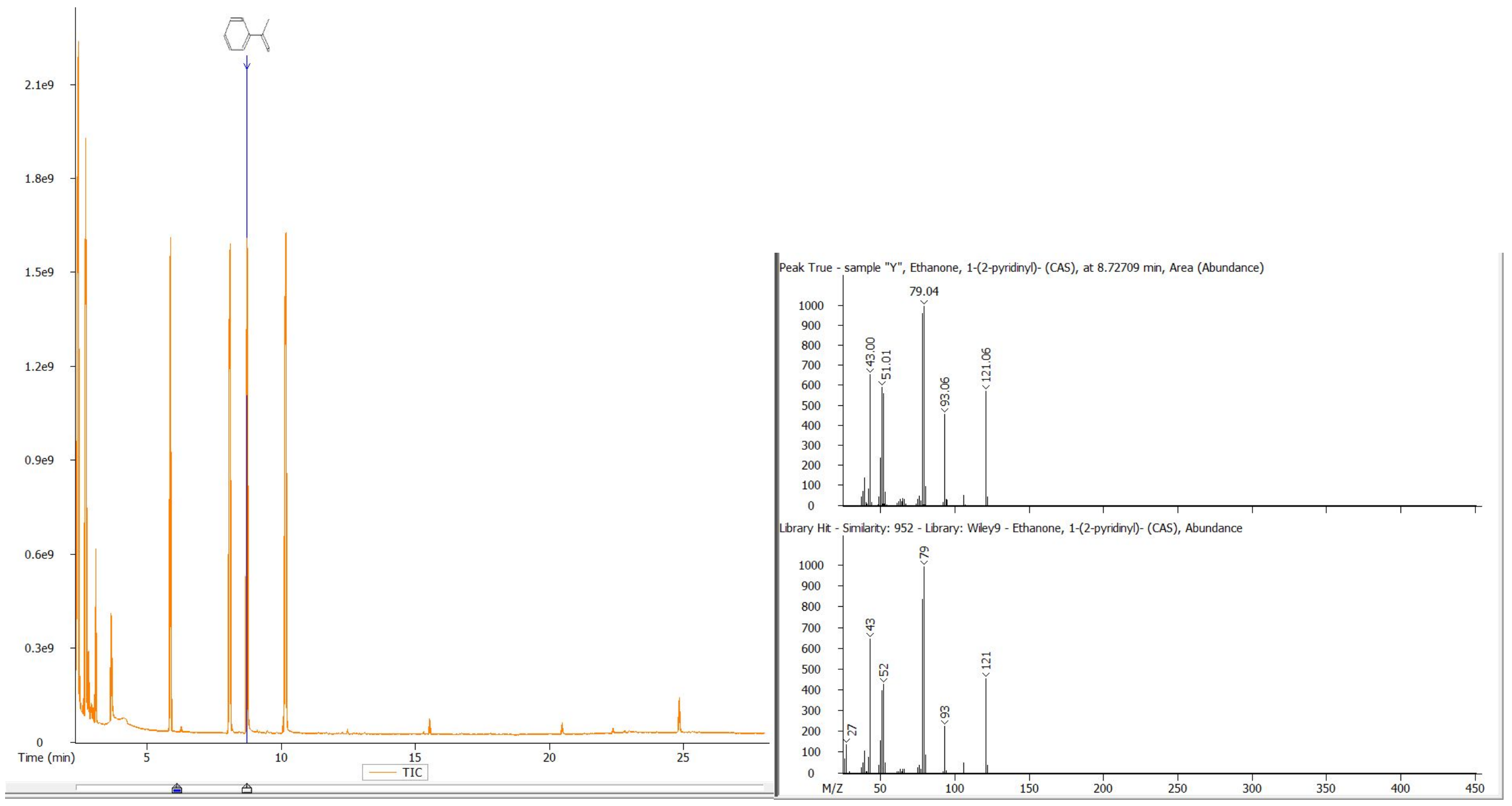




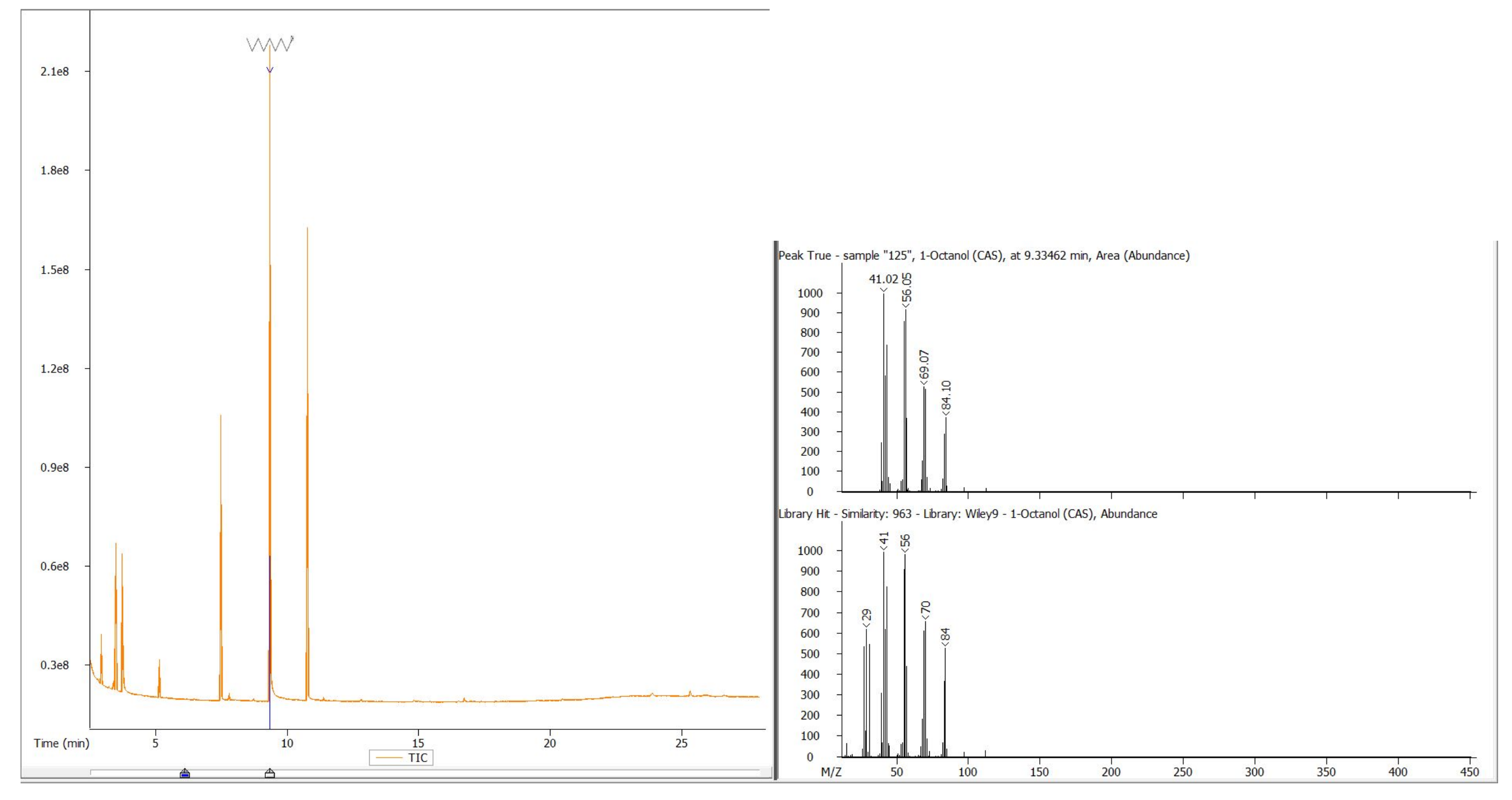




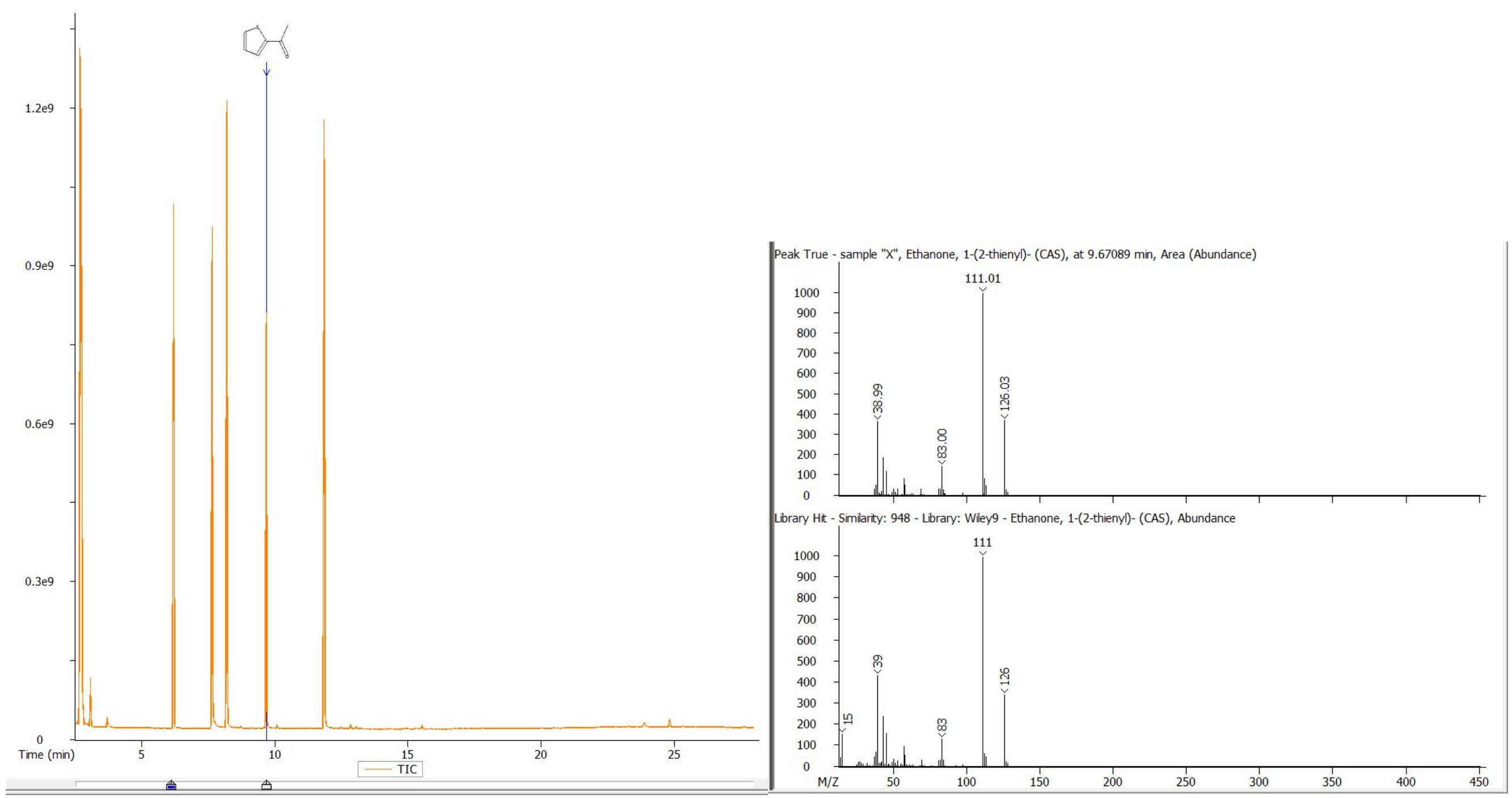




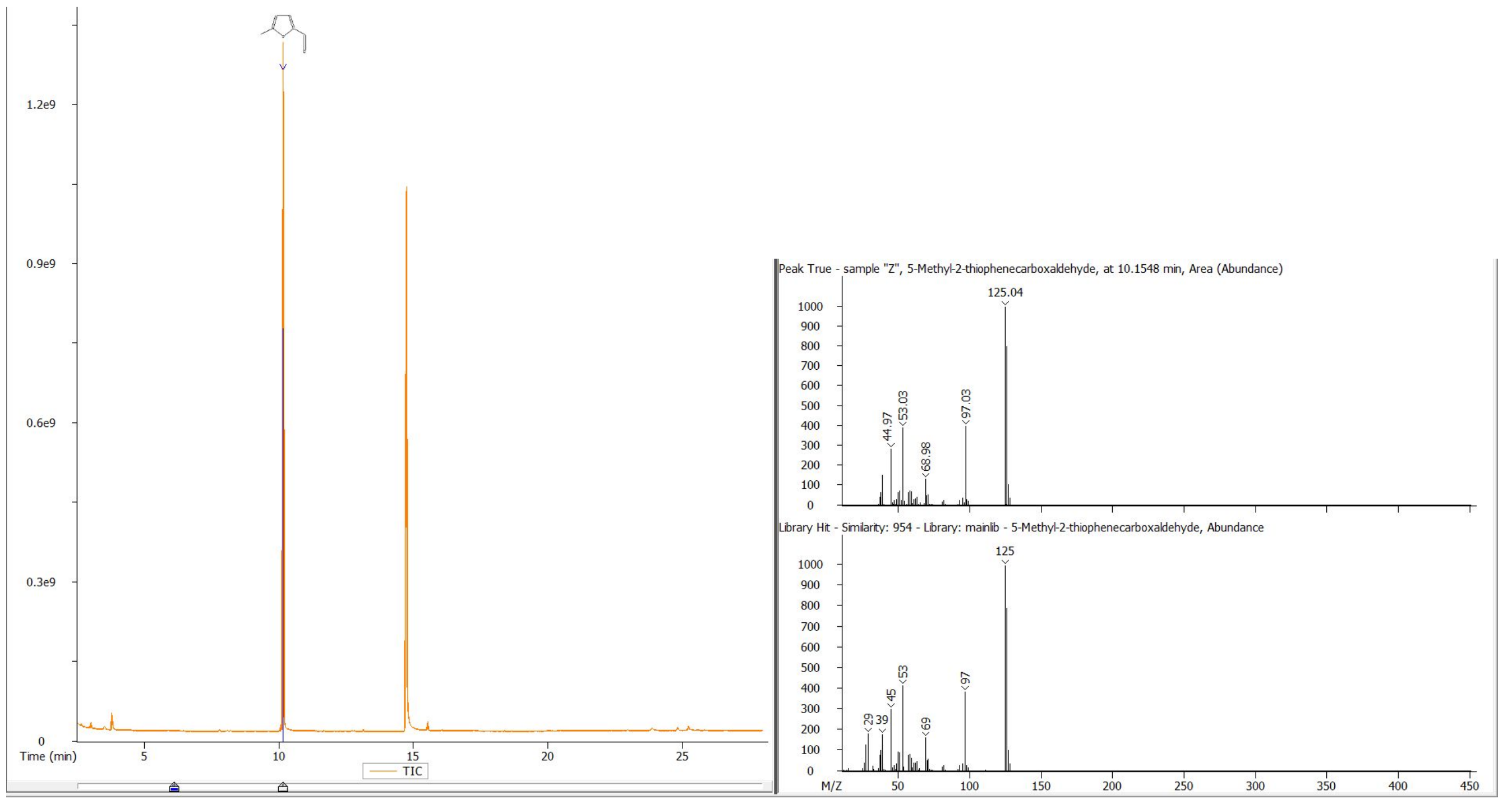




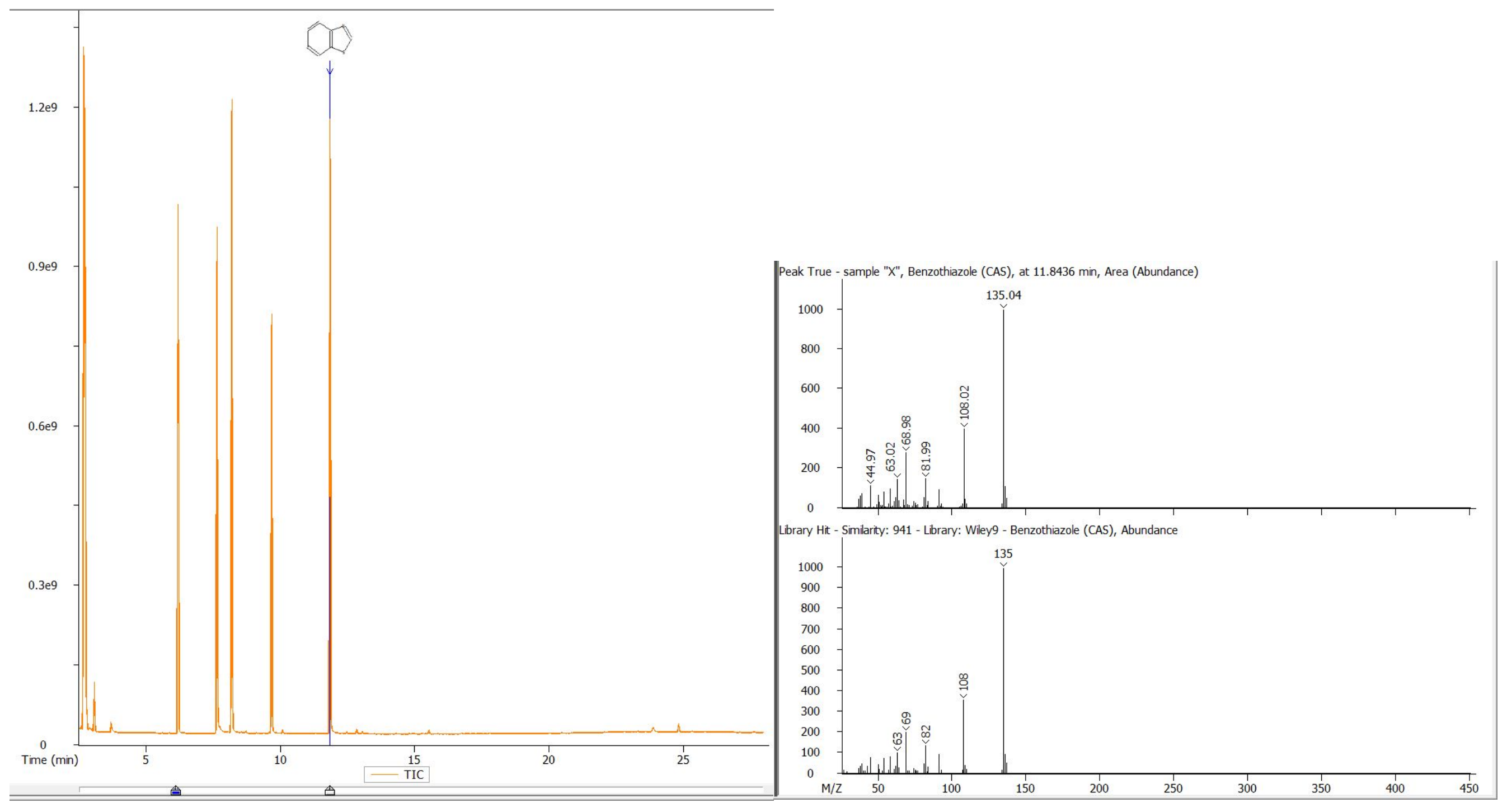




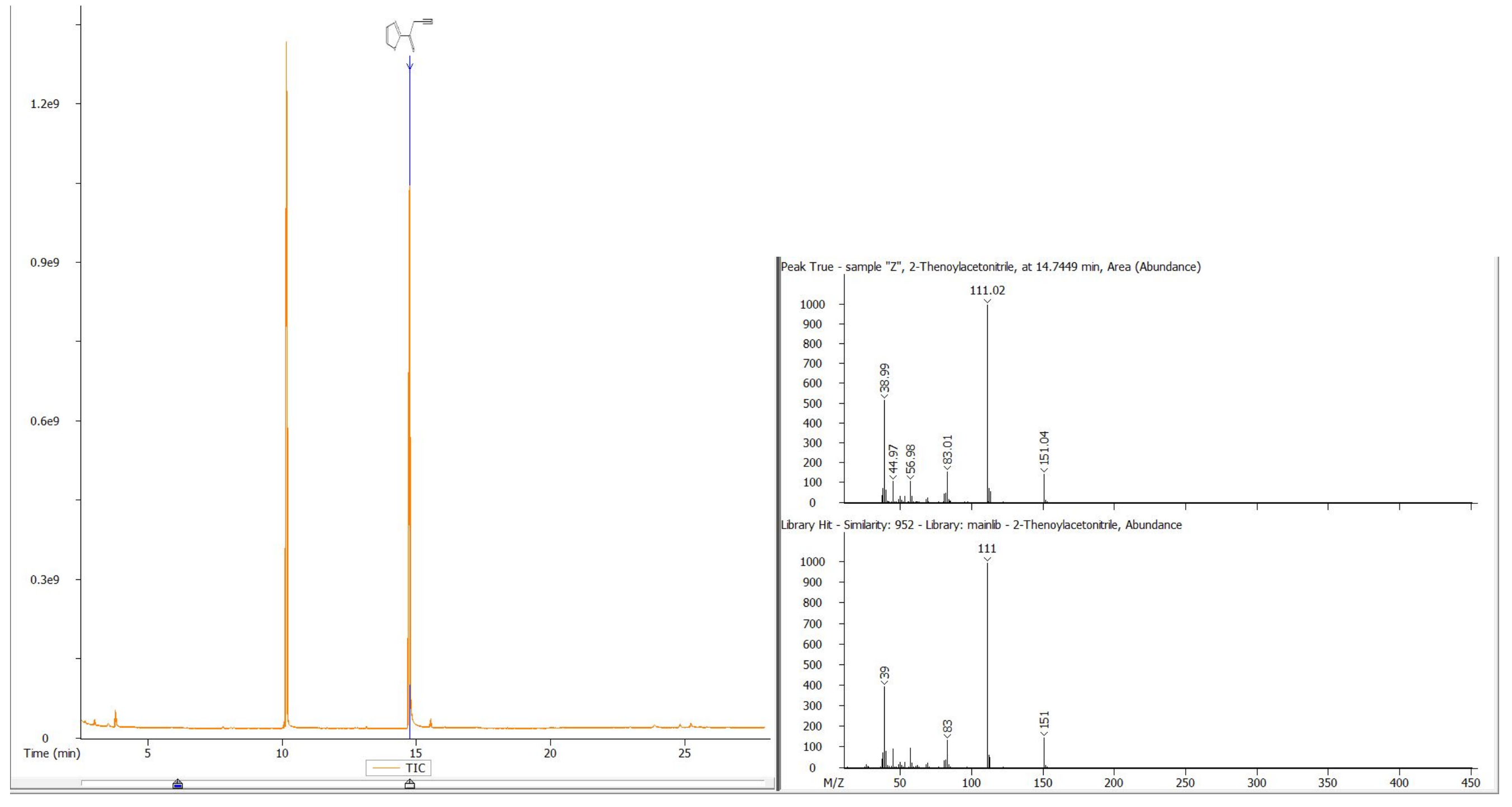

